\section{HSE}

Historia Social y de la Educación

Social and Education History

\section{Hipatia Press}

www.hipatiapress.com

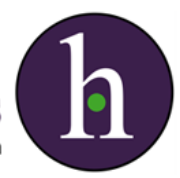

\title{
Volume 5, Number 1
}

\section{Hipatia Press}

www.hipatiapress.com

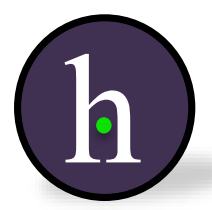

Affirmative action: an overview of the history of resistance, struggle and achievements of the black population in the Brazilian context- Daniela Mara Gouvêa Bellini \& Francisca de Lima Constantino

Segle XIX. Esperances i fracassos de la modernitat a l'educació. Situació d'Espanya- Joan Tahull, Iolanda Montero, \& Fidel Molina

Does Culture Matter in Economic Behaviour? - Edward O’Boyle

Effect of Yoga on Human Aggression and Violent Behaviour. A Review of the Indian Yoga Scriptures and Scientific Studies- A.G. Govindaraja Setty, Pailoor Subramanya, \& B. Mahadevan

Education across Europe: a visual conversation- Estefanía Fernández Antón 


\section{HSE}

Historia Social y de la Educación

Social and Education History
Hipatia Press

www.hipatiapress.com

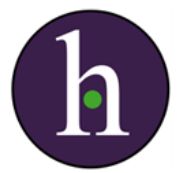

Instructions for authors, subscriptions and further details:

$\underline{\text { http://hse.hipatiapress.com }}$

\section{Affirmative action: an overview of the history of resistance, struggle and achievements of the black population in the Brazilian context}

Daniela Mara Gouvêa Bellini ${ }^{1}$, Francisca de Lima Constantino ${ }^{1}$

1) Universidade Federal de São Carlos (Brazil).

Date of publication: February $23^{\text {rd }}, 2016$

Edition period: February 2016 - June2016

To cite this article: Gouvêa, D.M. \& de Lima, F. (2016). Affirmative action: an overview of the history of resistance, struggle and achievements of the black population in the Brazilian context. Social and Education History 5(1), 1-25. doi:10.17583/hse.2016.1715

To link this article: http://dx.doi.org/10.17583/hse.2016.1715

\section{PLEASE SCROLL DOWN FOR ARTICLE}

The terms and conditions of use are related to the Open Journal System and to Creative Commons Attribution License (CC-BY). 


\section{Affirmative Action: an Overview of History of Resistance, Struggle and Achievements of the Black Population in the Brazilian Context}

Daniela Mara Gouvêa Bellini

Universidade Federal de São Carlos

(Brazil)
Francisca de Lima Constantino

Universidade Federal de São Carlos

(Brazil)

\section{Abstract}

This article seeks to present a reflection on affirmative actions that are characterized as public policies aimed at minority groups. On this perspective, we will make a cutting in the racial inequalities between blacks and whites in the Brazilian context, for the disparities between these groups are not marked only by social class, but also by the ambiguous racism that prevails in the country. Thereby, we seek to make the complaint of racial inequality in Brazil, as well as the announcement of answers achieved by the struggle of the black population, personified on the black movement and in actions in favor of black men and women who historically lived on the margins of society. In this sense, we organized the paper into three parts, plus the introduction and closing remarks. First, we present a brief historical and social context of race relations in Brazil. Then, we speak of about the steps and achievements of the black movement in the country. Finally, we highlight the affirmative action adopted for the benefit of black people, especially in the educational field, like the quota system in universities.

Keywords: affirmative action, black movement, education, Brazil 


\section{Acciones Afirmativas: un Panorama de la Historia de Resistencias, Lucha y Conquista de la Población Negra en el Contexto Brasileño}

Daniela Mara Gouvêa Bellini

Universidade Federal de São Carlos

(Brazil)
Francisca de Lima Constantino

Universidade Federal de São Carlos

(Brazil)

\section{Resumen}

Ese artículo presenta una reflexión sobre las acciones afirmativas que se caracterizan como políticas públicas dirigidas a grupos minoritarios. Desde esta perspectiva, se focalizarán las desigualdades raciales entre negros y blancos en el contexto brasileño, pues las disparidades entre estos grupos no están marcadas solamente por la clase social, sino también por el racismo ambiguo que prevalece en el país. Así, denunciamos a la desigualdad racial en Brazil, bien como buscamos hacer el anuncio de respuestas alcanzadas por la lucha de la población negra, personificada en el movimiento negro y en acciones ya logradas en favor de las mujeres y hombres negros. En este sentido, hemos organizado el trabajo en tres partes, además de la introducción y las consideraciones finales. En primer lugar se presenta un breve contexto histórico y social de las relaciones raciales en Brasil. Luego seguimos los pasos y logros del movimiento negro en el país. Por último, destacamos a las políticas de acción afirmativa adoptadas en beneficio de la gente negra, especialmente el sistema de cuotas en las universidades en cuanto campo de la igualdad educativa.

Palabras clave: acción afirmativa, movimiento negro, educación, Brasil. 
W hen we talk about affirmative action we must first understand what it means, in what context such actions were taken and who they benefited or benefit. Based on Piovisan (2005) certain subjects of rights or certain violations of law require a specific and differentiated response because there are certain groups that require special and specific protection in the face of their own vulnerability.

From this perspective, Piovisan (2005) points out that affirmative action can be seen as a powerful instrument of social inclusion, as it constitutes special and temporary measures to remedy a discriminatory past, this way, "affirmative action aims to speed up the process with the scope of substantive equality for vulnerable groups, such as ethnic and racial minorities and women, among other groups" (Piovisan, 2005, p.49).

Based on the National Curriculum Guidelines for the Education of Racial-Ethnic Relations (Brasil, 2004a), affirmative actions are characterized as repairs and recognition policies in response to racial $^{1}$ and social inequalities experienced by minority groups (blacks, indigenous, women, and children).

Women theorists and men theorists like Moehleck (2002), Maio and Santos (2009), Gomes (2009) point out in their study that throughout the 1970s, 1980s and 1990s, the black movement, as well as other social movements gained strength after a period of dictatorship with the country's democratization process. Based on the cited authors significant facts took place for the understanding of the changes and achievements gained in favor of the black population during these periods, which are: the promulgation of the 1988 Constitution; the Zumbi March of 1995; the approval of the Guidelines and Bases Law 9394/1996 (Brasil, 2004b); the Preparatory Regional Seminars for the World Conference Against Racism, Racial Discrimination, Xenophobia and Related Intolerance, the Third World UN Conference against Racism, Racial Discrimination, Xenophobia and Related Intolerance, held by the United Nations (UN) in Durban, South Africa in 2001 and, finally, the approval of the amendment of the Guidelines and Framework Law (LDB), Law 9394/96 by Law 10,639/2003 (Brasil, 2004a).

Such events, each in its own time boosted ways and measures that enabled not only a debate on racial inequalities but also the recognition of 
Brazilian racism, and the need for public policies in favor of historically marginalized populations in our country (black and indigenous) ${ }^{2}$.

Based on Gomes (2009), Brazil stands out for being one of the largest multiracial societies in the world and host a significant number of Africans dispersed in the Diaspora, however, this fact does not relieves the country of being racist, where prejudice and racial discrimination are marked with a past history of centuries of slavery ${ }^{3}$; the myth of racial democracy, the idea that blacks and whites ${ }^{4}$ live harmoniously, and an ambiguous racism that occurs not only because of an ethnic belonging expressed in the life, customs, traditions and history of the black population, but by the junction of this membership with the presence of diacritical marks, inscribed in the body (Gomes, 2008).

From this perspective, we seek to present some reflections on the adoption of affirmative action in a society marked not only by social, but also racial inequalities. The paper is organized into three sections, as well as the introduction and final considerations. In the first section, we present a brief overview of race relations in Brazil based in the context of historical and social transformations that the country has suffered from the colonial period to the present day. Then we dedicated ourselves to the Black Movement, by understanding that this, like other social movements, played and plays an important role across the achievements of the black population in Brazil. In the third section we reflect on the importance of affirmative action in the country, the impact of adopting this measure for the black population, and the current debate and the challenges posed to those who fight for a more equitable society.

The methodology for collection, election and usage of the basic texts to perform the historical review of the role of the black movement in Brazil considered productions of intellectuals and experts on the subject, who are also involved in some way with the movement. As for the government documents cited and analyzed, as well as being produced by the black movement itself, these pieces of legislation have a direct impact on public policies and the life of the black and white population. In editing the text, we followed the chronological order of facts and of laws and regulations. 


\section{HSE - Social and Education History, 5(1) 5}

\section{Race Relations in Brazil: from Past to Present}

As previously mentioned, Brazil is one of the largest multiracial societies in the world. However, it does not mean that the Brazilian people live in fact a racial democracy in which its population, especially blacks, whites and indigenous, is out of racial tensions. As we return our gaze back to the past of Brazilian history, and its relationship with the Africans and their descendants, we will come across a history of dehumanization of the African population, which until today has remnants that directly interfere in the lives of the black population and the relations between blacks and whites.

As Munanga and Gomes (2006) explain, the slave regime made Brazil a kind of society divided and organized into two unequal parts: the first consists of free women and men, the other for enslaved women and men the first white and the second black. This social division ended in benefits for the first group and disadvantages for the second, which carries with it the daily struggle to reframe its history.

Based on the studies of Ianni (2004), Munanga and Gomes (2006), slavery was the means that the Portuguese found to get the most profit from Brazil. Slave labor was the basis of the Brazilian economy until the midnineteenth century, first with the production of sugar and gradually the exploitation of other branches of agriculture such as cotton and coffee, and mining activities. As the authors and the author mentioned, the process of slavery in Brazil was dehumanizing and cruel, it transformed men and women, free in their land, into commodities, seen as objects and taking them to the loss of their identity.

Free beings in their native land, here were stripped of their humanity through a status that made them only animal workforce, things, goods or objects that could be bought and sold; sources of wealth for traffickers (sellers) and investments in "animal machines" work for buyers (planters) (Munanga \& Gomes, 2006, p.16).

Thus, Africans had to learn ways of survival and struggle to escape the physical, emotional and psychological imprisonment to which they were subjected. Many women commit abortions to rid their children of slavery, there were breakouts and murders to escape their subhuman way of living. 
And contrary to what we learned in school, Africans and their descendants have never accepted peacefully slave labor to which they were forced to carry out with no right to remuneration and decent life, thus sought strategies to resist and escape ill-treatment to which they were subdued.

Based on Ianni (2004), exploitation of compulsory labor, particularly slave labor, was subject to the movements of European commercial capital, which started to have other economic interests with the expansion of capitalism. Thus, from the second half of the nineteenth century, the economic and social structure of Brazil is profoundly modified and replaced by a less agricultural character and more commercial, less rural and more urban.

In this new context, the slave became a moot effective element; the slave regime ceases to be a beneficial deal (Ianni, 2004). To meet the new social, economic and political interests emerging in society in the mid nineteenth century, blacks find themselves officially "free" after three centuries of slavery. On May 13, 1888, the abolition of slavery is enacted. However, authors such as Maciel (1985) and Cunha Junior (2008) indicate that this freedom does not actually occurred; they explain that slavery remained for years, if not in practice, at least in people's thinking, i.e. now free blacks continued to receive the same treatment they used to have when they were in a condition of enslaved people. Moreover, Cunha Junior explains that by being freed blacks did not receive any attention from the government, there was no integration policy of this population to society and they were left out, as indicated by Maciel, losing their workplace.

As they were converted into citizens, the blacks met in a brutal way the alienated condition of freedom that was offered to them. The Brazilian society left the blacks to their own destiny, laying on their shoulders the responsibility to re-educate and transform themselves to meet the new standards and ideas of man, created by the advent of free labor, the republican regime and capitalism (Ianni, 2004, p.307).

In this way, the black population is at the same time "free and imprisoned," trapped in a past of dehumanization and abandoned to their fate, without housing, education, health and work, basic rights to human life. 
According to Ianni (2004), in 1889 and 1891, the Republican government gave orders to collect and burn the documentation on slavery, as erasing the data was a way to hide the facts. In addition, not asking about people's color in the census, for some years, meant a secondary factor of history erasure, or yet had no significance as a social fact. According to Ianni (2004), burning the records on slavery and not asking who were the blacks in the country, made the mobilization of the black population difficult, who did not know how many they were, where they lived and how they participated in the income and culture, which was very convenient to the white elite.

These actions were part of the political project of the Brazilian government, which wanted to make society white. The ideal of whitening was born in the post-abolition, based on scientific racism, which justified these and other atrocities against the black people, through the belief that the whites had a superiority, and that their blood (white) could purify African blood, considered "primitive", and so it would constitute a gradually "white and civilized" society (Oliveira, 2008).

According to the studies of Domingues (2002) and Oliveira (2008), the whitening policy was an action of promoting the self-denial of the black subject, for this subject starts desiring a white ideal, once that socially the beautiful and desirable is white, which leads to this policy a sense of white superiority and a sense of inferiority of the black. In this sense, we need to understand the complexity that permeates not only race relations between blacks and whites in the country but also the constitution of the self of these subjects.

The whitening ideology preached the integration of blacks via assimilation of white values and aimed to spread that there were no racial differences in Brazil and all lived here in harmony without conflicts (Oliveira, 2008, p.6).

In this perspective, Munanga (2006) explains:

In the construction of Brazil's racial system, the mestizo is seen as a transcendent bridge, where the white-black-indigenous triad is and dissolves into a common category founding of nationality. Hence the myth of racial democracy: we were mixed in the origin and 
today we are neither black or white, but a mixed-race people, a mongrel people (Munanga, 2006, p.131).

However, such thinking does not apply to practice because when we talk about equity there is a big gap between blacks and whites. The racial democracy myth serves only as a complicating factor in race relations in Brazil, as it hangs over the Brazilian society this idea that blacks and whites live harmoniously without conflicts and tensions. However, reality shows us that race relations in the country are stressed by racism and that skin color is a social marker that restricts social equality for blacks.

Brazilian society, through the myth of racial democracy, lives under a tangle of acceptance and rejection of ideas in relation to blacks. "This ambiguous behavior inhibits the debate on social rights of the black population, including the right of not being discriminated" (Santos, 2009, p.25). In addition, there is also the ambiguity between color and class, which thanks to the myth of racial democracy, permeates the idea of many Brazilians: the most important discrimination in Brazil would be social and not racial (Munanga, 2006). In this sense, the myth of racial democracy "is a fallacy to cover existing racist practices in the country, and exempt the white group of a reflection on itself" (Cavalleiro, 2000 p. 29).

From this perspective, we must consider that inequalities between blacks and whites go beyond the differences of social class and extend to a cruel racism, sometimes subtle, masked, or even friendly, which seeks through compensatory actions, to erase the feeling of rejection toward blacks (Santos, 2009). As stated by Gomes (2001, p.92): "Racism in Brazil is a complex and singular case, as it is stated by its own negation. He is denied vehemently, but remains present in the system of values that govern the behavior of our society ".

As we shall see, there is a gap between blacks and whites when we think the same opportunities. The myth of racial democracy and the ambiguous racism living Brazilian society often prevent a more open debate on racial inequalities in the country. The expansion of university policies, affirmative action and other policies has contributed to advances in this area. But we still have much to do, challenges to overcome and obstacles to surpass in the search for a more egalitarian and just society in which all identities and 
cultures are equally valued and recognized as part of the formation of Brazilian society.

We started speaking about the black movement in Brazil, as part of the record of struggle and demands of the black population for equal opportunities, recognition of their history and culture, and appreciation of their identity as subjects of rights.

\section{Black Movement and Education: Path of Struggle and Claims}

It can be considered that the black movement in Brazil comes from the history of Africans and their descendants in the Brazilian context, since the trafficking of African people in Brazilian land, that is, since the first acts of struggle and resistance against ill-treatment to which they were subjected. The enslaved blacks never accepted submissively slave labor, neither after the abolition had they expected the white elite to pity their situation. Escapes and the formation of quilombos ${ }^{5}$ undoubtedly represent a radical form of slave resistance against an oppressive and dehumanizing system (Haerter, Nunes \& Cunha, 2013).

But the black movement "is born" and officially takes its first steps into a more organized and representative form after abolition. As mentioned previously, with the enactment of the liberation of the slaves, blacks found themselves completely on the margins of society, with no integration policy aimed at them. From this perspective, women authors and men authors like Gonçalves and Silva (2000), Domingues (2009) and Gomes (2001), point out that schooling becomes of great importance for the black population and the central struggle of the black movement, that has always made the complaint of illiteracy among blacks and sought actions to provide access to education for children and adults, because they understood that schooling would allow social mobility and the appreciation of the black people.

Based on the women authors and men authors cited, the black movement goes through different stages: post-abolition beginning, their concern is focused on the complaint of the present racism in Brazilian society, in the school context and in taking action on basic education; over the years, claims gain a more concrete character and are consolidated in public policies for the black population. 


\section{Gouvêa \& Lima - Affirmative Action}

According to Domingues (2009), the black movement has gone through three phases. In the first phase (1889-1937), post-abolition moment, the movement promoted awareness campaigns among the black population on the importance of literacy; to this end, it opened small schools and literacy courses, in this period the main objective was basic education. In the second phase (1937-1978), the black movement has expanded a little more to its action, in addition to schools and literacy courses, coordinated educational oriented projects, but kept its attention on basic education. The third phase (1978-2003) is characterized by more systematic actions and public policies for the black population. It went on to claim more forcefully a review of the prejudice load in the teaching material and a afro-centered and multicultural education project with inclusive teaching practices and the adoption of African History in the curricula.

Here, we will retain a little more on the phases of the black movement for understanding this movement in the light of the black population in Brazilian society. According to Domingues (2009), the first phase of the black movement, the African-Brazilians were living in a state of social and political exclusion. With regard to education, blacks stayed away from school chairs, or when they had access was with great difficulty. Schools did not accept black children, and when they had the opportunity to be in school, they were so battered that her parents chose to take them away. In response to the racial discrimination they went through, blacks created associations such as clubs, organizations and unions.

According to Domingues (2009), these associations not only stayed in the field of complaint regarding the education of blacks, but created educational and cultural activities in its facilities, such as presentations, theatrical performances, soirées, sessions of poetry recitals, courses and lectures. Some associations have also opened schools: in 1908, Sociedade Amigos da Pátria [Friends of the Country Society], from São Paulo, founded a school and assisted more than 1,000 people. In addition to the state of São Paulo, in other regions of the country, blacks were organized and created schools that sought to assist all individuals regardless of color, gender, nationality, religious belief or profession. Black associations sought to educate the black population of the importance of schooling, as well as the duty with the government. 
Among the associations of the time, Frente Negra Brasileira (1931-1937) [Brazilian Black Front] is highlighted; this association was the one that best organized and developed itself, and was one of the most important within the black movement. It stood out by the number of participants, the achievements and the many activities undertaken. Its political and administrative organization was complex and diverse; it brought together more than sixty delegations distributed throughout the interior of São Paulo and other Brazilian states (Domingues, 2009).

In the first phase of the black movement, we can realize the great attention and concern focused on the education of blacks, because the movement had high expectations in relation to education, since for them the school education had the power to set aside racial prejudice and, ultimately, to eradicate it. "The concept of education articulated by the black movement at this stage was wide, it comprised both schooling and the cultural and moral formation of the individual" (Domingues, 2009, p.973).

In this sense, education transcended to the black movement the act of reading and writing. Access to education meant political power to fight for their rights, for a more just, egalitarian and democratic society. The first phase of the black movement is characterized by the concern to provide access to basic education which made the blacks feel "well, capable, proud of themselves and connected with the grammar of civilization and the modern world" (Domingues, 2009 p.976). This phase was also marked by the ban on all social movements. On December 2, 1937, the national government of Getulio Vargas imposed a decree that considered all movements illegal.

During the New State period, from 1937 to 1945, Brazil experienced a historic moment of great political repression and suppression of democratic rights. As a result, the social movements have suffered from some government actions that made them impossible. This period marks the second phase of the black movement that extends to the year 1978.

During this period some black movements have survived and others have surfaced with more parochial character. In 1943, there is a resurgence of the black movement, through the União dos Homens de Cor (UHC) [Black Men's Union], founded in Porto Alegre; this organization had as its central purpose to raise the economic and intellectual level of the black population throughout the national territory, with the aim of enabling it to join the social 


\section{Gouvêa \& Lima - Affirmative Action}

and administrative life of the country, in all sectors (Domingues, 2009). Based on Domingues (2009), the União dos Homens de Cor claimed the right to free public education or still a quota policy. The association was concerned not only with access, but also the permanence of black people in higher education.

The Teatro Experimental do Negro (TEN) [Blacks Experimental Theatre] was another important group from that stage; established in Rio de Janeiro in 1944, it had Abdias do Nascimento as its main leader. The TEN, in addition to forming a theater group for black people, organized conferences, congresses, beauty contests, opened a research center and a museum. Also it implemented a literacy course and denounced racial prejudice in textbooks. The TEN fulfilled an important role as a coping strategy to color prejudice (Domingues, 2009).

The second phase of the Black Movement maintained the basic education at the center of claims and went further, made the complaint of the teaching material with racist content and went on to fight for higher education. But not yet envisioned multicultural educational practices or systematic forms of educational proposals based on ethnic and racial diversity, or a teaching facing the introduction of African history in the school curricula (Domingues, 2009).

According to Domingues (2009), the third phase of the Brazilian black movement covers the years 1978 to 2003, it was marked by a moment of racism silencing, with the installation of the military dictatorship in 1964. But this did not mean the end of the movement, some voices of the black protest were not silenced and, in the 1970s, they organized the Centro de Cultura e Arte Negra (CECAN) [Center of Black Art and Culture], in São Paulo; the Sociedade de Intercâmbio Brasil-Africa (SINBA) [Brazil-Africa Exchange Society], in Rio de Janeiro; the african block Ilê Aiyê, Bahia.

The political leap only occurred in the late 1970 s, with the rise of popular struggles, the trade union, feminist, gay and student movements. A milestone in this process was the birth of the Movimento Unificado Contra a Discriminação Racial (MUCDR) [Unified Movement Against Racial Discrimination] in 1978. Later, its name was changed to Movimento Negro Unificado [Unified Black Movement]; the movement has invested in originating return to African roots as a fundamental element of any political and cultural practice. One of its concerns was to intervene in the educational 
sphere. In 1979, the Núcleo Cultural Afro-Brasileiro [Afro-Brazilian Cultural Center] organized the 1st Seminar on Interethnic Experimental Education.

In the 2nd Seminar on Interethnic Education, a committee was formed that prepared a school curriculum based on black culture. In 1984, the African-Brazilian entities of Bahia were striving to insert in the curricula of public schools disciplines grounded in black history and culture. In the 1980 s, several black movement groups emerge again claiming the right to quality education and appreciation of blacks.

In this sense, Gomes (2011) explains that in 1980, Brazil is going through a time of political openness and democratization of society, which enables a new form of performance of black Brazilians. For the author, women and black men started to work more actively in social movements of identity nature, which resulted in another set of questioning and new forms of action and political demand. Gonçalves and Silva (2000) imply that the black movement spent virtually the whole 1980s decade involved with the issues of democratization of education.

According to Gomes (2011), the black movement starts asking "the state, the Brazilian left and the social movements about its neutral and silent positioning on the centrality of race in the country shaping" (Gomes, 2011, p. 111). According to the author, the late 1980s and early 1990 s were a period of tensions, criticism and breaks between members of the black movement, the left parties and new social movements' entities, because the movement itself takes a stand of greater political action facing racial inequalities in the country.

From this perspective, we consider that Brazil, in the late twentieth century and early twenty-first century, carried out important actions for the black population. At the end of the 90s and beginning of the following decade, after long debates about affirmative action and quota systems in public universities, the Legislative Assembly of Rio de Janeiro State, in 2002 , approved the reserve of $40 \%$ of seats for black students in the entrance exam at the Universidade do Rio de Janeiro (UERJ) [University of Rio de Janeiro] and the Universidade Estadual do Norte Fluminense (Uenf) [State University of Fluminense North]. Another measure of national impact in our country was the enactment of Law No. 10,639, of January 9, 2003, which 
established the mandatory teaching of African and African-Brazilian Culture and History in elementary and high schools.

Based on what was presented, it can be said that the black movement played a key role in actions in favor of the black population and that even today the movement is important in the struggle for equity, overcoming racism and appreciation of the black identity. We turn now to discuss in more detail about the achievements set and gained by the black population in recent years, among them affirmative action, the Secretaria de Educação Continuada, Alfabetização, Diversidade e Inclusão (SECADI) [Department of Continuing Education, Literacy, Diversity and Inclusion] and Law 10,639/03 amending Law 9394/96.

\section{Affirmative Action and Public Policies: an Overview of Achievements for Equal Opportunities in the Brazilian Context}

From what was exposed about the historical context of black struggle and resistance in Brazil, we will pass on to the discussion of the importance of affirmative action and access to education in the country, without omitting ourselves in making a brief explanation of public policy for promoting a more egalitarian society among blacks, indians and whites.

Based on the National Survey by Household Sampling (Brasil, 2015), published by the Brazilian Institute of Geography and Statistics (IBGE), Brazilian population amounts to a total of 201.5 million people who declare their color in $46.1 \%$ white, $53.1 \%$ black (black and brown), and $0.8 \%$ claim to be indigenous or yellow.

Meeting what is presented, the Institute of Applied Economic Research IPEA (2014) provides recent data on the situation of the black population in the Brazilian context that supports the argument that inequalities in Brazil are not guided solely on social disparities, but also racial.

In comparative table of 2001 and 2012, it appears respectively the decrease from $38.1 \%$ to $14.7 \%$ of the black population living with a per capita income of 0.5 minimum wages ${ }^{6}$, while the white population decreased from $17.3 \%$ to $6.2 \%$. When we compare the population living with a per capita income of 1.5 minimum wages, also in 2001 and 2012, it appears that it increases from $27.7 \%$ to $44.9 \%$ the black population living on this income, while the white population number also increases from $39.2 \%$ to $44.9 \%$. 
Based on the data presented, we see a reduction in extreme poverty for both blacks and whites, but that does not mean we reached equity among these groups.

According to IPEA (2014), the change of the economic data over the years was due to the appreciation of minimum wage policies and their impact on the benefits of social security and assistance, for example, the Bolsa Família Program ${ }^{7}$ [Family Assistance Program].

Regarding the educational level, the IPEA (2014) brings net data, explaining the entry and stay of the black population in various educational stages. It is worth emphasizing that even with the entry of more blacks in higher education, yet we have a very low number of this population at the university. In 2001, out of the total population aged 17 and over, the percentage to enter higher education was $14.1 \%$ white and $3.2 \%$ black. In 2012 , the percentage rose to $22.2 \%$ white and $9.6 \%$ black. From the data provided, we can say that higher education begins to open its doors to the black population, but still represents a small percentage compared to the total number of this population in Brazil.

In 2003, Munanga (2003) stated that without public policies or legal measures, even with a supposed improvement in the Brazilian basic education in its quality level, black students would take approximately 32 years to reach the level of white students; furthermore, it would be necessary that the white students stood still in their current positions and waited for the black students to catch up so they could walk together on an equal footing.

From this perspective, it is understood that affirmative actions are key to overcoming inequalities historically accumulated in our context. Such actions are public policies made by the government or by private institutions, with the restorative function of seeking equality between whites, blacks, indigenous and other people or communities who have their rights denied, regarding housing, health, work and education ${ }^{8}$. In this context, the quotas for access to public university are considered affirmative actions.

Currently, federal law No. 12,711/2012 provides that at least the reserve of $50 \%$ of seats in federal public universities is intended for those who have completed high school fully in public schools. Of this amount, 50\% are reserved for students with an income lower or equal to 1.5 minimum wages per capita, and the remainder must be filled by candidates that are selfdeclared blacks, browns and indigenous. 


\section{Gouvêa \& Lima - Affirmative Action}

Note that the reserve of seats for blacks in universities, as a form of affirmative action, still represents tension and disagreements in the academic and social environment. Based on Osorio (2009), there are people who defend social quota claiming that there is a coincidence in attending a public school, being poor and being black, arguing that racial quotas would benefit only blacks and leave aside poor whites. Thus, social quotas would solve social inequality and of class in higher education.

However Osorio (2009) explains that, when considering only racial quotas, the coincidence between race, class and public school studies would be more efficient in the elimination of racial inequalities, understanding through the analyzed data that the black population is in inferior position to whites in all categories analyzed. Thus, it is understood that quotas should be neither only social or only racial, but should comprehend simultaneously the two categories, thinking that the goal is equal access to opportunities in higher education.

In this context, we understand that to overcome the inequalities between blacks and whites in the Brazilian context tireless struggles are made necessary to press the state for public policies, since such policies not only represent the possibility of access to universities, but also the mobility of the black population in different spaces. Accordingly, in tandem with affirmative action, special secretariats, statutes and laws were created over the years, specific to the achievement of equality between blacks and whites.

Currently, we have a Secretariat for the Promotion of Racial Equality Policies (SEPPIR) with Ministry status, created by Provisional Measure No. 111, of March 21, 2003, before the recognition of the struggles of the Brazilian black movement throughout the historical process Exclusion (Brazil, Equality Portal ${ }^{9}$ ).

SEPPIR's main purpose is to formulate, coordinate and articulate public policies and guidelines that promote ethnic and racial equality, understanding that in Brazil there are a lot of communities and people living on the margins of society without access to basic rights such as housing, food and education. Also within this Ministry there are actions addressed to people and traditional communities, that in this concept may be grouped as of African origin communities, maroon, Roma people, and others who have their own "social organization, which occupy and use territories and natural resources as a condition for their cultural, social, religious, ancestral and 
economic reproduction, using knowledge, innovations and practices generated and transmitted by tradition "(Brazil, Equality Portal $\left.{ }^{10}\right)$.

On the educational sphere, we count on the Ministry of Education (MEC), the Department of Continuing Education, Literacy, Diversity and Inclusion (SECADI), which aims to contribute to the development of inclusion by articulating the education systems to the educational policies "focused on appreciation of differences and diversity, the promotion of inclusive education, human rights and environmental sustainability, aiming at the realization of cross-cutting and cross-sectoral public policies "(Brazil, Ministry of Education Portal ${ }^{11}$ ).

Meeting these actions, Brazil advances when we consider current legislation. In 1996, Law No. 9394/1996 was created, regarding Guidelines and Bases of National Education (LDB), this law, in its article 3, section I, ensures "equal footing for access and stay in school." But based on the data presented above, we can say that this does not occur in fact, because the access of black people to education is still low, less expressive when compared to the number of whites in universities, or the illiteracy rate of the two groups.

As mentioned, the black population has always been denied their access to education in different ways. And through social pressures, ongoing struggle and proposals of the black movement, important achievements were obtained in the legislative ${ }^{12}$ framework, in addition to the above: 1) Law No. 10,639/2003 amending Law 9394/1996, establishing the guidelines and bases of national education, to include in the official curricula of the Education Network the mandatory theme "Afro-Brazilian Culture and History"; 2) Law No. 11,645/2008 amending Law No. 9,394/1996, as amended by Law 10,639/2003, which establishes the guidelines and bases of national education, to include in the official curricula of the school system the mandatory theme "Afro-Brazilian and Indigenous Culture and History; 3) Law No. 12,288/2010 establishing the Racial Equality Statute, amending Laws 7,716, of January 5, 1989, 9,029, of April 13, 1995, 7,347 of 24 July, 1985, and 10,778 of November 24, 2003; 4) Law No. 12,711/2012, known as the Law of Quotas, which guarantees reservation of seats in federal institutions of higher education linked to the Ministry of Education (MEC); 5) Law No. $12,990 / 2014$ reserves the blacks $20 \%$ (twenty percent) of the positions offered through public tenders for provision of effective positions 
and public jobs within the federal government scope, local authorities, public foundations, public companies and semi-public companies controlled by the Union.

When thinking about education, it is worth highlighting the performance of the Department for Continuing Education, Literacy, Diversity and Inclusion (SECADI) among their actions for the implementation of Law 10,639 and programs development, it made possible management processes, continuing education courses, distribution of paradidactic materials and researches (Gomes, 2011).

Based on Gomes and Jesus (2013), from the 2000s, Brazil went on to form a set of legal provisions that led to a focused educational policy for the assertion of cultural diversity and implementation of an education for ethnic and racial relations. According to the authors, the amendment of the LDB by Law 10,639/03, the CNE/CP1/2004 resolution, that defines the National Curricular Guidelines for the Education of Racial-Ethnic Relations and the Teaching of African and African-Brazilian Culture and History, based on the verdict $\mathrm{CNE} / \mathrm{CP} 3 / 2004$, in accordance with its legislation and its provisions can be regarded as central to the process of implementation of affirmative action policies in Brazilian education at different levels, stages and educational modalities .

From this perspective, we believe that Brazil in response to the proposals of the black movement, social pressures and other Allied agents of the antiracist struggle, has taken important steps to meet the demands of the population. The affirmative action policies represent the realization of claims of long years of struggle for health conditions, education, housing and a decent life to black people.

As indicated by Maio and Santos (2005):

In the most diverse spheres of Brazilian society, whether on the issue of education, health or socio-economic conditions, it is clear that there are inequities in the ethnic-racial grounds that need to be tackled. The fight against racism has occupied a prominent place in contemporary political debate. If there is agreement as to the existence and relevance of the problem, the crux of the debate focuses on ways of tackling it (p.207) 
In this sense, many achievements have been made, demands were met both on the legislative and on the education sphere, but we are still far from a more egalitarian society between blacks and whites. We believe that "if education alone does not transform society, without it neither does society change" (Freire, 2000, p.67), in that sense, "it inflicts the review of the role of education that not being the doer of everything, it is a key factor in reinventing the world" (Freire, 2001, p.10). Therefore, ensuring quality education as well as access and stay of all people, regardless of race, class, gender and culture, is the possibility of a more just and egalitarian society in which all people can live and have their choices respected.

\section{Final Considerations}

Based on the studies of Gomes (2011), we consider that the adoption of affirmative action policies such as Law 10,639/03 and its Curricula Guidelines for the Education of Racial-Ethnic Relations and for the teaching of African and Afro-Brazilian History as well as a reservation for blacks in the universities "clash with the practices and racial imagery present in the structure and functioning of Brazilian education, such as the myth of racial democracy, ambiguous racism, the whitening ideology and the naturalization of racial inequalities "(Gomes, 2011, p.116).

As indicated by Gomes (2011), we must understand that these achievements do not mean a state gift, but as we have seen throughout the text, it represents the fruit of a social struggle process, denied rights and the black movement's claims requiring as a State duty the recognition and legitimation of the race issue in public policies of health, labor, environment, land, youth, gender (Gomes, 2011).

Therefore, the imposition of these policies leads the Brazilian people to look at themselves and the contradiction they live when denying racism and at the same time, keeping visible inequalities between blacks and whites. Brazilian society has achieved concrete actions in favor of the black population, but we are still far from canceling out racial and social inequalities present in our context. Quoting Freire (2000), "world change implies the dialectization between the denunciation of the dehumanizing situation and the announcement of its overcoming deep down, our dream. (...) Changing is hard but possible " (p.81). In this sense, the demand of the 
State is important, but the action of each individual in the world and with others is key to overcoming or, at least minimizing the racial and social inequalities.

\section{Notes}

${ }^{1}$ The term race is used and understood here as a social construct and a political positioning. The Black Movement and several scholars in the field of race relations in Brazil make use of the term with a social and political sense related to the history of blacks in Brazil and the complex relationship between race, racism, prejudice and racial discrimination (Munanga \& Gomes, 2006).

${ }^{2}$ As we consider the equality of differences, we do not disregard the indigenous peoples who also live on the margins of our society. This portion of the population, alike the blacks, has their struggles and follows in pursuit of public policies in their favor.

${ }^{3}$ Brazil was the last country in the West to free the black population from slavery. From the beginning of the slave trade in the sixteenth century to its end in the nineteenth century, were brought from Africa about 9.5 million blacks to the Americas. From these, most were intended to Brazil, which imported thirty-eight percent of the total, being the rest sent to other countries (Ianni, 2004).

${ }^{4}$ It is worth mentioning that when we use the masculine form - black and white, we are not ignoring the black and white women.

(t.n) In Portuguese language, the words black and white carry the masculine suffix "o", although they correspond to men and women.

${ }^{5}$ Quilombos can be understood as political projects and freedom groups, spaces where relatively autonomous societies were recreated and with a strong presence in African traditions. It was certainly one of the most radical forms of resistance to the Brazilian slave system and meant reframing space of culture and ways of life, bringing together elements from different cultures, such as African, indigenous and other groups dissatisfied with the reality of the time. Quilombos were places where former slaves were the protagonists of their stories. The Quilombo de Palmares is highlighted in the history of Brazil, he remained alive for almost the entire seventeenth century and had over twenty thousand people, among Africans, Africans and their descendants, as well as other groups. It was led by Zumbi dos Palmares, now regarded as a symbol of struggle and resistance for the black population and the Brazilian history (Haerter, Nunes \& Cunha, 2013). Note that the November 20, day of Zumbi's death was established as National Black Consciousness Day.

${ }^{6}$ It is noteworthy that the current minimum wage is U\$ 202.80 .

(t.n) This amount corresponds to $\mathrm{R} \$ 788,00$ (Brazilian currency). 
${ }^{7}$ The Bolsa Família is a direct transfer program income that benefits families in poverty and extreme poverty throughout the country. The Bolsa Família integrates the Brazil Without Poverty Plan, whose operations focus on the millions of Brazilians with a per capita income below U\$ 19.85 per month and is based on guaranteed income, productive inclusion and access to public services (http: //www.mds.gov.br/bolsafamilia).

(t.n) U\$ 19.85 corresponds to R\$ 77.00 (Brazilian currency).

${ }^{8} \mathrm{http}: / /$ www.portaldaigualdade.gov.br/assuntos/o-que-sao-acoes-afirmativas

${ }^{9}$ http://www.portaldaigualdade.gov.br/sobre-a-seppir/o-ministerio

$10 \mathrm{http}: / / w w w . p o r t a l d a i g u a l d a d e . g o v \cdot b r / s o b r e / p e r g u n t a s-f r e q u e n t e s$

11

http://portal.mec.gov.br/index.php?option=com content\&view=article\&id=290\&Itemid=816

12 The laws cited in this paragraph are available for public access and are included in the references of this article respectively as: 1) Brasil, 2004a; 2) Brasil, 2008; 3 ) Brasil, 2010; 4) Brasil, 2012; 5) Brasil, 2014.

\section{References}

Brasil. (2004a). Diretrizes Curriculares Nacionais para a Educação das Relações Étnico-Raciais e para o Ensino De História e Cultura AfroBrasileira e Africana. Brasília. DF. Retrieved from http://www.acaoeducativa.org.br/fdh/wp-content/uploads/2012/10/DCNs-Educacao-das-Relacoes-Etnico-Raciais.pdf

Brasil. (2004b). [Lei de Diretrizes e Bases da Educação Nacional (1996)] LDB: Lei de Diretrizes e Bases da Educação:(Lei 9.394/96) e legislação correlata / Coordenação André Arruda. - Rio de Janeiro: Roma Victor. Retrieved from http://www.planalto.gov.br/ccivil_03/Leis/L9394.htm Brasil. (2008). Lei $n^{\circ} 11.645$, de 10 de março de 2008. República Federativa do Brasil: Poder Legislativo, Brasília-DF. Retrieved from http://www.planalto.gov.br/ccivil_03/_ato20072010/2008/lei/111645.htm

Brasil. (2010). Lei $n^{\circ} 12.288$, de 20 de julho de 2010. República Federativa do Brasil: Poder Legislativo, Brasília- DF. Retrieved from http://www.planalto.gov.br/ccivil 03/ Ato20072010/2010/Lei/L12288.htm\#art60

Brasil. (2012). Lei $n^{\circ} 12.711$, de 29 de agosto de 2012. República Federativa do Brasil: Poder Legislativo, Brasília-DF. Retrieved from 
http://www.planalto.gov.br/ccivil_03/_ato20112014/2012/lei/112711.htm

Brasil. (2014). Lei $n^{\circ} 12.990$, de 9 de junho de 2014. República Federativa do Brasil: Poder Legislativo, Brasília-DF. Retrieved from http://www.planalto.gov.br/ccivil_03/_Ato20112014/2014/Lei/L12990.htm

Brasil. (2015). Pesquisa Nacional por Amostra de Domicílios Estudos. Síntese de indicadores sociais - uma análise das condições de vida da população brasileira - 2013. IBGE - Instituto Brasileiro de Geografia e Estatística. Retrieved from http://biblioteca.ibge.gov.br/visualizacao/livros/liv94414.pdf

Cavalleiro, E. (2000). Do silêncio do lar ao silêncio escolar - racismo, preconceito e discriminação na educação infantil. São Paulo, Contexto. Cunha Jr. (2008). Abolição inacabada e a educação dos afrodescendentes. Revista Espaço Acadêmico, nº 89.

Retrieved from http://www.espacoacademico.com.br/089/89cunhajr.pdf Domingues, P. J. (2002). Negros de Almas Brancas? A ideologia do branqueamento no interior da comunidade negra em São Paulo, 19151930. Estudos Afro-Asiáticos, 24(3), 563-599. Retrieved from http://www.scielo.br/pdf/eaa/v24n3/a06v24n3

Domingues, P. J. (2009). O recinto sagrado: educação e antirracismo no Brasil. Cadernos de Pesquisa, 39(138), 963-994. Retrieved from http://www.scielo.br/pdf/cp/v39n138/v39n138a14.pdf

Freire, P. (2001). Política e educação. Coleção Questões da Nossa Época, V. 23, 5. ed - São Paulo, Cortez.

Gomes, N. L. (2001). Educação cidadã, etnia e raça: o trato pedagógico da diversidade. In: Racismo e anti-racismo na educação: repensando nossa escola /Eliane Cavalleiro (Organizadora). São Paulo: Selo Negro. 8396.

Gomes, N. L. (2008). Sem perder a raiz: corpo e cabelo como símbolos da identidade negra. $2^{\mathrm{a}}$ ed. - Belo Horizonte: Autêntica. 
Gomes, N. L. (2009). In: Negritude: usos e sentidos. Kabengele Munanga Belo Horizonte: Autêntica Editora - (Coleção Cultura Negra e Identidades).

Gomes, N. L. (2011). Diversidade étnico-racial, inclusão e equidade na educação brasileira: desafios, políticas e práticas. $R B P A E, 27(1), 109$ 121. Retrieved from http://seer.ufrgs.br/rbpae/article/viewFile/19971/11602

Gomes, N. L. \& Jesus, R. E. de (2013). As práticas pedagógicas de trabalho com as relaçoes étnico-racias na perspectiva de Lei 10.639/2003:desafios para a política educacional e indagações para a pesquisa. Educar em Revista, Curitiba, Brasil, 47. Editora UFPR. 19-33. Retrieved from http://www.scielo.br/pdf/er/n47/03.pdf

Gonçalves, O. A. L \& Silva, G. B. P. (2000). Movimento Negro e educação. Revista Brasileira de Educação, $n^{0}$ 15, p.134-158. Set/Out/Nov/Dez . Retrieved from http://www.scielo.br/pdf/rbedu/n15/n15a09.pdf Haerter, L., Nunes, G. H. L. \& Cunha, D. T. R. (2013). Refletindo acerca da contribuição da cultura quilombola aos currículos da educação básica brasileira, através da história da presença da história da África e AfroBrasileira. Identidade, vol.18, $\mathrm{n}^{\mathrm{o}} 3$. Retrieved from http://periodicos.est.edu.br/index.php/identidade/article/view/1175 IPEA. (2014). Situação social da população negra por estado / Instituto de Pesquisa Econômica Aplicada; Secretaria de Políticas de Promoção da Igualdade Racial. - Brasília : IPEA, 2014. Retrieved from http://www.ipea.gov.br/portal/images/stories/PDFs/livros/livros/livro_sit uacao-social-populacao-negra.pdf

Ianni, O. (2004). Raças e classes sociais no Brasil. São Paulo: Brasiliense. Maciel, C. S. (1985) Discriminações raciais: negros em Campinas (18881926) alguns aspectos. Dissertação de Mestrado. Departamento de História. Instituto de Filosofia e Ciências Humanas. UNICAMP. Maio, M.C. \& Santos, R.V. (2005). Política de cotas Raciais, os "olhos da sociedade" e os usos da antropologia: O caso do vestibular da Universidade de Brasília (UNB). Horizontes Antropológicos, Porto 
Alegre, 11(23), 181-214. Retrieved from http://www.scielo.br/pdf/ha/v11n23/a11v1123.pdf

Moehleck, S. (2002). Ação afirmativa: história e debates no Brasil.

Cadernos de Pesquisa, 117, 197-217. Retrieved from

http://www.scielo.br/pdf/cp/n117/15559.pdf

Munanga, K. (2003). Política de ação afirmativa em benefício da população negra no Brasil: um ponto de vista em defesa de cotas. In: Educação e Ações Afirmativas; entre a injustiça simbólica e a injustiça econômica. Brasília, INEP. 115-128.

Munanga, K. (2006). Rediscutindo a mestiçagem no Brasil - Identidade nacional versus identidade negra. - $2^{\mathrm{a}}$ ed., 1reimp. - Belo Horizonte: Autêntica.

Munanga, K. \& Gomes N. L. (2006). O negro no Brasil de hoje. São Paulo: Global. (Coleção para entender).

Oliveira, I. M. A.(2008). A ideologia do branqueamento na sociedade brasileira. Secretaria do Estado do Paraná.Universidade Estadual do Norte do Paraná. Paraná. Retrieved from http:/www.diaadiaeducacao.pr.gov.br/portals/pde/arquivos/1454-6.pdf Osório, R. G. (2009). Classe, raça e acesso ao Ensino Superior no Brasil. Cadernos de Pesquisa, 39(138), 867-890. Retrieved from http:/www.scielo.br/pdf/cp/v39n138/v39n138a09.pdf

Piovisan, F. (2005) Ações afirmativas da perspectiva dos direitos humanos. Cadernos de Pesquisa. São Paulo, 35(124), 43-55. Retrieved from http://www.scielo.br/pdf/cp/v35n124/a0435124.pdf

Santos, G. (2009). Relações raciais e desigualdade no Brasil. São Paulo:

Selo Negro (Consciência em debate / coordenada por Vera Lúcia Benedito). 
Daniela Mara Gouvêa Bellini: NIASE/ Universidade Federal de São Carlos (Brazil).

Dr ${ }^{\mathrm{a}}$. Francisca de Lima Constantino: NIASE/ Universidade Federal de São Carlos (Brazil).

Contact Address: Rod. Washington Luis - km 235, São Carlos SP/Brazil - CEP: 13565-905 


\section{HSE}

Historia Social y de la Educación

Social and Education History
Hipatia Press

www.hipatiapress.com

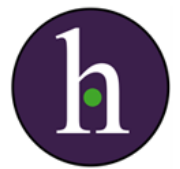

Instructions for authors, subscriptions and further details:

$\underline{\text { http://hse.hipatiapress.com }}$

Segle XIX. Esperances i fracassos de la modernitat a l'educació. Situació d'Espanya

Joan Tahull ${ }^{1}$, Iolanda Montero² i Fidel Molina ${ }^{1}$

1) Universitat de Lleida. GESEC (Grup d'Estudis sobre Societat, Salut, Educació i Cultura) (Spain)

2) Departament d'Ensenyament (Generalitat de Catalunya)

Date of publication: February $23^{\text {rd }}, 2016$

Edition period: February 2016 - June2016

To cite this article: Tahull, J., Montero, I., \& Molina, F. (2016). Segle XIX. Esperances i fracassos de la modernitat a l'educació. Situació d'Espanya. Social and Education History 5(1), 26-51. doi:10.17583/hse.2016.1718

To link this article: http://dx.doi.org/10.17583/hse.2016.1718

\section{PLEASE SCROLL DOWN FOR ARTICLE}

The terms and conditions of use are related to the Open Journal System and to Creative Commons Attribution License (CC-BY). 


\section{Segle XIX: Esperances i Fracassos de la Modernitat a l'Educació. Situació d'Espanya}

Joan Tahull

Universitat de Lleida (Spain)

Iolanda Montero

Fidel Molina

Departament d'Enseyament

Universitat de Lleida (Spain)

\section{Resum}

La Modernitat s'inicia al segle XV i cristal-litza al XIX amb unes característiques molt concretes. Aquest període es caracteritza per l'ús de la raó com a element prioritari en l'organització de les diverses institucions socials. També van aparèixer destacats corrents liberals. El procés de modernització tingué moltes dificultats per consolidar-se en les escoles espanyoles al llarg del segle XIX. Aquest article pretén mostrar algunes d'aquestes dificultats: inversions minses, equipaments educatius deficients, alt nombre d'analfabets, consideració social del mestre negativa... La investigació mostra la institució educativa en un context més ampli: històric, social i cultural. Massa vegades s'ha presentat l'escola com una institució aïllada i isolada, separada d'allò que s'esdevé fora de l'aula. També, s'interpretaa partir dels elements socials i culturals més significatius.Aquesta visió ens obrirà a noves perspectives per comprendre l'educació del segle XIX. Unes elits molt rellevants $\mathrm{i}$ amplis sectors de la societat valoraven negativament la Modernitat i els corrents liberals; també, aquesta visió la tenien de totes les aportacions modernes i liberals per transformar les escoles.

Paraules clau: poder, societat, racionalitat, escola. 


\section{Siglo XIX. Esperanzas y Fracasos de la Modernidad en Educación. El Caso de España}

Joan Tahull

Universitat de Lleida (Spain)

Iolanda Montero

Fidel Molina

Departament d'Enseyament

Universitat de Lleida (Spain)

\section{Resumen}

La Modernidad surge en el siglo XV y cristaliza en el XIX con unas características muy específicas. Este periodo se caracteriza por el uso de la razón como elemento prioritario en la organización de las diferentes instituciones sociales. También aparecieron importantes corrientes liberales. El proceso de modernización tuvo muchas dificultades para consolidarse en las escuelas españolas a lo largo del siglo XIX. Este artículo pretende mostrar algunas de las dificultades: inversiones escasas, equipamientos educativos deficientes, muchos analfabetos, consideración del maestro negativa... La investigación muestra la institución educativa en un contexto más amplio: histórico, social y cultural. Muchas veces se ha presentado la escuela como una institución aislada, separada de lo que sucede fuera del aula. También, se pretende interpretarla a partir de los elementos sociales y culturales más significativos. Esta visión dará nuevas perspectivas para comprender la educación del siglo XIX. Unas élites muy relevantes y amplios sectores de la sociedad valoraban negativamente la Modernidad y las corrientes liberales; también, esta visión la tenían de todas las aportaciones modernas y liberales para transformar las escuelas.

Palabras clave: poder, sociedad, racionalidad, escuela 


\section{Nineteenth \\ Century. Hopes and Failures of Modernity in Education. Situation of Spain}

Joan Tahull

Universitat de Lleida (Spain)

Iolanda Montero

Fidel Molina

Departament d'Enseyament

Universitat de Lleida (Spain)

\section{Resumen}

Modernity begins in the fifteenth century and it consolidates in the nineteenth with very specific characteristics. This period is characterized by the use of reason as a priority element in the organization of the various social institutions. Also, some important liberal currents appeared. The modernization process had many difficulties to consolidate in the Spanish schools throughout the nineteenth century. This article aims to show some of the difficulties: low investment, poor educational facilities, many illiterate people, a negative consideration of the teacher ... The investigation shows the school in a broader context: historical, social and cultural. Many times the school has been presented as an isolated institution, separated from what happens outside the classroom. It also aims to interpret the school from the most significant social and cultural elements. This vision will give new perspectives to understand the education of the nineteenth century. Some relevant elites and broad sectors of society valued modernity and liberal currents negatively; this negative point of view was due to modern and liberal contributions to transform schools.

Palabras clave: power, society, rationality, school. 
quest article $^{1}$ tracta de l'educació a Espanya al llarg del segle XIX. Vol presentar les principals característiques de l'escola i situar-la 1 en un context històric, social i cultural. Massa vegades s'ha estudiat la institució educativa com una entitat tancada i isolada en ella mateixa, separada de tot allò que s'esdevé a l'exterior de les aules. Aquesta investigació pretén relacionar escola i societat. Veure les connexions i imbricacions d'aquests elements. Mostrar com els fets històrics més destacats tenen una significació directa als centres educatius. El marc social i cultural determina la vida quotidiana de les aules.

La Modernitat sorgeix a finals del segle XV i es desenvolupa al llarg dels segles fins que cristal-litza al XIX amb unes característiques molt específiques. La política, l'economia, les qüestions socials... tenen transformacions cabdals, molt importants. Hi ha un trencament sobtat $\mathrm{i}$ brusc. S'implementa en els diferents àmbits de la societat un procés de racionalització i apareixen aires de llibertat. L'educació no és aliena a aquests canvis socials i culturals i els introdueix a les aules. Hi ha un interès per l'ensenyament i per desenvolupar una escola més racional i lliure. Durant aquest segle s'estableix una relació entre ensenyament i benestar material i moral. Els partits polítics del moment feien constantment referència a la importància de l'educació per la regeneració del país. Tanmateix, aquestes afirmacions contrastaven amb la realitat. La professió docent estava desprestigiada. La situació de l'educació a Espanya era molt negativa i el professor tenia poca consideració social.

En la següent investigació mostraré els principals elements de la Modernitat i les connexions amb la institució educativa. Per desenvolupar-la, seguiré diferents apartats. Començaré amb unes consideracions prèvies, on situaré els principals elements socials i culturals de la Modernitat a Espanya al llarg del segle XIX. Presentaré les principals característiques d'aquest període i la plasmació en diversos països europeus (França i Anglaterra principalment). El següent apartat tractarà sobre la importància de l'educació al llarg del segle XIX. Diferents corrents, autors i lleis consideren l'escola una institució fonamental d'una nova societat. A continuació, veurem com aquests ideals progressistes topen amb una realitat conservadora i reaccionaria. Moltes reformes mai es consoliden i la millora educativa és 


\section{Tahull, Montero i Molina - Segle XIX}

molt lenta. Acabaré aquest article presentant unes consideracions finals, on es mostren les conclusions.

Per tal de realitzar aquest article s'han utilitzat diferents fonts bibliogràfiques, les quals m'han ajudat a construir el relat com un tot. Un problema important a totes les investigacions, també en aquesta és la subjectivitat. Tothom interpreta la realitat i la descriu a partir de si mateix. Tanmateix, la subjectivitat no s'ha de veure com una limitació i/o parcialitat, al contrari, és un element propi i interessant de l'objecte d'estudi. En tot cas, l'investigador ha de triangular la informació, és a dir, ponderar, valorar, situar i contrastar les dades (Ander Egg, 2000). Tota la informació recollida per tal de realitzar l'article m'ha permès tenir una visió àmplia i profunda de la Modernitat, el segle XIX i l'educació. La triangulació ha estat un eina metodològica fonamental per la construcció del relat. Evidentment, no tota la informació recollida apareix en el text, però totes les dades han estat importants per construir el relat i ponderar la informació.

\section{Consideracions Prèvies. Principals Elements Socials i Culturals}

Aquest segle inclou el període històric que arrenca al 1800 i finalitza al 1899. Els segles, molts cops, no coincideixen amb els fets històrics de referència. Dos esdeveniments d'una gran rellevància van determinar l'inici i el final d'aquesta etapa. El fet històric que va tenir una influència directa al segle XIX fou la Revolució Francesa (1789), la qual va crear les condicions d'una nova societat, primer a França i després a la resta d'Europa i del món. L'esdeveniment fonamental que es considera la finalització dràstica del segle XIX fou la Primera Guerra Mundial (1914-1918). Els somnis i il-lusions d'aquest període van finalitzar de forma contundent amb el conflicte bèl·lic.

S'ha de tenir en compte que els fets del segle XIX estaven relacionats amb esdeveniments anteriors. Les diverses manifestacions s'enllacen les unes amb les altres. La Revolució Francesa té connexions amb el procés de racionalització i secularització iniciat a finals del segle XV. L'evolució d'aquests fets van donar lloc al xoc violent i dramàtic del 1789.

La Revolució Francesa va trencar amb un model social, el qual es caracteritzava pel fet que determinats col·lectius tenien importants privilegis. 
La noblesa i els membres de la religió catòlica tenien uns drets assolits. Per contra, hi havia la part dèbil de l'estructura social, el poble. Aquest agrupava diversos collectius, pagesos i treballadors principalment. Aquests eren els sectors productius. La societat de l'Antic Règim era una estructura social configurada per dos grups genèrics, els productors i els beneficiaris. Els primers estaven integrats per una part molt important de la població; per contra, els segons era un grup molt reduït.

Una altra característica de la societat d'abans de la Revolució Francesa, era la rigidesa i la poca mobilitat social. El fet de néixer en una classe social determinava d'una forma radical el futur de l'infant. La família influïa en la futura vida de l'individu de manera substancial. Les possibilitats econòmiques de la majoria de les famílies eren de supervivència bàsica. Les seves condicions estaven sempre al límit de la pobresa. En aquella societat, la situació dels treballadors (pagesos) era molt vulnerable; qualsevol imprevist comportava una situació econòmica límit. Ells subvencionaven els privilegis de les elits, mitjançant els diversos impostos. Moltes vegades el poble vivia en una situació econòmica insostenible.

Els col·lectius més desfavorits, una part important de la societat, estaven en total desacord amb aquest sistema social i econòmic. El consideraven perjudicial per als seus interessos. Hi havia una situació d'extrema desigualtat social. Aquest descontent i la irrupció de noves idees liberals van crear les condicions per enfonsar l'Antic Règim. Una de les manifestacions més importants d'aquest trencament fou la Revolució Francesa, amb la introducció d'idees de llibertat, fraternitat i igualtat. Aquests elements entraven en flagrant contradicció amb els valors d'abans de la revolució. Van construir el model d'una nova societat. Els privilegis de la noblesa $\mathrm{i}$ l'Església havien de ser eliminats. Aquest procés no fou d'un dia per un altre, en alguns casos aquesta evolució va durar molt temps. Així mateix, s'ha de tenir en compte que aquest fet va ser diferent als diversos països europeus. Va començar a França i es va estendre per la resta d'Europa. La seva influència fou d'intensitat variada, hi van haver nacions que van acollir l'esperit revolucionari amb entusiasme; en canvi, d'altres, per diferents motius, se'n van allunyar. L'objectiu era assolir una societat més justa i igualitària. Ningú havia de tenir uns privilegis determinats per haver nascut en un lloc o una família concreta. 


\section{Tahull, Montero i Molina - Segle XIX}

Al llarg del segle XIX, un altre fenomen, no menys rellevant, va tenir una importància cabdal. La Revolució Industrial va transformar de dalt a baix Anglaterra i la resta d'Europa. S'ha de tenir en compte que ambdós fets estan íntimament relacionats. La Revolució Francesa va crear les condicions socials d'un desenvolupament econòmic mai conegut fins al moment. La Revolució Industrial va desenvolupar-se en primer lloc a Anglaterra, a la segona meitat del segle XVIII; però al llarg del XIX es va estendre pels diversos països europeus. Durant aquest segle el desenvolupament industrial determinava el grau de riquesa i progrés de cada país. Anglaterra, al llarg d'aquest període que abraça 150 anys, fou considerat el país més industrialitzat $\mathrm{i}$ influent del món.

La Revolució Industrial es caracteritzà per les importants transformacions en els àmbits econòmic, social i polític. Es passà d'un model econòmic dominat pel treball manual a la fàbrica. Va haver-hi el pas d'una economia artesanal (gremial) a una economia industrial. Aquesta revolució es produí a causa de la progressiva mecanització de les indústries, principalment tèxtils. La mecanització de les fàbriques va comportar un fort augment de la producció. Cada cop feien més productes a preus més competitius. La racionalització va entrar al món de l'empresa.

Un element fonamental que va aparèixer en aquest estadi, en un grau mai vist fins llavors, fou el comerç. L'augment de la producció determinava que l'oferta i la demanda s'havien de trobar. Això va comportar un augment important de les vies de comunicació. Els consumidors havien de tenir accés als béns. Aquest increment de la producció va possibilitar un fort desenvolupament del comerç nacional i internacional. Les vies de comunicació van multiplicar-se en poc temps. El tren i el vaixell foren els principals mitjans utilitzats per transportar productes. La Revolució Industrial va trencar les condicions d'un model econòmic artesanal (més proper i senzill) a un sistema més mecanitzat (més complex i específic). La transformació del sistema econòmic va produir canvis fonamentals en la societat.

L'organització del taller artesanal era diferent a la fäbrica. Al primer, el treballador era una artesà de la seva feina, un professional. Tenia un domini acurat de la tècnica per fer i acabar el producte. Així mateix, era el responsable de totes les fases de la producció. Hi havia una relació directa entre el professional i el resultat final. L'artesà estava relacionat íntimament 
amb el producte final. Per contra, el treballador de la fàbrica no tenia aquesta connexió amb l'empresa, ni amb el béns produïts. No tenia una visió global de tot el procés, solament d'una part específica. Estava incrustat dins un complex engranatge. Únicament era una peça d'un puzzle i la seva funció consistia a repetir moviments rutinaris i mecànics. Coriat exposa el canvi d'estatus del treballador:

Al acabar con el control obrero sobre los modos operatorios, al sustituir los secretos profesionales por un trabajo reducido a la repetición de gestos parcelarios -en pocas palabras, al asegurar la expropiación del saber obrero y su confiscación por la dirección de la empresa- el cronómetro es, ante todo, un instrumento político de dominación sobre el trabajo, el taylorismo va a transformarse en un verdadero conjunto de gestos de producción, en un código formalizado del ejercicio del trabajo industrial, con la organización científica del trabajo. Como instrumento esencial de ese proceso de reducción del saber obrero de fabricación a la serie de sus gestos elementales, el cronómetro es, por la misma razón, mucho más que eso (Coriat, 2001, p.3).

El rol del treballador quedava desvaloritzat a la fàbrica. Les tasques mecàniques $\mathrm{i}$ rutinàries de la indústria no exigien uns coneixements $\mathrm{i}$ una formació molt extensa. Qualsevol individu, amb poques capacitats, podia aprendre ràpidament allò que s'havia de fer. La tasca era fàcilment intercanviable per qualsevol altre treballador. No era necessària una formació global i integral, com als tallers gremials. Hi hagué una transformació social del treballador, passant de l'obrer professional a l'obrer-massa. Aquest va entrar majoritàriament a la fàbrica, tenint una menor qualificació i menys organització col·lectiva. Anteriorment, els gremis tenien molta força i defensaven els seus interessos amb contundència. Amb el trencament d'aquestes estructures i la progressiva implantació del treball industrial, el treballador perdia impuls per defensar els seus drets. Molts cops, els assalariats es representaven a si mateixos. Aquests treballadors tenien un sentiment de col·lectivitat més difús, en comparació als artesans. 


\section{Tahull, Montero i Molina - Segle XIX}

La Revolució Industrial estableix els fonaments d'una societat nova. Aquest marc social i cultural té relació amb l'economia. Les organitzacions empresarials desenvolupen al màxim la racionalitat i la cientificitat. S'havien d'optimitzar recursos $\mathrm{i}$ assolir la màxima rendibilitat. Per aconseguir-ho, hi ha una nova interpretació del temps. Deixa de ser valorat com quelcom difús i infinit i passa a ser analitzat en la seva màxima concreció. El cronòmetre permet planificar i ser més eficient en les accions. L'objectiu era fer més amb menys temps. La rendibilitat d'una empresa es mesurava per la gestió eficaç del temps. Tots els processos podien millorar, aprofundint en la racionalització.

Els canvis a les fàbriques, durant el segle XIX, van tenir conseqüències profundes en la societat. La implementació d'aquests mètodes transformà una forma de treballar que s'havia donat al llarg dels segles. Així mateix, van aparèixer conflictes socials pels canvis en les organitzacions productives. Molts cops, la relació entre el patró i el treballador era difícil. Aquests havien perdut el control de la producció dels béns. La màquina marcava el ritme a seguir pels treballadors. Les condicions de treball tenien tendència a uniformitzar-se i homogeneïtzar-se en tot el procés productiu. Aquest model era vist amb recel pels treballadors. La relació entre l'home i la tècnica era difícil. Van haver-hi conflictes, al llarg del segle XIX, d'individus desesperats trencant màquines de les fàbriques. Per ells, eren les culpables de les seves desgràcies. Una altra forma de lluitar pels seus drets era boicotejar els productes de les empreses. La història de la classe obrera recull diverses companyes de boicot, fins i tot, en alguns casos, van provocar la desaparició d'alguna empresa.

\section{Impuls de l'Educació. L'Escola pren Importància a la Societat}

L'escola va desenvolupar-se i estendre al llarg del segle XIX. Tenia l'encàrrec de formar els futurs ciutadans i legitimar l'estructura social existent. Durant el segle es desenvolupà un model social i cultural que s'apropià dels valors moderns. L'escola havia de transmetre les bondats $\mathrm{i}$ possibilitats d'aquesta nova societat. En el següent fragment s'explica la transformació de l'individu i la societat durant la Revolució Industrial i la relació amb l'àmbit escolar: 


\section{HSE - Social and Education History, 5(1)35}

La més gran autonomia de l'individu en la societat industrial no és fruit de la dissolució de l'organització social, sinó el resultat de les exigències funcionals d'un cert tipus de societat global. L'educació juga un paper fonamental en aquest tipus de societat per tal d'assegurar la cohesió social entre els individus, al mateix temps que ha de respectar l'especialització necessària al funcionament social (Homs, 1991, p.27).

L'autor ${ }^{2}$ descriu el canvi de paradigma en una societat industrial. En aquest model els individus tenen menys lligams i més autonomia. El context és més complex, fragmentat i especialitzat. L'escola havia de construir un nou individu i una nova societat. Crear un ciutadà adaptat a la societat del moment. L'escola havia de donar els fonaments per una societat estructurada i cohesionada; però també, individualitzada i especialitzada. La Modernitat s'havia incrustat de forma desigual als països europeus, també a Espanya. La introducció d'aquests elements a l'àmbit educatiu espanyol fou molt lent. Hi havia necessitat d'un fort impuls per transformar l'escola, per la formació, per l'adaptació del país a una nova conjuntura. Espanya s'havia d'adaptar a la Modernitat. Tanmateix, aquestes necessitats topaven amb la realitat. Brenan considera que "el liberalismo nunca echó profundas raíces en España" (1978, p. 279).

Al llarg del segle XIX van haver-hi diferents aportacions legislatives rellevants en referència a l'educació. Les transformacions socials i culturals demanaven una translació d'aquestes realitats a les escoles. S'havien de fer lleis educatives adequades als temps. Les transformacions econòmiques exigien una educació per tots els ciutadans. En una societat més atomitzada els individus havien d'exercir la llibertat d'una forma més responsable. L'escola havia de formar ciutadans per gestionar el procés d'individualització. Al llarg del segle, a Espanya, l'educació era un element clau $\mathrm{i}$ un àmbit de lluita social $\mathrm{i}$ política. Les diverses sensibilitats ideològiques volien crear una educació afí a les seves tesis. Els dos pols principals eren els liberals i els conservadors. En l'àmbit educatiu, els liberals feien les propostes més avançades de l'època. El desenvolupament de les tesis progressistes no era fàcil. Molts sectors interpretaven aquests ensenyaments contraris als seus interessos. L'Església catòlica, i els partits 


\section{Tahull, Montero i Molina - Segle XIX}

conservadors, pressionaven a tots els sectors per defensar els seus posicionaments. La qüestió religiosa a l'educació era un tema de debat continu al llarg del segle XIX, sense solucionar-se d'una forma acceptable. L'Església volia influir en tot lo educatiu:continguts, metodologies, matèries... Considerava la institució educativa com un continu de si mateixa. A Espanya, durant el segle XIX, l'Església estava fortament incrustada en els àmbits més elevats de poder. La seva influència era molt important. Ossembach afirma que "el establecimiento del Estado liberal suposo en muchos aspectos un conflicto con la Iglesia y las instituciones religiosas. Esta tensión fue muy relevante principalmente en el terreno de la educación" (Ossembach, 2012, p. 32).

Aquests conflictes eren diferents en els països europeus, per exemple França havia tingut la Revolució Francesa (1789), un esdeveniment que configurà la seva identitat al llarg dels segles XIX i XX. Aquests fets van esmicolar l'estructura social de l'Antic Règim i creà un nou model social secularitzat i modern. Durant els segle XIX i XX, l'escola francesa no tingué les lluites ideològiques d'Espanya. Un cop consolidat el trencament, el model era més clar i estable. L'ensenyament laic era un element fonamental de l'escola pública moderna. Matèries pròpies de l'Antic Règim: el grec, el llatí...van ser substituïdes per altres: la llengua francesa, les matemàtiques, la història, la geografia, les ciències naturals... El procés de modernització a França fou radical i intens. El model era centralitzat, unificat, secularitzat i uniforme.

En canvi, el procés a Anglaterra fou diferent. La Revolució Industrial va començar al país anglosaxó i d'aquí va estendre's per tota Europa. El procés de racionalització aplicat a la fàbrica, a la cadena de muntatge, va crear les condicions d'una nova economia i d'una nova societat. Tanmateix, aquest procés de modernització i racionalització de les tècniques de treball, no va donar-se amb la mateixa intensitat a l'àmbit educatiu. L'existència d'un currículum nacional, el finançament, el control públic, l'organització administrativa de l'educació... van tardar a arribar a Anglaterra. L'educació estava, a finals del segle XIX i principis del XX, endarrerida en referència a altres països europeus. Per exemple, Prússia va legislar l'educació obligatòria a l'escola fins als 14 anys el 1826, en canvi, Anglaterra va fer-ho l'any 1921 (Lozano, 1994). 
En referència a Espanya, diferents normatives van legislar sobre ensenyament. Hi havia un cert interès per organitzar aquest àmbit. La Constitució de Cadis (1812) senyalava els principis educatius fonamentals. Els principis liberals es presentaven de forma limitada i retallada. El principi d'escolarització obligatòria donava una formació bàsica a tots els infants,però no tothom hi estava d'acord. Per alguns sectors no era prioritari. Aquests assumptes estaven presents a la llei de manera difusa; en canvi, en referència a l'educació religiosa no hi havia ambigüitats. La llei manava explicar determinats continguts obligatoris a tot l'estat:la moral cristiana, la Constitució... La Constitució de 1812 era un acord genèric que demanava la concreció de lleis i reglaments més específics (Rotger, 1990).

A partir de la Constitució, com a document principal, les diverses sensibilitats ideològiques havien de consensuar l'educació de tots els nens espanyols. Aquesta era una gran oportunitat per desenvolupar una política educativa agosarada, profunda $i$ integradora. Alguns dels millors especialistes de l'època van fer propostes interessants, com "El Informe de la Junta creada por la regencia para proponer los medios al arreglo de los diversos ramos de la instrucción pública”, publicat el 1813 i conegut com Informe Quintana. Exposava els principis generals òptims dels liberals progressistes. L'escola havia de desenvolupar els talents, ensenyar els drets $\mathrm{i}$ les obligacions i fer els ciutadans més feliços. S'havia de garantir la igualtat d'oportunitats.Tots els infants, amb esforç, intel-ligència i sort, havien de tenir possibilitats de millorar la seva situació inicial. Els privilegis i drets adquirits havien de ser superats per construir una societat més justa $\mathrm{i}$ igualitària. Aquest document fou important, però mai es va portar a la pràctica.

\section{Limitacions de la Implementació de Polítiques Educatives Progressistes}

\section{Marc Legislatiu}

L'Informe Quintana donava eines per desenvolupar una educació diferent, més progressista, però no va tirar endavant. Moltes tesis eren considerades excessivament progressistes per l'època. Aquest document mai va ser llei d'obligat compliment. El 1821 va aprovar-se el Reglamento General de la Instrucción Pública, un document menys ambiciós. Aquest reglament 


\section{Tahull, Montero i Molina - Segle XIX}

organitzava el sistema educatiu i el dividia en tres nivells: Primera Ensenyança, Segona Ensenyança i Tercera Ensenyança. La primera era el fonament de l'ensenyament, la més important i necessària. L'accés era universal, per tothom. Els alumnes havien d'aprendre a llegir, escriure i comptar; també conèixer els drets i les obligacions dels ciutadans, sempre des de la moral cristiana. La Segona Ensenyança tenia un contingut propi i permetia l'accés al nivell superior. No hi havia continuïtat entre la primera $\mathrm{i}$ la segona ensenyança; en canvi sí, entre la segona i la tercera. Aquests dos nivells no eren universals, estaven destinats a sectors minoritaris. El tercer nivell encara era més elitista, destinat a grups reduïts. Aquests ocuparien en el futur els llocs privilegiats de la societat (Rotger, 1990).

La Llei Moyano (1857) fou la llei espanyola que va organitzar l'educació de la segona meitat del segle XIX. La seva influència en el temps fou molt llarga. Va introduir l'obligatorietat i gratuïtat de l'ensenyança bàsica a les classes més desfavorides. La llei introduïa l'obligatorietat de l'educació, però al mateix temps, no s'invertien els diners necessaris. Hi havia una situació de desconcert. La norma afirmava quelcom que no es materialitzava. Molts articles de la llei mai es van desenvolupar ja que no tenien assignació pressupostària. Aquest document mantenia els privilegis de l'Església.

La lluita ideològica va durar tota la segona meitat del segle. La relació entre religió, política i educació era molt pròxima. Qualsevol intent d'aplicar polítiques progressistes era tallat d'arrel. Els conservadors utilitzaven la repressió i un control intens per mantenir la situació sota control. Molts professors lluitaven per una altra educació, més oberta i plural. Va haver-hi un debat intens a propòsit de la llibertat de càtedra. La perspectiva sobre aquest tema era radicalment diferent en funció de l'opció política. Els límits no estaven clars i eren interpretats de forma diversa:

La libertad de cátedra, es decir, el derecho del profesor a enseñar la verdad, escondía una variedad de preguntas: ¿puede el profesor enseñar cosas que atenten contra la moral?, ¿o contra el Estado? Si el profesor debe enseñar la verdad, ¿dónde está esa verdad?, ¿en la ciencia?, ¿en la religión católica? Si la libertad del profesor debe ser limitada, ¿quién tiene capacidad de hacerlo?, ¿puede intervenir el Estado controlando la labor docente de los profesores? A todas estas preguntas se contestó de muy diversa manera. Para los 
conservadores, las enseñanzas del profesor no podían atentar contra los principios de la religión católica, ni contra la monarquía constitucional, reservándose el Estado el poder de intervenir en estas materias a través del control de programas y de libros de texto. En el extremo opuesto, los republicanos defenderán la no injerencia del Estado (Sánchez Agustí, 2002, p. 81).

La qüestió de la llibertat de càtedra va aixecar moltes polèmiques. Professors prestigiosos van ser apartats del lloc de treball per no seguir les directrius conservadores del govern. Destaquen els fets de 1868, els quals van tenir com a conseqüència els expedients disciplinaris i la inhabilitació per exercir la docència de coneguts professors: Sanz del Río, Salmerón, Giner de los Ríos...

\section{Idees Progressistes. Corrents Renovadors}

La llei Moyano va tenir una influència duradora. La lluita per la qüestió religiosa va quedar lluny de resoldre's. A final del segle XIX, va aparèixer un moviment alemany que va tenir importància a Espanya, el Krausisme. Aquesta doctrina defensava la tolerància ideològica i la llibertat de càtedra, contra el dogmatisme $\mathrm{i}$ el fonamentalisme eclesiàstic. El seu fundador fou Krause (1781-1832), qui defensava la tolerància de l'individu vers les diferències religioses, culturals i polítiques.

La filosofia krausista tingué implicacions pedagògiques directes. L'aprenentatge ha de consistir en un contacte directe amb la natura. Per Krause, la pedagogia ha de ser experimental, s'ha de veure i tocar. També, dóna molta importància a les excursions; s'ha d'observar, sense intermediaris, allò estudiat. El professor ha d'acostar a l'alumne l'objecte examinat. Així mateix, el coneixement ha de ser progressiu. Els nivells més primerencs han de ser principalment empíric. L'alumne ha de tocar, veure $\mathrm{i}$ manipular els objectes. A mesura que va adquirint coneixements, aquests seran més generals, complexos i abstractes. En els nivells superiors s'ha de relacionar i cercar lligams entre les diverses matèries. Els conceptes no s'han d'interpretar en compartiments estancs; al contrari, s'han de cercar connexions. El coneixement veritable relliga els sabers específics. El saber no es presenta fragmentat, sinó unit, com un tot. Aquesta filosofia va més 


\section{Tahull, Montero i Molina - Segle XIX}

enllà d'una determinada manera de veure i organitzar la realitat;també és important les relaciones humanes entre persones, l'ètica. Totes les creences s'han d'acceptar, respectar, tolerar i valorar (Molero, 1987).

El krausisme va tenir una influència destacada a Espanya. Pels sectors progressistes era un referent, donava eines per reivindicar les seves tesis. Principalment, la Universitat era un focus d'irradiació del moviment. Professors com Giner de los Ríos, Sanz del Río, Sama, De Castro, Salmerón i Sainz Rueda van ser alguns dels representants més il·lustres. A Espanya, la Institución Libre de Enseñanza (ILE) va difondre i aprofundí la filosofia krausista. Aquesta va ser fundada el 1876 per alguns dels professors universitaris progressistes més rellevants del moment. Aquesta institució volia provocar una renovació en la vida social, cultural i educativa espanyola. La lluita contra els sectors més conservadors era constant. La influència del krausisme, i més concretament de la ILE, va més enllà del segle XIX i abraça el XX, fins la Guerra Civil espanyola. Al segle XX, destacats polítics, intel·lectuals, escriptors, pintors espanyols de prestigi mundial van ser fortament influïts pels seus ideals (Ruiz \& Tellado, 2014).

En la mateixa línia del krausisme, en l'interès per les reformes pedagògiques, va aparèixer a l'altra banda de l'Atlàntic un psicòleg, filòsof $i$ pedagog que va transformar l'educació Occidental. Aquest renovador nordamericà fou Dewey (1859-1952), qui va introduir el pragmatisme a l'àmbit educatiu $^{3}$. El coneixement no està donat d'una vegada per totes, sinó que és un procés dinàmic sense fi. El coneixement no és dogmàtic ni estàtic. Està subjecte a la provisionalitat $i$ al canvi. L'experiència valida en últim terme el valor d'una tesi. El coneixement, per ser considerat valuós, ha de ser empíric. S'ha d'haver contrastat amb els fets. L'educació s'ha d'allunyar dels coneixements fixos, d'aquells que no tenen contacte directe amb les coses. Els sentits són més importants que l' intel·lecte ja que ratifiquen el saber.

Les aportacions de Dewey a l'educació són diverses i àmplies. Les metodologies aplicades a l'aula han de potenciar els trets característics dels infants. Pel pedagog nord-americà, cada alumne té uns trets concrets que el fan únic i irrepetible. Els educadors han de vetllar per les especificitats de l'alumnat. Dewey diu que "l'infant és intensament actiu, i el problema de l'educació és el problema de promoure les seves activitats específiques, de donar-los una direcció. Amb una direcció, amb un mètode organitzat, aquestes activitats tendeixen cap a uns resultats valuosos"(1985, p.43). 
L'autor interpreta l'infant de forma diferent a com s'entenia fins llavors. Aquest no necessita ser domesticat ni ensinistrat; al contrari, té una individualitat que el fa radicalment diferent. L'autor defensa la personalització de l'educació, així com també, el fet de marcar un camí adequat, una direcció correcta. A més a més, defensa que els infants han d'aprendre amb satisfacció. L'aprenentatge ha de ser agradable i divertit. Per Dewey "tothom està disposat a admetre que el més desitjable seria que l'escola fos un lloc en el qual l'infant pogués realment viure i adquirir-hi una experiència vital plena en si mateixa de sentit i de satisfacció" (1985, p. 53). L'aprenentatge ha de ser entretingut i s'ha de buscar el màxim interès del nen. Les activitats planificades han de motivar; d'aquesta manera, l'infant aprèn $\mathrm{i}$ consolida els coneixements amb més rapidesa i seguretat.

Aquestes aportacions innovadores van aparèixer al món Occidental, també a Espanya. Aquí, la lluita entre els dos pols ideològics va ser dura i llarga. L'opció conservadora obstaculitzava totes les reformes per millorar l'escola. Tenien més influència política i aconseguien mantenir les seves tesis. També, els articles més progressistes de les lleis mai s'aplicaven. Hi havia distància entre les normes educatives i la plasmació a la realitat. Algunes situacions eren paradoxals i contradictòries.

Les elits, polítics, ciutadans...pensaven que l'educació era quelcom important. S'anava establint relació entre ensenyament i benestar, material i moral. La Modernitat exigia una escola adaptada als nous temps. S'havia de capacitar els alumnes vers una societat més complexa, dinàmica i canviant. L'escola havia de formar individus responsables en l'ús de la llibertat:

La llibertat i la ignorància són vistes com a idees contradictòries. A mesura que la ignorància va desapareixent $i$ el poble va adquirint més instrucció, aquest aconsegueix més dosis de llibertat i d'autogovern. Aquest procés provoca que les supersticions i el misticisme absurd vagin desapareixent, ja que aquests elements empresonen el pensament dels homes (Escolano, 1992, p.15).

Progressivament, durant el segle XIX, l'educació va guanyant rellevància en la construcció del futur ciutadà. La instrucció serveix per crear societats més democràtiques. Dewey (1985) estableix la connexió entre democràcia i escola. L'ensenyament protegeix els individus contra la dictadura dels més 


\section{Tahull, Montero i Molina - Segle XIX}

forts i, també, contra la irracionalitat de les masses. Les metodologies modernes posaven en el centre de les activitats: la racionalitat, la planificació, l'ordre, la coherència i la llibertat. Van aparèixer noves metodologies i formes d'abordar la relació amb l'alumnat. Tanmateix, a Espanya aquestes propostes no van desenvolupar-se com en d'altres països. En el següent apartat, presentaré algunes dificultats que va tenir l'escola espanyola per modernitzar-se.

\section{Les dificultats per tenir una escola moderna}

El desenvolupament de l'educació al llarg del segle XIX tingué moltes dificultats a Espanya. Molts projectes no van arribar a concretar-se. La ILE tenia ambiciosos projectes educatius per tot l'Estat, destacava un centre educatiu de referència a Madrid. L'escola de la capital, entre 1879 i 1880, va quedar petita i s'havia d'ampliar. Per aquest motiu, la institució va projectar la construcció d'un nou edifici modern. L'objectiu era construir una escola ales afores de la ciutat, més a prop de la natura. Un centre per aplicar les metodologies pedagògiques més avançades. La institució va adquirir un solar a la Castellana, llavors als afores de la ciutat, i el 1882, el 2 de maig, s'hi va posar la primera pedra.

L'arquitecte Carlos Velasco va fer els plànols del nou centre escolar. Aquest va fer-se seguint l'extensa bibliografia pedagògica estrangera en referència a aquest tipus de construccions. Les obres van començar a un bon ritme, però a poc a poc van anar apareixent dificultats pressupostàries. Hi havia una diferència important entre els recursos disponibles i els necessaris. La ILE va abandonar el projecte i posar a la venda el terreny. L'edifici que havia de ser referent nacional de l'educació va quedar en no res (Sánchez Agustí, 2002, p. 146).

Un dels problemes més greus de l'ensenyament era la precarietat de les seves instal-lacions. Laspalas (1993) explica com el mestre havia de fer classe en llocs poc adients: l'habitació d'una casa, la sala de l'Església, una ermita, un graner, el passadís d'un edifici...La llei Moyano no va significar una millora evident de l'educació a Espanya. El següent fragment dóna una radiografia de l'ensenyament durant aquest segle. Fareferència al número d'escoles, la seva situació, el règim de propietat, l'analfabetisme...: 
Necesario es decirlo, siquiera confesarlo. Estamos muy atrasados en educación popular, mucho más atrasados de lo que se cree. ¿De qué sirve que haya en España veintitrés mil ciento trenta y dos Escuelas públicas, si de ellas siete mil ciento cincuenta y una son incompletas y de temporada, algunas con el pingüe sueldo (¡qué vergüenza!) de cuarenta y dos pesetas anuales?... ¿De qué sirve que tengamos veintidós mil trescientos vientisiete locales de escuela, si nueve mil ciento vientisiete son alquilados, y seis mil ciento veintinueve en estado ruinoso o de condiciones anti-higiénicas?... ¿No causa esto rubor? (...) ¿De qué sirve que acuse la estadística un notable aumento en los que saben leer y escribir, si el setenta y uno por ciento de los que dicen que leen y escriben no son capaces de poner su nombre medianamente escrito, ni de leer cuatro líneas seguidas sin decir un cúmulo de disparates? (...) ¿Y los maestros? Salen de las Escuelas Normales ansiosos de gloria profesional y exuberantes en ricos frutos para la Educación, más apenas empiezan la vida pública, cuando entran en un campo lleno de dificultades y poblado completamente de espinas, y después de luchar un día y otro día, un mes y otros meses, y aun varios años seguidos; huérfanos de protección y abatidos por el cansancio, los más sucumben ante este fanatismo siempre imperante y en todas partes protegido (Sánchez Agustí, 2002, p. 147-149).

L'autor presenta la situació educativa d'Espanya de manera dramàtica. Diferents dades corroboren aquesta exposició. La llei Moyano estableix l'obligatorietat de l'educació elemental, però aquesta s'incomplia sistemàticament. A Valladolid, el 1885, més de 17.000 nens en edat d'escolarització obligatòria del districte universitari d'aquesta ciutat no estaven matriculats a cap escola; suposava un 26.59\% del total (Martín Jiménez, 1994, p. 55). En algunes zones, més de la meitat dels infants, no anaven a cap col-legi. Mayordomo (1878), en els mateixos anys,també presenta dades de Valladolid, el 31.9\% dels alumnes d'educació elemental no anava amb regularitat a classe. Les xifres globals de la província són d'un $58.53 \%$ dels alumnes. La situació de les nenes encara era pitjor ${ }^{4}$.

A Espanya, a la segona meitat del segle XIX, hi havien 12 milions d'analfabets. Els alfabetitzats suposen el 33\% de la població total, enfront del $20 \%$ de 1860 . Aquestes dades continuen sent dolentes, però aquesta 


\section{Tahull, Montero i Molina - Segle XIX}

millora estava distribuïda de forma desigual. Hi havia zones més o menys alfabetitzades. El nord d'Espanya (Cantàbria, Catalunya, la Rioja, Castella i Lleó i el País Basc) tenia un nivell d'instrucció més alt; en canvi, el sud (Andalusia, Extremadura i Múrcia), juntament amb Galícia, era més baix (Escolano, 1992).

Laspalas (1993-1994) presenta un estudi de l'estat de l'ensenyament elemental a Pamplona a principis del segle XIX. Aquesta investigació dóna dades dels hàbits d'assistència a l'escola obligatòria. L'assistència dels nens era desigual i inestable. Els pares decidien el moment de l'any per començar l'escola $\mathrm{i}$ el temps de permanència dels seus fills. Quan pensaven que ja no era necessari continuar, els treien. Aquesta situació determinava l'educació, era molt difícil seguir un programa comú d'aprenentatge. També era molt difícil comptabilitzar el número d'alumnes que seguien o no seguien l'escola. En tot cas, l'autor creu que a poc a poc augmentaven els nens escolaritzats, amb diferències significatives per zones. També, reitera que la situació de les nenes era pitjor, més irregular i inestable.

El mestre tenia una consideració social diferenciada, en funció de diferents variables. El docent tenia més o menys prestigi en funció de la institució on exercia (religiosa - pública), l'àmbit (urbà - rural), nivells educatius (primera - segona - tercera ensenyança - universitat), gènere (nens - nenes)... L'educació era un tema central del debat polític. Les elits constantment feien referència a la importància de la formació per la regeneració del país. Afirmaven que l'única opció de futur d'Espanya vàlida era posar al centre de la vida social la qüestió educativa; tanmateix, aquestes declaracions entraven en contradicció flagrant amb fets quotidians. Molts cops, el mestre era maltractat pels poderosos i, també per les classes més humils. A l'àmbit rural se'l considerava que vivia sense treballar, de l'esforç dels altres ${ }^{5}$. Les retribucions dels docents eren baixes, en alguns casos miserable:

Y no es desdeñable por catastrofista la afirmación de que muchos maestros han muerto en el cumplimiento de su misión por hambre o por persecución. Por el contrario, toda la geografía española está llena de estos lamentables casos, haciendo realidad un dicho español que afirma <tienes más hambre que un maestro de pueblo>. En Almisaraz (Valencia) fue asesinado un joven maestro por el grave delito de reclamar sus haberes; en Beos (Málaga) una benemérita 


\section{HSE - Social and Education History, 5(1)45}

profesora murió de hambre después de adeudarla considerables atrasos; en Benamargosa (Málaga), tuvo que dedicarse la mujer del maestro a pedir limosna para sostener a éste al frente de su escuela... (Sánchez Agustí, 2002, p. 178).

Aquests casos estan documentats en tota la geografia espanyola. L'educació tenia un problema greu de finançament i els professors i alumnes patien les conseqüències. Els ajuntaments tenien la responsabilitat de construir escoles, pagar als mestres i garantir la gratuïtat de l'ensenyament. Molts consistoris no tenien els recursos suficients. Tanmateix, era molt variable, en alguns municipis les condicions eren millors; en funció de la sensibilitat i la importància que l'equip de govern donava a l'educació. Hi ha una relació directa entre consideració social i retribució. La societat paga més o menys en funció de la importància de la professió. Pel que sembla, la valoració social del docent era baixa. També, en referència a la professió, s'ha de destacar la formació inicial, el Magisteri. Aquests estudis tenien poc prestigi. Determinades classes socials no volien que els seus fills fossin mestres, orientaven els seus fills a professions com: advocats, enginyers, metges...Per aquests, ser mestre era una professió poc rellevant. A més a més, tal com s'ha comentat hi havia una estreta relació entre escola i política, això comportava que el mestre estigués sotmès a les arbitrarietats locals. S'han documentat casos de mestres designats a dit, a partir de pràctiques clientelars, per les autoritats locals. Alguns docents estaven estretament involucrats en les lluites polítiques municipals. En alguns casos, l'ajuntament contractava mestres sense tenir la formació adequada (Garcia, 2013).

Determinats sectors socials van lluitar per tal que l'Administració augmentés els recursos públics a l'educació i dignifiquessin la professió de mestre, els resultats van ser pobres. Moltes d'aquestes iniciatives eren puntuals i no tenien la potència per canviar l'estat de les coses. Algunes organitzacions estaven preocupades per millorar la formació del professorat i organitzaven conferències, debats, congressos... per divulgar metodologies més innovadores i intuïtives. A Madrid, el 1882, va celebrar-se el primer congrés pedagògic. Molts mestres i professors d'arreu d'Espanya van assistir-hi. Van haver-hi ponents destacats, com el parlament de Giner de los Ríos. Al llarg d'aquesta dècada van fer-se altres congressos importants reflexionant sobre 
l'ensenyament. Destaca el congrés de València, realitzat a finals de juny, el mateix any. També, el 1882 hi ha haver el congrés de Pontevedra, va tractar sobre l'educació de les nenes ${ }^{6}$. El 1883 es va celebrar un congrés a Valladolid. El 1888 un congrés a Barcelona. L'Assemblea Nacional de Mestres va organitzar el 1891 a Madrid un congrés per tal de reflexionar sobre la figura del docent a la societat espanyola. Van haver-hi esdeveniments d'aquest tipus arreu d'Espanya. Un nombre significatiu de docents tenien interès per reflexionar $\mathrm{i}$ millorar la pràctica educativa. Tanmateix, a nivell general, els resultats no avançaven significativament. La qüestió educativa a Espanya va quedar estancada durant molts anys. Per les elits, no era una prioritat.

\section{Consideracions Finals}

A Espanya durant el segle XIX hi va haver un trencament de la cosmovisió anterior. Els corrents moderns i liberals consideraven la raó i la llibertat els fonaments d'una nova societat. Aquestes novetats s'incrustaven en totes les institucions socials occidentals, d'una manera o altra. L'educació també va rebre una empremta fonamental. Diversos autors i polítics consideren l'escola un element cabdal de transformació de la societat i d'adaptació als nous temps. Tal com s'ha esmentat, en el context internacional destaquen les aportacions de Krause, Dewey...; a Espanya, la ILE, autors com Giner de los Ríos, Sama, de Castro... També, novetats legislatives com l'Informe Quintana, la llei Moyano...que legislen per un ensenyament públic, gratuiit, lliure i de qualitat. Tanmateix, aquests posicionaments topen clarament amb interessos contraris. No tothom interpreta aquesta opció la més idònia. Aquesta era la situació d'Espanya en referència a l'educació. Diferents conflictes entre forces polítiques interpreten la societat de forma molt diferent. El procés modern de racionalització, iniciat a finals del segle XV, s'anava implementant amb moltes dificultats. L'aparició de l'Estat liberal va comportar conflictes amb l'Església i les institucions religioses. Aquesta tensió fou especialment rellevant a l'àmbit educatiu (Ossembach, 2012).

L'estat de l'educació a Espanya al llarg del segle XIX era que les inversions de l'Administració eren molt minses. Els equipaments educatius en molts casos eren lamentables. També, el sou als mestres era escàs. Tenien 
una remuneració molt baixa. Al mateix temps, la consideració social del mestre era negativa. La societat no considerava important la tasca del docent. Garcia (2013) diu que els mestres eren designats, en alguns casos, a dit per les autoritats locals. Hi havien pràctiques clientelars. Molts cops no tenien la formació adequada per ser educadors. El valors moderns encara no estaven consolidats a Espanya. El procés de racionalització, secularització i llibertat era difícil d'acceptar per molts sectors conservadors de la societat espanyola.

Aquest article pretén en primer lloc contextualitzar l'estat de l'educació a Espanya al llarg del segle XIX. Presentar les principals característiques de l'escola. També, vol comprendre les relacions entre modernitat, valors liberals i educació a Espanya durant aquest període. Tal com hem vist, la institució educativa va tenir seriosos problemes, per diferents motius: econòmics, prestigi, lluites ideològiques, religió... Aquest article pretén explicar aquests fets, situacions i saber perquè van esdevenir d'aquesta manera. Considero que la institució educativa s'ha d'analitzar tenint en compte el marc social i cultural. L'escola no està tancada $i$ isolada en ella mateixa, com molts cops és presentada, sinó que és una institució oberta a la societat, als seus valors, referents, significats, ideologies, cultures... Per aquest motiu, determinades dinàmiques socials són molt difícils de trencar ja que estan incrustades molt a dins, formen part de la cultura, de la forma de ser i d'interpretar el món. La Modernitat va tenir moltes dificultats per introduir-se a Espanya al llarg del segle XIX per la mateixa cultura espanyola, per la forma de ser. Brenan (1978) ho expressa dient que el liberalisme mai va quallar realment a Espanya. Els aires de modernitat $\mathrm{i}$ llibertat no van consolidar-se a l'escola a l'igual que tampoc no van instal-lar-se en altres institucions socials. Aquesta investigació vol posar de relleu la importància del context social i cultural per tal d'entendre les dinàmiques, situacions, polítiques, valoracions... esdevingudes a l'escola espanyola del segle XIX. 


\section{Tahull, Montero i Molina - Segle XIX}

\section{Notes}

${ }^{1}$ Aquest article s'ha extret d'una part de la tesi doctoral de l'autor, Dr. Joan Tahull (2012), L'autoritat a l'educació, entre la Modernitat i la Postmodernitat. Anàlisi sociològica del concepte autoritat al sistema educatiu català. Estudi comparatiu del model educatiu franquista i l'actual (1939-2011). Tesi defensada el 10 de març de 2012.

${ }^{2}$ Pròleg Homs, p. XXVII, a Durkheim (1991).

${ }^{3}$ El pragmatisme es caracteritza per un acostament del pensament a la vida. Així mateix, aquest moviment fa un replantejament de la dicotomia entre teoria i pràctica. Dewey defensa que és una falsa distinció. L'educació ha d'intentar fer que dels coneixements més abstractes siguin aplicables a la realitat. L'autor nord-americà, així com els krausistes, defensa que l'educació ha de consistir en la formació de qüestions pràctiques. S'ha de formar a l'alumne per tal que sigui capaç de resoldre els problemes de la vida.

${ }^{4}$ Per tenir una descripció de la situació de la dona és interessant la consulta de l'obra de Ballarín (2001), concretament el segon capítol, La construcción educativa de las diferencias en el siglo XIX, de les pàgines 33 a 59, i el tercer, Posibilidades y límites de la educación de las mujeres, de 59 a 85 . L'autora exposa quina era la situació de la dona en referència a la política, la religió i l'educació.

${ }^{5}$ Diversos articles del diari La Libertad presenten la situació difícil del mestre a l'àmbit rural. S'afirma que el poble considera el mestre com algú que viu a la seva esquena, ja que no treballa de forma productiva. "Puesto que no cava, no siega, ni dice misa". Veure a García, E. "Problema pedagógico III". La Libertad, núm. 2.333, 6 d'agost de 1888. "Para muchos salvajes, que aún los hay en los pueblos, el maestro es un ser viviente, un mal trabajador y un trasto incómodo. Por eso ni los consideran, ni los atienden, ni les pagan”. Veure a Prieto, C. “Campo neutral". La Libertad, núm. 4.118, 15 de setembre de 1893. Veure a Sánchez Agustí (2002, p. 381).

${ }^{6} \mathrm{~S}$ 'ha de tenir en compte que l'educació de les nenes va ser una qüestió problemàtica al llarg del segle XIX. Molts sectors ideològics estaven en desacord amb l'educació de les noies. "La escuela pública para las niñas se aceptó, inicialmente, como un mal menor, dirigido a la moralización de las clases populares, pero esta solución siguió considerándose indeseada durante algún tiempo, pues se mantuvo la idea de que la educación de las niñas era un asunto moral y privado (...) El desarrollo de la instrucción pública en la España del siglo XIX es reflejo de la mentalidad discriminatoria; aunque finalmente estableció la obligatoriedad escolar para las chicas, éste sirvió a la reproducción y amplificación de las diferencias entre hombres y mujeres" (Ballarín, 2001, p. 42). 


\section{Referències}

Ander Egg, E. (2000). Métodos y técnicas de investigación social. Buenos Aires: Lumen-Humanitas.

Ballarín, P. (2001). La Educación de las mujeres en la España contemporánea: siglo XIX-XX. Madrid: Síntesi.

Brenan, G. (1978). El laberinto español. Antecedentes sociales y políticos de la Guerra Civil. Barcelona: Ibérica de Ediciones y Publicaciones.

Coriat, B. (2001). El taller y el cronómetro: ensayo sobre el taylorismo, el fordismo y la producción en masa. Madrid: Siglo XXI.

Dewey, J. (1985). Democràcia i escola. Vic: EUMO Editorial.

Dewey, J. (1997). Mi credo pedagógico. León: Universidad de León.

Durkheim, E. (1991). Educació i sociologia. Vic: EUMO Editorial.

Escolano Benito, A. (1992). Leer y escribir en España: doscientos años de alfabetización. Madrid: Fundación Germán Sánchez Rupérez.

Escolano Benito, A. (2002). Historia de la educación: edad contemporánea. Madrid: UNED.

Garcia, V. (2013). La educación en la España de finales del siglo XIX. Revista Iberian, 7, 35-50. Recuperat de http://dialnet.unirioja.es/servlet/articulo? codigo $=4687077$

Homs, O. (1991). Pròleg, a Durkheim, E. (1991). Educació i sociologia. Vic: EUMO Editorial.

Martín Jiménez, I. (1994). El sistema educativo de la Restauración: primaria y secundaria en el distrito universitario de Valladolid (19871900). Valladolid: Junta de Castilla y León

Mayordomo, A. y otros (1878). Memoria sobre el estado de la Educación e instrucción en las escuelas públicas de Valladolid presentada por la junta Local de $1^{a}$ Enseñanza al Excelentísimo Ayuntamiento de esta capital. Libreria de Gavieria y Zapatero. Valladolid.

Laspalas, F. J. (1993). La reivención de la escuela: cinco estudios sobre la enseñanza elemental durante la edad moderna. Pamplona: Ediciones Universidad de Navarra. 
Laspalas, F. J. (1993-1994). El ciclo escolar de la enseñanza elemental en Pamplona a principios del siglo XIX. Revista Historia de la educación, XII-XIII, 327-340. Recuperat de

http://dialnet.unirioja.es/servlet/articulo? codigo $=87479$

Lozano, C. (1994). La educación en los siglos XIX y XX. Madrid: Síntesis.

Ossenbach, G. (2012). Génesis de los sistemas educativos nacionales en el mundo occidental, a Tiana, A. y otros (2012). Historia de la educación (Edad Contemporánea). Madrid: Universidad Nacional de Educación a Distancia.

Molero, A. (1987). El modelo de maestro en el pensamiento de la Institución Libre de Enseñanza. Revista interuniversitaria de formación del profesorado, 3, 7-22. Recuperat de http://dialnet.unirioja.es/ejemplar/11358

Rotger, J. M. (1990). Sociologia de l'educació. Vic: EUMO Vic.

Ruiz, L. \& Tellado, I. (2014). Joaquín Sama, la Institución Libre de Enseñanza y su amistad con Giner de los Ríos y los Machado. Revista Historia Social y de la Educación 3(2), 185-202. doi:

10.4471/hse.2014.11

Sánchez Agustí, M. (2002). La Educación española a finales del XIX: una mirada a través del periódico republicano La Libertad. Madrid: Milenio.

Tahull, J. (2012). L'autoritat a l'educació, entre la modernitat i la postmodernitat. Anàlisi sociològica del concepte d'autoritat al Sistema Educatiu Català. Estudi comparatiu del model educatiu franquista $i$ l'actual (1939-2011). [en línea]. Tesis doctoral. Universidad de Lleida. Recuperat de http://www.tdx.cat/handle/10803/80750.

Tahull J. \& Montero, Y. (2015). Malestar en la escuela. Conflicto entre profesores. Revista Educar, 51(1), 169-188. doi: 10.5565/rev/educar.658 Terrén, E. (1999). Educación y modernidad: entre la utopía y la burocracia. A Coruña: Anthropos. 
Joan Tahull Fort: profesor al Departament de Sociologia i Geografia de la Universitat de Lleida. Membre de GESEC (Grup d'Estudis sobre Societat, Salut, Educació i Cultura)

Iolanda Montero: Psicopedagoga i Mestra. Departament d'ensenyament de la Generalitat de Catalunya.

Fidel Molina Luque: Catedrátic de Sociologia. Departament de Sociologia i Geografia de la Universitat de Lleida. Membre de GESEC (Grup d'Estudis sobre Societat, Salut, Educació i Cultura)

Contact Address: joantfort@geosoc.udl.cat 


\section{HSE}

Historia Social y de la Educación

Social and Education History
Hipatia Press

www.hipatiapress.com

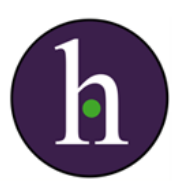

Instructions for authors, subscriptions and further details:

$\underline{\text { http://hse.hipatiapress.com }}$

\section{Does Culture Matter in Economic Behaviour?}

Edward O'Boyle ${ }^{1}$

1) Mayo Research Institute (USA)

Date of publication: February 23rd, 2016

Edition period: February 2016 - June2016

To cite this article: O'Boyle, E. (2016). Does Culture Matter in Economic Behaviour?.Social and Education History 5(1), 52-82. doi:10.17583/hse.2016.1796

To link this article: http://dx.doi.org/10.17583/hse.2016.1796

\section{PLEASE SCROLL DOWN FOR ARTICLE}

The terms and conditions of use are related to the Open Journal System and to Creative Commons Attribution License (CC-BY). 


\section{Does Culture Matter in Economic Behaviour?}

Edward O'Boyle

Mayo Research Institute (USA)

\section{Abstract}

In this article we address the following question: does culture play a role in economic behavior? We conclude that culture influences economic behavior in all three areas of economic activity: work, consumption, and leisure. Our proof lies not so much in replicating certain experimental results, but in documenting in real-world circumstances how culture influences economic behavior. Attention to the role of culture in economic affairs acknowledges that humans are more than the one-dimensional, autonomous, individuals, as premised in mainstream economics, whose very existence is temporal, whose role in economic affairs is strictly instrumental, and whose behavior is virtually the same across cultures. We have argued that humans are two-dimensional twice over. First, humans are individual beings and social beings: solitary and communal, self-made and culture-bound, autonomous and dependent, rational and emotional, self-centered and other-centered. Second, humans are both matter and spirit. The duality of the human person, rooted in individuality and sociality, affords an opportunity to unify economic theory wherein individuality is the focus of microeconomics and sociality is the center of macroeconomics. Putting the isolated individual at the very heart of economics closes down that opportunity and assures that mainstream economic theory will remain truncated indefinitely. The makeover of mainstream economics will take place once neo-classical economists accept that the ultimate end of economic systems relates not to maximum personal net advantage but to integral human development.

Key words: Culture and economic behavior, mainstream economics and individualism, personalist economics and personalism, duality of the human person. 


\title{
¿Importa la Cultura en el Comportamiento Económico?
}

\author{
Edward O'Boyle \\ Mayo Research Institute (USA)
}

\section{Resumen}

En este artículo se aborda la siguiente pregunta: ¿juega la cultura un rol relevante en el comportamiento económico? Concluimos que la cultura influye en el comportamiento económico en las tres áreas de la actividad económica: trabajo, consumo y ocio. Nuestro artículo no radica tanto en aportar resultados experimentales, como en documentar el modo en que la cultura influye sobre el comportamiento económico en curcunstancias reales. Centrar la atención en el rol que desempeña la cultura en los asuntos económicos permite reconocer que los humanos son algo más que seres unidimensionales, autónomos, individuales, como supone la economía mainstream, cuya existencia es temporal, cuyo rol en los asuntos económicos es estrictamente instrumental y cuyo comportamiento es prácticamente el mismo en todas las culturas. Argumentamos que los seres humanos presentan dos dimensiones por partida doble. En primer lugar, los seres humanos son seres individuales y sociales: solitarios y comunales, que se hacen a sí mismos y culturalmente vinculados, autónomos y dependientes, racionales y emocionales, centrados en sí mismos y en los demás. En segundo lugar, los seres humanos son tanto materia como espíritu. La dualidad del ser humano, arraigado en la individualidad y en la sociabilidad, brinda la oportunidad de unificar la teoría económica en la que la individualidad es el foco de la microeconomía y la sociabilidad es el centro de la macroeconomía. Poner al individuo aislado en el corazón mismo de la economía cierra esa oportunidad y garantiza que la teoría económica mainstream permanecerá indefinidamente truncada. El cambio de imagen de la economía mainstream tendrá lugar cuando los economistas neoclásicos acepten que el fin último del sistema económico no reside en el máximo beneficio neto por persona sino en el desarrollo humano integral.

Palabras clave: Cultura y comportamiento económico, economía mainstream e individualismo, economías personalistas y personalismo, dualidad del ser humano. 
$\mathrm{n}$ article published by Joseph Henrich 15 years ago begins with this question: Do all humans share the same economic decisionmaking processes? Using experimental evidence from playing the Ultimatum Game with Peruvian villagers (the Machiguenga) and UCLA graduate students, Henrich questions the validity of the premise that notwithstanding cultural differences "all humans share the same economic decision-making processes, the same sense of fairness, and/or the same taste for punishment." (Henrich 2000, p. 978).

As with other experimental economists Henrich employs "fairness" and "punishment" to characterize human behavior that rewards a person who is "fair" and punishes a person who is "unfair." A 50-50 split of the money offered to the players indicates fairness and a 0-100 split indicates unfairness.

In the following we address the same question raised by Henrich: does culture play a role in economic behavior? However, before we can proceed it is necessary to define the terms that are central to addressing that question properly. We conclude that culture indeed matters, calling for a reconstruction as to how we think about economic affairs.

\section{Defining Terms}

Justice. If fair and unfair are synonyms in experimental economics for "just" and "unjust," the terms are used inappropriately. In the most general sense, justice has to do with what one person owes another person or group of persons. In economic affairs this obligation is defined in terms of the three kinds of human interactions: (1) between equals, (2) between the superior and his/her subordinates, and (3) between a member and the group to which he/she belongs (Dempsey 1958, p. 165).

In the first type of interaction, commutative justice spells out the duty of buyer to seller in a routine exchange: to exchange things of equal value and to impose equal burdens on one another. In the second kind of interaction, 
distributive justice spells out the duty of the work-group supervisor to the members of that group: to distribute the benefits and burdens among group members in some equal or proportional fashion. In the third type of interaction, contributive justice sets forth the duty of a member to the rest of the group: insofar as a member receives benefits through group membership, that member has a duty to maintain and support the group. To illustrate, duping a buyer with counterfeit goods and passing bad checks violate commutative justice. Racial and gender discrimination violate distributive justice. Insurance fraud and insider trading violate contributive justice.

In Ultimatum Games experiments where the two paired persons do not know one another, as in Henrich's experiments, it is not possible for either one to be driven by fairness or punishment because both persons must have specific knowledge of the other to establish a legitimate basis for fairness or punishment. Without such knowledge, it is impossible to pass judgment on another. Anonymity, in other words, rules out any reasonable grounds for describing their behavior as fair or unfair.

Additionally, just and unjust, fair and unfair, do not apply in the Ultimatum Game because the money offered to the proposer-responder pair is not owed to either one or both under any of the three principles of economic justice. Rabin (1993, pp. 1281-1302) introduces "kindness" as a synonym for fairness, and shortly thereafter Camerer and Thaler (1995, pp. 216-217) interpret Rabin as meaning punishment or "manners" and proceed to introduce "polite" and "rude" for fair and unfair. Their effort fails because etiquette reduces to a set of rules such as tennis players shaking hands at the net at the end of the game. Because the rules of etiquette often are arbitrary they cannot be confirmed or rejected by rational discourse. Justice, on the other hand, is much more than a set of rules subject to change. Put simply, etiquette is conformance, justice is virtue.

The permanent nature of the principles of justice as applied to economic affairs is confirmed by observing the chaos in modern economic systems that do not restrain and punish persons engaged in such practices as counterfeiting goods, passing bad checks, openly discriminating against 
minorities in the workplace, defrauding their insurance companies, or using confidential information to take advantage of others in stock market transactions.

The money allotted in Ultimatum Game is a gift $^{1}$ governed not by etiquette but by generosity. Indeed Camerer and Thaler (1995, p. 215) use "generous" in the very same article in which they embrace the economics of etiquette, and Rabin uses "generous" in the article that impressed Camerer and Thaler. Thus, it is not a question of how much the proposer in the experiment owes the responder. Rather it is a question as to how generous the one should be in sharing the gift with the other. Unlike the virtue of justice, generosity does not require the giver to have specific knowledge of the recipient. For these reasons, we suggest that "generous" and "selfish" are better suited to the Ultimatum Game than any other pair commonly used.

Generosity and selfishness, in turn, may be conditioned by a variety of factors including whether the proposer and responder see one another ${ }^{2}$ as friends/neighbors or as rivals/adversaries. Most importantly generosity and selfishness reflect how both parties value human life itself. Two options are available: a human being has value only in instrumental terms or is precious quite apart from any instrumental value and is properly considered an end and not just a means. Thus, following John Paul II (1981, § II), the effect of work on the worker is more important than the things produced through work Clearly, these contrasting views, which are importantly shaped by both faith and reason, are fundamental to cultural development. In this regard, note that such enduring works of art and music as Michelangelo's ceiling in the Sistine chapel and Handel's Messiah are inspired by faith and revelation, and such magnificent structures as the Gateway Arch and the Golden Gate Bridge spring from human intelligence and aesthetics.

Culture. Culture, it seems, is only loosely defined in experimental economics, and probably has different meanings among experimental economists. Dulles (1999, p. 2) provides a helpful definition. 
[Culture] is a social force that encompasses individuals and welds them into communities. It shapes their prejudices, ideas, values, habits, attitudes, tastes, and priorities... Whereas politics and economics are concerned with proximate and limited goods, culture has to do with the meaning of human existence as a whole. It inquires into what we are as human beings, and what reality is in its most comprehensive dimensions.

Culture is expressed, for example, through art, literature, and music, reflecting long-lasting social values such as equality, freedom, and community and such cherished traits of character as courage, fidelity, and truthfulness.

Pop culture also finds expression in art, literature, and music, and with the passage of time may not endure. The music of the Frank Sinatra and Ella Fitzgerald has endured well beyond the stage of popular whim and fancy. The Lady Gaga and Miley Cyrus sensations may not. Ong (1970) who has written extensively on culture asserts that, in terms of the communications media, cultures can be divided into three successive stages: (1) oral, (2) script that originates with the invention of the alphabet and alphabetic movable types, and (3) electronic.

\section{The Role of Culture in Economic Behavior}

Henrich's Experiment. Following Ong's three-stage classification scheme and taking into account Henrich's description of the culture of the Machiguenga, it is clear that theirs is one and possibly two stages behind the culture of the UCLA students in his experiment. If culture truly matters in economic behavior, the differences in his experimental evidence could be attributed to cultural differences as Henrich himself asserts. And if Ong is accurate on another matter - that only high-tech cultures give rise to personalist philosophies (Ong, 1981) - it is possible that the very philosophical foundations of the two groups included in Henrich's experiment are substantially different in that the Machiguenga could not possibly hold to a personalist philosophy, thereby reinforcing his argument 
that cultural differences could account for differences in economic behavior as indicated in his experiments.

The fact that the sharing among the Machiguenga rarely takes place outside extended kin circles, as Henrich reports (2000), could provide a reason as to why their behavior was so different than the behavior of the UCLA students if the proposer and responder regarded each other as outside their respective circles. If they found out later that indeed they had been wrong in this regard, the proposer would have good reason to share the money more equally with the responder to bring their behavior into compliance with the cultural norm of sharing within the extended family circle. If they discovered later that they were not from the same circle, there would be no good reason for the proposer to change the original settlement

Another possible explanation for the differences Henrich observed is that the Machiguenga no doubt were living much closer to a poverty-level existence than the UCLA students and it would be reasonable for the proposer to take the lion's share of the money in order to do more to relieve the poverty within his/her own extended kin circle.

Dysfunctional Economic Behavior. Because they are dysfunctional in the sense that they exceed any reasonable or normal limit on work, consumption, or leisure and therefore inflict loss or punishment on themselves, their families, and others, workaholics, shopaholics, and compulsive gamblers do not conform to the norms of rational economic behavior as asserted by mainstream economics. To illustrate, in a study based on a convenience sample of 406 students at a private university in Texas nine percent were identified as compulsive buyers ${ }^{3}$ whose behavior was associated with credit card usage (Roberts \& Jones 2001). Lee and others (2000) found that among women who are television shoppers ten percent were compulsive buyers and that this subgroup had more symptoms of binge eating than did the other women in the sample. In a report derived from three-experiments involving 145 college students, Vohs and Faber (2007) found that unwanted spending may occur when temporary lapses in 
self control are exhibited. Thus the origins of impulsive spending are not in the product but the consumer.

Killinger (1997, p. 6) defines the workaholic as "a person who gradually becomes emotionally crippled and addicted to control and power in a compulsive drive to gain approval and success". ${ }^{4}$ Drawing on a typology attributed to Spense and Robbins, Burke and others (2008, pp. 31) identify workaholics as persons who score high on work involvement and driveness, and low on work enjoyment. They organized their study around three workaholism types: work enthusiasts, work addicts, and enthusiastic addicts. Based on a survey conducted through the internet that involved 327 respondents at work in professional and managerial jobs, most of whom were women, the authors found that work addicts had a "generally negative set of experiences" in terms of perfectionism, delegating work, job satisfaction, and work engagement (Burke \& others 2008, pp. 30, 37).

Using data from an online survey of 1,329 respondents, Van Beek and others (2011) confirmed that workaholics are driven by controlled motivation, that is by external and internal rewards and punishments. They recommended that in order to differentiate workaholics from other hardworking employees workaholism should be measured not only as working excessively but also working compulsively (Van Beek, Taris \& Schaufeli, 2011).

Robinson (1998) states that work addiction is a learned addictive response to a dysfunctional family of origin and when that child becomes an adult workaholic the family lives according to rules dictated by the career and work habits of the workaholic.

The roots of workaholism lie in the Calvinistic tenet that self-indulgence is destructive and work is redemptive. Killinger identifies two other sources: the dysfunctional family wherein work itself is one member's drug of choice; and the materialism, consumerism, technological growth, and competition within which workaholism has flourished (Killinger, 1997).

As the workaholic breaks down, decision-making becomes more difficult due to more episodes of chronic fatigue, panic attacks, loss of concentration, 
and obsessive overwork. Mistakes follow because as "the Feeling function no longer informs judgment," all that matters is the "A to B goal" (Killinger 2013, p. 3).

According to the American Psychiatric Association when persons are engaged in internet gaming

... certain pathways in their brains are triggered in the same direct and intense way that a drug addict's brain is affected by a particular substance. The gaming prompts a neurological response that influences feelings of pleasure and reward, and the result, in the extreme, is manifested as addictive behavior (American Psychiatric Association, 2013a, n.p.).

A gambling disorder "activates the brain reward system with effects similar to those of drugs of abuse and ... resemble(s) substance abuse disorders to a certain extent" (American Psychiatric Association 2013b, p. 16). Compulsive gamblers often have "substance abuse problems, mood or personality disorders, or attention-deficit/hyperactivity disorder." In addition they may abuse alcohol and experience depression. Complications include legal and financial problems, job loss, problems with relationships, and suicide (Mayo Clinic 2014, n.p.).

In the context of economic behavior we refer to gaming and compulsive gambling as disordered uses of one's leisure in that used properly leisure has positive or healing effects on the human body and human spirit.

Persons who are dysfunctional in the ways indicated above can be reinforced in that behavior by employers, merchants, and casinos who turn a blind eye to the harm being done. For example, the change in slot machines from mechanical to microprocessor-controlled devices encouraged rapid play, allowed the casino operators to reduce the number of jackpot payoffs, making tremendous payoffs possible. As a consequence, many former lowstakes players lost control of their gambling behavior (McCown \& Chamberlain, 2000). 
It follows that cultural differences can make for important differences in economic behavior for one overriding reason. Human beings are not machine-like products each one identical to every other one in the production process. A human being is one-of-a-kind, different from all other humans, and cloning aside never to be repeated. Human behavior cannot be accurately represented by the homo economicus of mainstream economics that rationalizes all economic behavior as maximizing personal net advantage.

If the physical environment influences economic behavior surely the same must be said for the cultural environment. Henrich (2000, p. 978) poses three questions that lead the way in helping to link culture and economic behavior.

(1) Where do people get the rules, expectations, or notions of fairness from?

(2) Why do these rules, expectations, and notions affect real economic behavior?

(3) How much can the varying rules, expectations, and notions affect real economic behavior?

The answers to these questions, in turn, will either re-affirm the neoclassical assumption that humans share the same economic decision-making processes or overturn it. (Henrich, 2000).

Henrich's First Question. Humans develop their own set of rules, expectations, or notions of fairness by reflecting on their own life experiences and by accepting them on the word of another, that is through reason and faith. The university is an important institution that studies human behavior in order to understand it better for the purpose of setting down rules, expectations, and notions of fairness in the form of: (1) codes of ethical conduct for the professions; (2) statutory law governing criminal behavior; (3) tax codes specifying how the burden of supporting the 
government is to be distributed, and the like. These rules, expectations, and notions of fairness may differ for the moral absolutist and the moral relativist even if they have attended the same university. Or they may be the same because the two share the same faith and frequent the same place of worship. In any case rules, expectations, and notions of fairness develop over years and are transmitted and reinforced at various times by family, school, place of worship, judicial system, and other social institutions.

Kohlberg (1981) studied the moral decision-making process and identified six discrete steps: perception, discernment, resolution, assessment, decision, and action. His six-step process is circular rather than linear. A person's basic knowledge of the good is a prerequisite for sensing whether a moral problem is present and whether he/she has some personal responsibility in the matter. It is determined as well by direct personal experience with the other steps, especially with the action step. That is, what is learned in the action step improves one's ability to more readily perceive other moral problems thereafte (O'Boyle, Dawson \& Tansey, 1996). Drawing upon Kohlberg, we identify six stages in a person's own cognitive moral development: (1) avoidance of punishment; (2) desire for reward; (3) anticipated disapproval of others; (4) anticipated dishonor; (5) maintaining respect of equals and community; and (6) self-condemnation for departing from one's principles. In general, a person progresses to higher stages of moral development with age, but there is no assurance that he/she will have progressed to the last stage upon reaching adulthood.

It follows that different persons are at different stages of their own cognitive moral development and therefore some are better prepared than others to handle ethical issues in economic affairs, and in fact may act differently in the same situation. Thus, employers following virtually the same decision-making process but at different stages in their cognitive moral development likely will behave differently. To illustrate, an employer at the avoid-punishment stage might take no action at all in a clear case of workplace discrimination especially if there is no punishment likely to befall him/her, whereas an employee in anticipated-dishonor stage might act 
promptly in order to avoid any dishonor. Some senior managers might be more prone to schemes that defraud their stockholders when the payoff is large enough, while others would not, whatever the size of the payoff, because the former have an underdeveloped conscience while the latter are much further along in their ethical development. Similarly, workers in the same firm may respond differently to defects in workmanship or unsafe work processes, one blowing the whistle while others remain silent. And for the same reason consumers and employees may respond quite differently to the same shoplifting and embezzling opportunities.

Students of economics, who under the influence of logical positivism have formally rejected normative economics, are ill-prepared to address ethical issues in economics with the possible exception of matters relating to distributive justice. In effect, commutative justice and contributive justice are dismissed because all such matters are addressed by the free and informed interaction between economic agents in a market economy or are subsumed under the common good that is served through the "invisible hand." In other words, issues of conflict wherein ethics plays a role are sorted out by homo economicus.

Henrich's Second Question. Rules, expectations, and notions of fairness affect economic behavior because they are the mechanisms used to bring economic behavior into compliance with the dominant social values of the culture. When there are changes in the values that are formalized by specific rules, expectations, and notions of fairness, the transmission mechanism must change in order to produce the desired economic behavior with as little disruption as possible

Rules, expectations, and notions of fairness change as our insights into human action deepen. For example, we have come to understand the silent injustice of the gentlemen's agreement, the glass ceiling, redlining and many other unjust practices and we are witnessing considerable efforts to condemn these practices as unacceptable behavior in economic affairs. As social values change or are ranked differently as to their importance, economic 
behavior changes too under the influence of new rules, expectations, and notions of fairness.

Changes such as these originate in and are reinforced by changes taking place deep within the socioeconomic order and that are changing the very institutions that we rely upon to provide stability and continuity as to the rules, expectations, and notions of fairness governing economic behavior. For some time, we have been under the influence of two powerful revolutions. One revolution is based on information technology is affecting the five central economic processes of production, distribution, exchange, consumption, and investment. The other revolution originates in a shift along all four axes of tension underlying the social order and the basic institutions that express the fundamental values embodied in culture: (1) away from the sacral toward the secular; (2) away from the absolute toward the relative; (3) away from the objective toward the subjective; and (4) away from the group toward the individual (Becker, 1992). Culture matters in economic behavior and becomes much more visible when economic institutions are shaken by revolutionary change.

These four shifts are slowly redefining our culture from one of life and hope to one of death and despair. This cultural revolution, in turn, is further promoting the individual and dismissing the person by redefining how we perceive the economic realities around us. Notice how these two revolutions are linked by internet sales of pornography, by chat rooms that redirect human behavior from spouse and children to others through human imagination and fantasy, by video games, motion pictures, and cable television that are deliberately marketing adult materials to children.

Day-trading over the internet that can distort the true risks involved in such practices, replacing them with the false promise of instant wealth and a lifetime of ease and comfort. Notice as well internet sales of powerful drugs without a prescription are raising false expectations that self-medication will produce more favorable outcomes than better-informed prescribed medication. And take note of the huge and growing demand for illegal drugs in the United States alone that are taken ostensibly to meet the needs of the 
human body or human spirit but all too often lead to death and despair in addiction and homicides attributed to an overdose or a "deal which went bad." And notice how suicide and mercy killing increasingly are rationalized by mainstream economics on cost-benefit (pleasure-pain) considerations. Conventional economics rationalizes a human life that is not worth living.

Henrich's Third Question. Culture itself and cultural change can and do affect real economic behavior profoundly. Note, for instance, the huge cultural change that occurred after the end of World War II and how the baby boom that followed is still affecting economic affairs. Before the war, a woman's place was in the home. After the war, especially after the development of the birth control pill, women could pursue professional careers and, with the passage of time, have done so in even greater numbers and proportions with the approval of the rest of society.

In 1985 Nobel Laureate James Buchanan (1985, p. 15) took the profession to task in language that hardly can be misunderstood.

Our graduate schools are producing highly trained, highly intelligent technicians who are blissfully ignorant of the whole purpose of their alleged discipline. They feel no moral obligation to convey and to transmit to their students any understanding of the social process through which a society of free persons can be organized without overt conflict while at the same time using resources with tolerable efficiency.

Fifty years earlier, Keynes (1935, pp. 16-17) offered a similar criticism:

The classical theorists resemble Euclidean geometers in a nonEuclidean world who, discovering that in experience straight lines apparently parallel often meet, rebuke the lines for not keeping straight -- as the only remedy for the unfortunate collisions which are occurring. Yet, in truth there is no remedy except to throw over the axiom of parallels and to work out a non-Euclidean geometry. Something similar is required to-day in economics. We need to throw over the second postulate of the classical doctrine and to work out the behaviour of a system in which involuntary unemployment in the strict sense is possible. 


\section{Reconstructing Economics to Incorporate Culture}

How then do we reconstruct economics to incorporate culture? We propose four points of departure from the mainstream way of thinking: economic agency, literary skills, personalistic modeling, and philosophical foundations.

First, we must examine much more carefully the idea that economic affairs are best understood and economics is best taught in terms of the autonomous, self-interested, thoroughly rational, utility calculating and maximizing individual.

To insist that the autonomous individual is absolutely essential to the way in which one thinks about economic affairs requires one to absolutely reject the cultural environment as informing economic behavior, all the while clinging to the logical inconsistency that the physical environment is a factor in economic decision-making.

Because more is required than simply adding a social dimension to the individual dimension of homo economicus it is necessary to cast aside that dated concept of the economic agent. In brief, we propose replacing the individual with the person, more precisely the acting person, the dynamic person of action. This revision would acknowledge that economic behavior of consumers, for instance, is at times other-centered, utility-satisficing, dependent, and driven by such powerful emotions as fear and love, and that poverty, for example, is a problem of insufficient resources to meet minimal material needs and should be fully integrated into our treatment of consumer behavior.

Lutz and Lux (1988) proposed a new economics - humanistic economics - that argues that homo economicus is not an accurate representation of human behavior in economic affairs, that economic science cannot any longer ignore the insights from psychology to the effect that human needs are hierarchical in the sense that consumers proceed to higher-level needs such as the need to belong after lower-level needs such as food, shelter, and clothing have been met. In addition, needs are not reducible to wants, and 
that notwithstanding the mainstream view that all wants are commensurable, human needs are incommensurable.

Years later a set of papers was collected in O'Boyle's Personalist Economics and published in 1998. The book was organized around three subjects: premises, description of economic affairs, and economic policy. In the section on premises, he argues for replacing homo economicus with homo socio-economicus wherein the social dimension of human nature is incorporated into the economic agent along with the individual dimension. More recently and all the while retaining the individuality and sociality of the economic agent, O'Boyle has replaced homo socio-economicus with the dynamic acting person to incorporate more directly and accurately the philosophy of personalism as a replacement for the individualism of mainstream economics.

Danner and O'Boyle identify the econòmic agent not as a collection of preferences or capabilities but an:

... embodied spirit, a spirit which can act externally only through its body, not like a rider on a horse nor a ghost in a machine, but essentially and necessarily bonded to the body. The 'I,' therefore, retains its identity even though the body renews itself many times in a lifetime (Danner \& O’Boyle 1999, p. 50).

For Danner, the ultimate purpose of economic activity is not maximum personal net advantage. Rather, it is whether it adds to or takes from the integral development of those who engage in that activity. For Danner (2002, p. 129) “... every person is in a real sense an economic person."

As an embodied self-consciousness, personhood is best portrayed in a career of self-development, the effort and action of becoming personal by blending contraries: spirit/body, male/female, individual/social, self-aware yet reaching out, unified but constantly changing, free but morally restrained (Danner, 2002, p. 53). 
Davis thinks about economic agency in terms of individuals who are socially-embedded in social and economic relationships and act through participation in groups. In arguing for the outward directedness of the economic agent he does not reject inward directedness. Rather, the economic agent is both (Davis, 2003; Davis, 2011). Additionally and importantly, for Davis the "socially-embedded individual" is an active being who is able to influence the social structure (Davis, 2003; Davis, 2011). Davis connects social embeddedness to the capabilities approach and represents the economic agent not in terms of preferences but capabilities.

Davis (2011) claims that social embeddedness means embedding individuals in a social world, coupled with human capabilities including a personal identity capability that helps them maintain or re-establish their personal identities in complex and changing social interactions that can reduce them to mere social aggregates, allows him to offer the concept of the individual thus modified as an appropriate replacement for homo economicus because it offers a better explanation of human behavior in economic affairs.

Second, we must again emphasize the importance of literary skills both in terms of presenting our premises as well as describing economic affairs and proposing policy recommendations. Some concepts and ideas are better rendered in literary form than in the mathematical form. For example, what mathematical expressions adequately substitute for such enduring expressions as "the invisible hand," "the Protestant ethic," "the euthanasia of the rentier," "there is no such thing as a free lunch," "the tragedy of the commons," "the prisoner's dilemma," "in the long run we are all dead," "creative destruction," and "the reserve army of the unemployed"? Helping students acquire literary skills means that it is necessary to reverse the systematic purging from the economics curriculum of the courses on history of economic thought, comparative systems, and economic history, not to mention ethics and metaphysics where mainstream economics is woefully inadequate. 
Metaphors such as the one that Alfred Marshall employed to answer the question What determines price? can be most helpful if economists are evermindful that metaphors are pedagogical devices that are truly useful when they are modified properly to take into account the human persons who are being represented. We have in mind something like the following that draws on Schumpeter.

The economy is like a twin-engine aircraft in which competition and cooperation supply the power for lift, and intervention and regulation function as the aircraft's control surfaces that the pilot uses to give the craft guidance and direction. Admittedly the economy can operate successfully on one engine alone, but it performs much better on two engines functioning together. Credit creation fuels both engines, and caring for one another supplies the engine oil. Justice operates like the oil filter removing such dangerous deposits as ill will, discrimination, and disunity that originate in violations of commutative, distributive, and contributive justice.

The entrepreneur is the pilot who charts the destination and course for the aircraft and who bears the immediate responsibility if anything untoward happens. The central bank is charged with the responsibility of maintaining the aircraft to assure that a serious malfunction beyond the control of the pilot results in a "soft landing" rather than "crash." Bankruptcy is the parachute that saves the pilot's life in an extreme emergency and lets him/her survive to fly again.

Culture is to the economy what weather is to the aircraft. A culture of death and despair is bad weather for flying; a culture of life and hope is favorable weather. Just as meteorologists help us recognize different weather systems, philosophers, writers, and others offer a deeper understanding of our culture. Ignoring their warning signals can be fatal.

Third, in bringing greater understanding to economic affairs, some modeling less exact and mechanical than econometric models but more deeply probing of the person and therefore at once more accurate and more personalistic is necessary. Mathematical models use reductionism to deliver more precision and detail to our description of economic realities, and thus 
more superficial certainty. What we need is greater accuracy and understanding of the very same economic realities, even when it means less authentic certainty. We have in mind the exhaustive study of experience rating in unemployment insurance by Becker whose final remarks are a model of pushing the data and information as far as the limit of authentic certainty permits:

... if we choose to maintain a set of income maintenance programs that are closely geared to the market and operate like deferred wages, with benefits proportioned to wages and with taxes levied solely on payrolls and employers, unemployment insurance as presently constituted will be a necessary part of such a system and experience rating is likely to be considered a desirable part of unemployment insurance (Becker, 1972, p. 325).

We also point to diagrammatic and schematic renderings as an alternative to econometric models. ${ }^{5}$ Our business in economics is to search for the truth ever mindful that the precise findings from econometrics at times are not the whole truth because the human spirit is not entirely within our understanding. The human spirit is and more than likely always will be part mystery. In these circumstances, the researcher cannot achieve the kind of authentic certainty with econometric models that mainstream economics promises.

Figure 1 presents a schematic that summarizes much of what we have said in the preceding. It brings together five different premises as a point of departure - slave, object, agent, human, and person - with their philosophical foundations in the context of Becker's four axes of tension and the OneMany dichotomy in a way that relates to a market economy and a planned economy. We include slave for two reasons: (1) slavery is a part of human history and thus of economic history; and (2) the effects of slavery in the United States persist more than 150 years after the Emancipation Proclamation, and though the civilized world denies it and condemns it, slavery is an ongoing practice directly in the sense that slaves are being brought into many western countries and indirectly in that the goods 


\section{HSE - Social and Education History, 5(1) 71}

produced by slaves are sold in the United States and elsewhere (Bales, 1999).

Figure 1 is arranged to be consistent with Ong's observation that only high-tech cultures give rise to personalist philosophies (Ong 1981, p. 200) and with John Paul's insistent re-affirmations that person is nearly divine (more below). Accordingly, slave hierarchically is the lowest starting point for thinking about economic affairs and person the highest with human, agent, and object between the two in that order. Figure 2 focuses on person, human, agent, and object in the same hierarchical order as in Figure 1 and indicates why the autonomous individual effectively splits economic theory in two, and why in principle human and person bring unity to economic theory. 
72 O'Boyle - Does Culture Matter in Economic Behaviour?

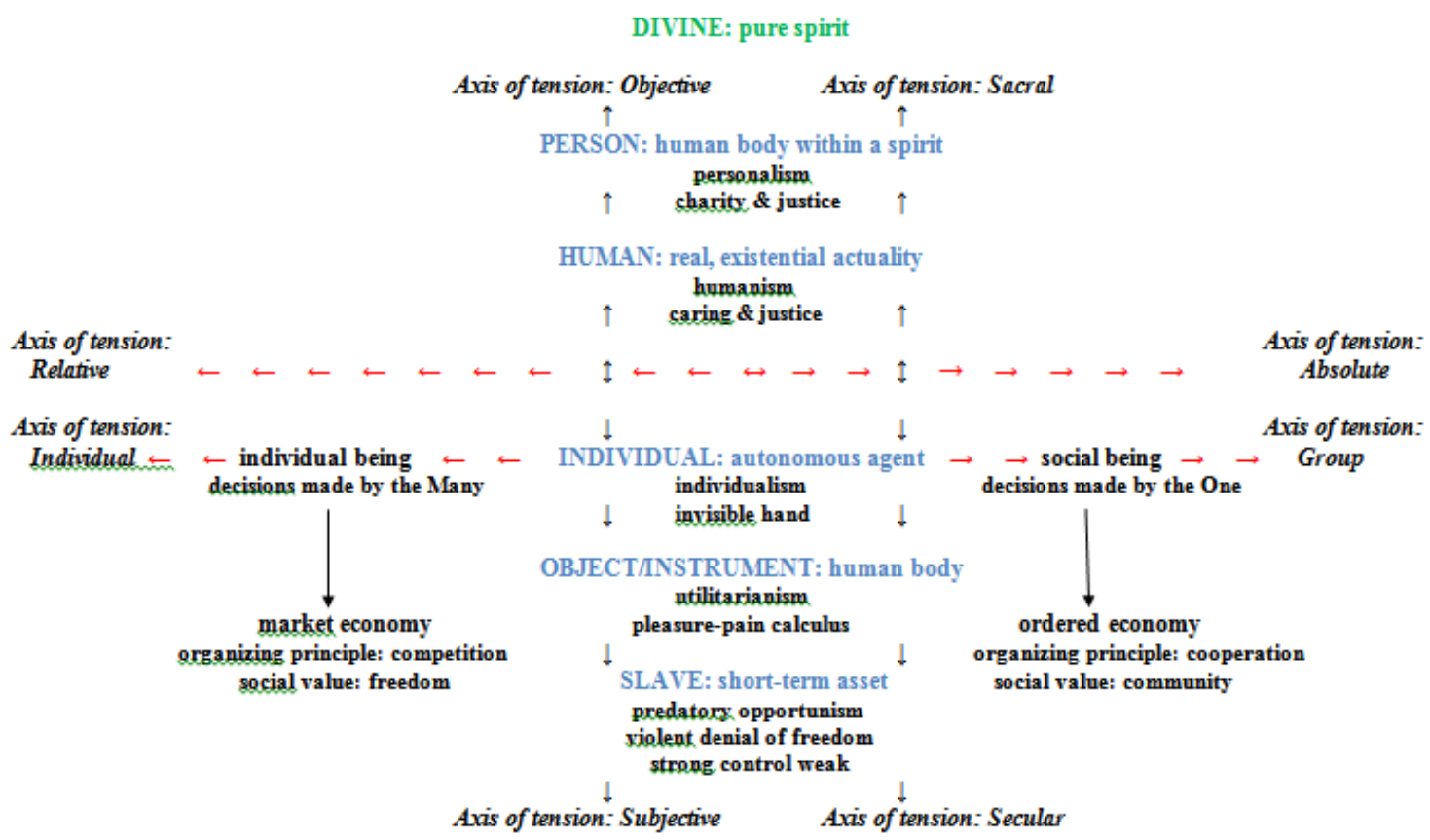

Figure 1. From Slave To Person: The Central Premise in Economics 


\section{HSE - Social and Education History, 5(1) 73}

Microeconomics and Macroeconomics Fused into a Unified Theory Because Both

Personalism and Humanism Rest on the Premise that Humans are at once Individual Beings and Social Beings

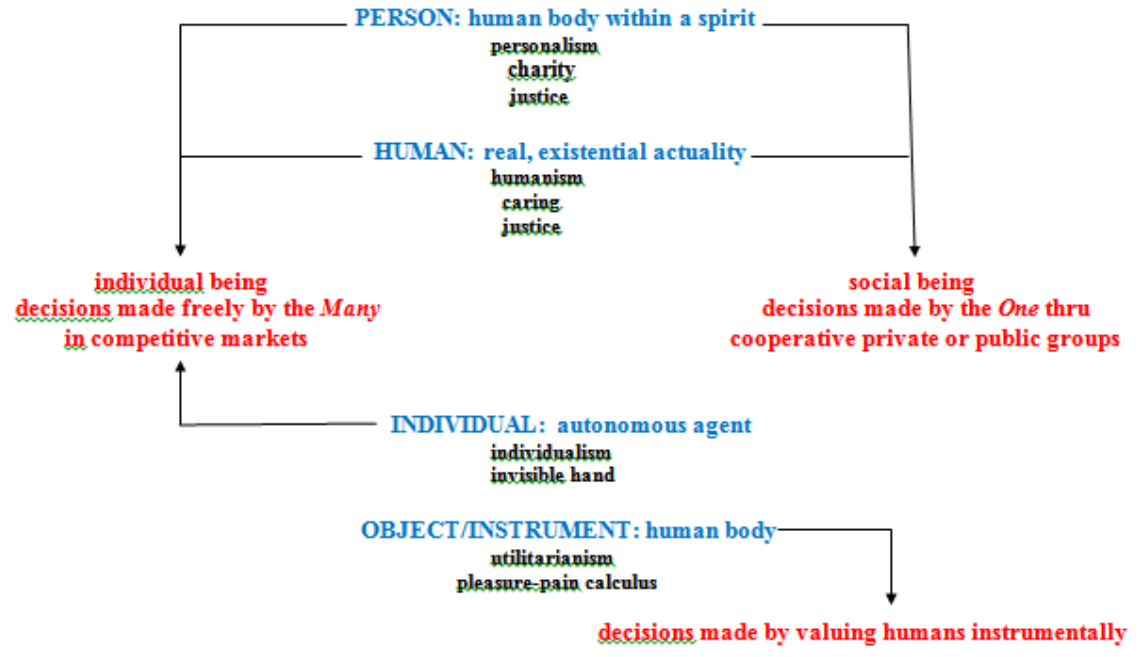

Microeconomics \& Macroeconomics Split Apart Because Individualism Rejects Human Sociality \& Socialism Rejects Human Individuality

Figure 2. From Object to Person: Connection to Economic Theory 
Fourth, we must re-examine the philosophical foundations of economics beginning with the recognition that a philosophy other than individualism that developed in the second stage of communications media, the script stage, no longer serves us as well as it once did. Taking seriously Ong's (1981) observation that only high-tech cultures "have given rise to personalist philosophies" it is entirely reasonable to argue that personalism is a better foundation for thinking about human behavior in economic affairs than is individualism.

Very recent times have activated concern with the human person as person to a degree of explicitation unknown before, and that at many levels of awareness. At the highest level of speculative thinking such philosophers as Martin Buber and Gabriel Marcel and many phenomenologists have worked out self-consciously personalist philosophies. Such theologians as Hans Urs von Balthasar have pointed out that in the past, when nature overshadowed humanity, human beings had approached God through nature, whereas today, when technology has reduced nature's dominance and put human beings over nature, philosophy has become anthropologized and tends to approach God through the human lifeworld and the human person. Existentialism is a by-product of the technological scenario ... Earlier cultures, less able to analyze themselves than is a high-technology culture infused by thought processes made possible by the technologies of writing and print (and now electronics), were less explicit about both depersonalization and the personal problems of the human person (Ong, 1981, pp. 200-201).

Thus the need to replace the passive homo economicus of mainstream economics with the dynamic acting person of personalist economics. This substitution promises to unify economic theory that for many years has labored under the micro-macro split. That fracture can be healed when economic decision-making is seen in terms of the One-Many dichotomy wherein homo economicus connects only to the Many and the acting person relates to both. Initial steps have been taken in this direction (O'Boyle, 
2014). What we have sketched in Figure 1 and Figure 2 are the bare bones of a new paradigm that we hope someday will deepen our understanding and description of economic behavior even if they are not as mathematically precise as we would like.

\section{Concluding Comments}

Our concluding remarks begin with two observations. First, as Henrich suggests, culture influences economic behavior in all three areas of economic activity: work, consumption, and leisure. Second, the proof inheres not so much in replicating Henrich's experimental results, but in documenting in real-world circumstances how culture influences economic behavior. For example, are there differences in work behavior that originate in family type? Or differences in consumption behavior originating in ethnicity? Or differences in leisure behavior originating in nationality or religious affiliation?

Attention to the role of culture in economic affairs acknowledges that humans are more than the one- dimensional, autonomous, individuals, as premised in mainstream economics, whose very existence is temporal, whose role in economic affairs is strictly instrumental, and whose behavior is virtually the same across cultures. Though living in different cultures, humans according to mainstream economics are not influenced by those differences when it comes to economic affairs. In the mainstream way of thinking, the individual according to Waters (1988) acts freely, selfinterestedly, and calculatedly in a self-regulating economy, with behavior that is knowable with mathematical certainty and empirical precision, whose worth is determined instrumentally.

We have argued instead that humans are two-dimensional twice over. First, humans are individual beings and social beings: solitary and communal, self-made and culture-bound, autonomous and dependent, rational and emotional, self-centered and other-centered. Second, humans are both matter (visible outwardness) and spirit (invisible inwardness). 
Following John Paul (1998), the human being is the one who pursues the truth, and whose body is the medium whereby a person expresses him/herself (Wojtyla, 1979).

The duality of the human person, rooted in individuality and sociality, affords an opportunity to unify economic theory wherein individuality is the focus of microeconomics and sociality is the center of macroeconomics. Putting the isolated individual at the very heart of economics closes down that opportunity and assures that mainstream economic theory will remain truncated indefinitely.

Ong (1967, p. 181) regards the human being as a "bridge connecting the material and spiritual, which means, under grace, the material and the divine." In Fides et Ratio (John Paul, 1998) John Paul puts the person between the human and the divine. Three years earlier in Evangelium Vitae, John Paul professed the sacred dignity of the human person several times.

Ong (1981) points to the role of human communication in either affirming personhood or reducing humans to things. Indeed, all such communication displays some regard for the other human being as a person and when communication comes to a halt the person is reduced to a thing. By avowing the isolated individual and denying the role of culture in economic behavior, mainstream economics effectively reduces humans to mere instrumentalities, to things. This objectification of humans is necessary because culture, as Dulles (1999) observes, is inseparable from religion. It is essential, therefore, to exclude culture and the values associated with it through its inseparability from religion in order to cling fast to the claim that economics must be value-free to have any authenticity as a science. This exclusion reflects as well as helps fortify the shift away from the sacral toward the secular (see Figure 2).

Mainstream economics converges with a culture of death and despair. Humans are not ends in themselves but only a means whose value depends on their usefulness and who have no value whatsoever once they no longer are useful. This development, in turn, destroys the very foundation of the democratic state, John Paul warns (1995), because once the inviolate dignity 
of every human being is denied, the personhood and the rights of the weak also are denied, allowing the strong to dispose of them freely and to claim that what they do reinforces individual freedom and therefore is good and justified. Because the powerful claim rights that they deny to the powerless, the principle of equality is dismantled and the inevitable outcome is a transformation from democracy to tyranny.

Turning mainstream economics away from its current premises is a difficult task because it entails carefully re-examining what has been taken as given, what indeed is thought to be immutable. But the task is not impossible. A growing number of professional organizations in economics are attracting new members to institutional economics, feminist economics, humanistic economics, environmental economics, socio-economics, radical economics, and personalist economics all of which hold one position in common: there is something fundamentally flawed or missing in neoclassical economics. A number of respected academics including James Buchanan, Geoffrey Harcourt, Walter Adams, Wallace Peterson, John Elliott, Amartya Sen, Severyn Bruyn, and many others have voiced their criticism of mainstream economics, offering other descriptions of economic affairs and advocating other policy positions proceeding from different premises $^{6}$.

The makeover of economics will take much time because the mainstream way of thinking about economic affairs is deeply entrenched. However, it will take place once neo-classical economists accept that the ultimate end of economic systems relates not to maximum personal net advantage but to integral human development

\section{Notes}

1 "Given" or "allotted" is the operative word in experimental economics.

${ }^{2}$ In direct face-to-face experiments or in the mind's eye in blind or double-blind experiments.

${ }^{3}$ Identified and defined first by O'Guinn and Faber in 1989 as "chronic, repetitive purchasing that becomes a primary response to negative events or feelings" (quoted in Faber \& O'Guinn, 1992, p. 495; emphasis added). 
${ }^{4}$ Killinger's book was published in 19 countries and nine languages. A new edition appeared in 2004 (Psychology Today, n.d.).

5 McKenna's 1955 intermediate macro-economic text is an excellent example. His representation of the components of aggregate demand and aggregate supply (McKenna, $1955)$ is especially noteworthy.

${ }^{6}$ See Waters (1993) for a listing of the twentieth-century social economists who "best contributed to supplying the building blocks of a realistic and personalist economy."

\section{References}

American Psychiatric Association (2013a). "Internet Gaming Disorder," Retrieved from http://psychiatry.org/psychiatrists/practice/dsm/dsm-5 American Psychiatric Association (2013b). "Highlights of Changes from DSM-IV-TR to DSM-V," Retrieved from http://www.dsm5.org/Documents/changes from dsm-iv-tr to dsm-5.pdf Bales, K. (1999). Disposable People: New Slavery in the Global Economy. Berkeley, CA: University of California Press.

Becker, J. (1972). Experience Rating in Unemployment Insurance: An Experiment in Competitive Socialism. Baltimore, MD: The Johns Hopkins Press.

Buchanan, J. (1985). Liberty, Markets, and State: Political Economy in the 1980s. New York, NY: New York University Press.

Burke, R., Davis, R., \& Flett, G.. (2008). Workaholism Types, Perfectionism, and Work Outcomes, The Journal of Industrial Relations and Human Resources, 10, 30-40.

Camerer, C., \& Thaler, R. (1995). Anomalies: Ultimatums, Dictators and Manners, Journal of Economic Perspectives, 9(2), 209-219. Retrieved from http://www.jstor.org/stable/2138174

Danner, P. (2002). The Economic Person: Acting and Analyzing. Lanham, MD: Rowman and Littlefield.

Danner, P.; \& O’Boyle, E. (1999). Personalist Economics Is Human Economics Because It Puts the Human Person at the Center of Economic 
Affairs, Forum for Social Economics, 29(1), 47-61. doi: 10.1007/BF02761671

Davis, J. (2003). The Theory of the Individual in Economics. London, UK: Routledge.

Davis, J. (2011). Individuals and Identity in Economics. Cambridge, UK: Cambridge University Press.

Dempsey, B. (1958). The Functional Economy: The Bases of Economic Organization. Englewood Cliffs, NJ: Prentice-Hall.

Dulles, A. (1999). Centesimus Annus and the Renewal of Culture, The Journal of Markets \& Morality, 2(1), 1-7. Retrieved from http://www.marketsandmorality.com/index.php/mandm/article/viewFile/ 636/626

Faber, R., \& O'Guinn, T. (1992). A Clinical Screener for Compulsive Buying, Journal of Consumer Research, 19(3), 459-469. Retrieved from http://www.jstor.org/stable/2489402

Henrich, J. (2000). Does Culture Matter in Economic Behavior? Ultimatum Game Bargaining Among the Machiguenga of the Peruvian Amazon, American Economic Review, 90(4), 973-979. Retrieved from http://www.jstor.org/stable/117318

John Paul II (1981). Laborem Exercens. Retrieved from http://w2.vatican.va/content/john-paul-ii/en/encyclicals/documents/hf_jpii_enc_14091981_laborem-exercens.html

John Paul II (1995). Evangelium Vitae. Retrieved from http://w2.vatican.va/content/john-paul-ii/en/encyclicals/documents/hf_jpii_enc_25031995_evangelium-vitae.html

John Paul II (1998). Fides et Ratio. Retrieved from http://w2.vatican.va/content/john-paul-ii/en/encyclicals/documents/hf_jpii_enc_14091998_fides-et-ratio.html

Keynes, J. M. (c.1935). The General Theory of Employment, Interest, and Money. New York, NY: Harcourt, Brace and Company.

Killinger, B. (1997). Workaholics: The Respectable Addicts. Buffalo, NY: Firefly Books. 
Killinger, B. (2013). "Workaholism and Denial," Psychology Today. Retrieved from https:/www.psychologytoday.com/blog/theworkaholics/201305/workaholism-and-denial

Kohlberg, L. (c.1981). The Philosophy of Moral Development: Moral Stages and the Idea of Justice. San Francisco, CA: Harper \& Row.

Lee, S.-H., Lennon, S., \& Rudd. N. (2000). Compulsive Consumption Tendencies Among Television Shoppers, Family and Consumer Sciences Research Journal, 28, 463-488. doi: 10.1177/1077727X00284003

Lutz, M., \& Lux, K. (1988). Humanistic Economics: The New Challenge. New York, NY: The Bootstrap Press.

McCown, W., \& Chamberlain, L. (2000). Best Possible Odds: Contemporary Treatment Strategies for Gambling Disorders. New York, NY: John Wiley \& Son.

McKenna, J. (1955). Aggregate Economic Analysis. New York, NY: The Dryden Press.

Marshall, A. (1948). Principles of Economics: An Introductory Volume. New York, NY: The MacMillan Company.

Mayo Clinic (2014). Compulsive Gambling. Retrieved from http://www.mayoclinic.org/diseases-conditions/compulsivegambling/basics/symptoms/con-20023242

O’Boyle, E. (1998). Personalist Economics: Moral Convictions, Economic Realities, and Social Action. Norwell, MA: Kluwer Academic Publishers. O'Boyle, E. (2001). Personalist Economics: Unorthodox and CounterCultural, Review of Social Economy, 59(4), 367-393. doi: 10.1080/00346760127091

O’Boyle, E. (2014). Principles of Personalist Economics. Retrieved from http://http://www.mayoresearch.org/files/P

ECONOMICS may 9 2014.pdf

O’Boyle, E., Dawson, L., \& Tansey, R. (1996). Applying the American Marketing Association's Ethical Code Within a Moral Development Framework, Journal of Ideology, 19, 93-115. 
Ong, W. (1967). In the Human Grain: Technological Culture and Its Effect on Man, Literature, and Religion. New York, NY: The MacMillan Company.

Ong, W. (1970). The Presence of the Word: Some Prolegomena for Cultural and Religious History. New York, NY: Simon and Schuster, 1970; originally published by Yale University Press

Ong, W. (1981). Fighting for Life: Contest, Sexuality, and Consciousness. Ithaca, NY: Cornell University Press.

Psychology Today (n.d.). "Barbara Killinger, Ph.D.," Retrieved from https://www.psychologytoday.com/experts/barbara-killinger-phd

Rabin, M. (1993). Incorporating Fairness into Game Theory, American Economic Review, 83(5), 1281-1302. Retrieved from http://people.hss.caltech.edu/ camerer/NYU/07-Rabin.pdf

Roberts, J., \& Jones, E. (2001). Money Attitudes, Credit Card Use, and Compulsive Buying Among American College Students, The Journal of Consumer Affairs, 35(2), 213-240. doi: 10.1111/j.17456606.2001.tb00111.x

Robinson, B. (1998). The Workaholic Family: A Clinical Perspective, The American Journal of Family Therapy, 26(1), 65-75. doi: 10.1080/01926189808251087

Van Beek, I., Taris, T., \& Schaufeli, W. (2011). Workaholic and Work Engaged Employees: Dead Ringers of Worlds Apart?, Journal of Occupational Health Psychology, 16(4), 468-482. Retrieved from http://www.ncbi.nlm.nih.gov/pubmed/21787085

Vohs, K., \& Faber, R. (2007). Spent Resources: Self-Regulatory Resource Availability Affects Impulse Buying, Journal of Consumer Research, 33(4), 537-547. doi: 10.1086/510228

Waters, W. (1988). Social Economics: A Solidarist Perspective, Review of Social Economy, 46(2), 113-143.

Waters, W. (1993). A Review of the Troops: Social Economics in the Twentieth Century, Review of Social Economy, 51(3), 262-286. doi: $10.1080 / 758537258$ 
82 O'Boyle - Does Culture Matter in Economic Behaviour?

Wojtyla, K. in collaboration with Tymieniecka, A.T. (1979). The Acting Person. Dordrecht, Holland: R. Reidel Publishing Company.

Edward O'Boyle: Mayo Research Institute (USA)

Contact Address: edoboyle737@gmail.com 


\section{HSE}

Historia Social y de la Educación

Social and Education History
Hipatia Press

www.hipatiapress.com

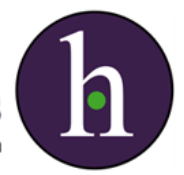

Instructions for authors, subscriptions and further details:

http://hse.hipatiapress.com

\section{Effect of Yoga on Human Aggression and Violent Behaviour-}

\section{A Review of the Indian Yoga Scriptures and Scientific Studies}

A.G. Govindaraja Setty ${ }^{1}$, Pailoor Subramanya ${ }^{1}$ \& B. Mahadevan ${ }^{2}$

1) Swami Vivekananda Yoga University (SVYASA), India

2) Indian Institute of Management, Bangalore, India

Date of publication: February 23rd, 2016

Edition period: February 2016-June 2016

To cite this article: Govindaraja Setty, A.G., Subramanya, P., \& Mahadevan, B. (2016). Effect of Yoga on Human Aggression and Violent Behaviour- A Review of the Indian Yoga Scriptures and Scientific Studies. Social and Education History 5(1), 83-104. doi:10.17583/hse.2016.1859

To link this article: http://dx.doi.org/10.17583/hse.2016.1859

\section{PLEASE SCROLL DOWN FOR ARTICLE}

The terms and conditions of use are related to the Open Journal System and to Creative Commons Attribution License (CC-BY). 


\section{Effect of Yoga on Human Aggression and Violent Behaviour - A Review of the Indian Yoga Scriptures and Scientific Studies}

\author{
A.G. Govindaraja Setty \\ Swami Vivekananda Yoga \\ University (India)
}

Pailoor Subramanya

Swami Vivekananda Yoga

University (India)

B. Mahadevan

Indian Institute of Management, Bangalore (India)

\section{Abstract}

Among the deviant human behaviors, aggression appears to be the most prevalent and disturbing one, affecting one and all. Uncontrolled aggression/violent behavior could cause a significant toll, equally affecting both involved and the non-involved. This delinquent human behavior has been well addressed in Indian yogic scriptures. It provides a theoretical framework to understand the causes, ill-effects, need for peace, harmony, and ways to correct the aggression behavior. It is also claimed that yoga is a way for inner bliss and external coherence; and with this time-tested technique, it is possible to bring about a sense of inner peace and emotional stability, thus having potential to correct aggressive behaviors. This review paper also brings out the studies made to find out effect of yoga on human aggression/violent behavior.

Keywords: Yoga, aggression, violence, violent behaviour 


\title{
El Efecto del Yoga en la Agresividad
}

\section{Humana y en el Comportamiento Violento - Una Revisiónde las Escrituras Indias de Yoga y Estudios Científicos}

\author{
A.G. Govindaraja Setty \\ Swami Vivekananda Yoga \\ Pailoor Subramanya \\ University, Bangalore (India) \\ Swami Vivekananda Yoga \\ University, Bangalore (India) \\ B. Mahadevan \\ Indian Institute of Management, Bangalore (India)
}

\section{Resumen}

\begin{abstract}
Entre las conductas humanas desviadas, la agresión aparece como una de las más frecuentes y alarmantes, afectando a todas las personas sin excepción. La conducta agresiva/violenta incontrolada puede causar graves consecuencias, afectando tanto a las personas directamente implicadas como a las no implicadas. Este comportamiento humano delictivo ha sido abordado con profundidad en las escrituras indias yóguicas. Ello aporta un marco teórico para entender las causas, efectos nocivos, la necesidad de paz, harmonía y las formas para corregir las conductas violentas. También se afirma que el yoga es una forma de alcanzar la paz interior y la coherencia exterior; y con esta técnica probada en el tiempo es posible lograr un sentimiento de paz interna y de estabilidad emocional, por lo que tiene potencial para corregir conductas agresivas. Esta revisión bibliográfica pone de relieve los estudios llevados a cabo para identificar los efectos del yoga en las conductas humanas agresivas/violentas.
\end{abstract}

Keywords: Yoga, agresión, violencia, comportamiento violento 


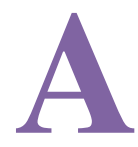

Among the deviant human behaviors, aggression and violence appear to be the most prevalent and highly disturbing, affecting one and all in the society, hence considered a serious global health problem (WHO, 2014). Some of the studies say that this aberrant behavior normally surfacing in childhood becomes habitual and continues at all age points of an individual and that in childhood it might lead to rejection from family as well from fellow children, relational tribulations leading to isolation during adolescence and criminal, illegal or unlawful behavior in adulthood (Huesmann \& Guerra, 1997) and the whole society looks down at such an individual. Further, it could affect both the involved and the noninvolved; and unchecked aggression and violence exact a significant toll on human societies.

Though normally men score slightly higher on aggression, this deviant attitude is not gender-sensitive. Significant correlates of interpersonal violence were found in younger age. Intensity of aggression is directly attributable to one's amount of frustration. Though aggressive behaviors evolved as adaptations to deal with competition, they can have destructive consequences. Family members have been the object of violence in more than $50 \%$ of cases (Kumar, Akhtar, Roy \& Baruah, 1999). Worldwide, mass media reports, a number of violent acts affecting one and all, that are neither country specific (Miron, 2001) nor religion specific (Cobban, 2005) and world over findings regarding violence-related behaviors are remarkably similar. The economic cost associated with violence-related injuries, disabilities, and premature deaths is estimated to be in billions of dollars. The gravity of the problem could be understood from the fact that 49 World Health Assembly Geneva, declared violence as leading global public health problem and urged members to assess the problem of violence in their territories; and convey details to WHA, besides clearly defining their approach to deal with it. Further, WHA requested the Director-General for public health to address the problem of violence, promote research on violence on priority and document them for the benefit of member nations.

"Aggression" and "violence" are generic terms. Oxford dictionary defines "aggression" as "feelings of anger or antipathy, readiness to attack or confront, resulting in hostile or violent behavior". WHO defines "Violence" as "intentional use of physical force or power, threatened or actual, against 
oneself, another person, or against a group or community or section of people, which either results or has a high likelihood of resulting in injury, death, psychological harm, mal-development or deprivation". "Violent behaviors" are latent perception variables towards violence, which are guided by one's own value systems.

\section{Aggression and Violence: Indian Scriptural Perspective}

Aggression and violence have been well addressed in Indian scriptures (Vedas, Upanishads, Bhagavad Gìtā, Brahma Sutras, Yoga Sutras, and Bhakti (Devotion) Sutras), which are also considered as conventional yoga texts. This traditional literature provides a theoretical framework to understand the aggression and violence in conventional background. In every Indian scripture, there is invariably a mention on aggression and violence, ill effects, ways to avoid, and need for harmony and coherence. These include teachings under 'The doctrine of ahimsa' (Rajapakse, 1988; Phillips, 2010). 'Ahimsa' means and includes avoiding any harm (physical, mental or emotional), to remain passive in any situation, without the desire to harm anyone (Muktibodhananda, 2004). Himsa is brought out by three ways namely, 'violence done', 'violence got done' and 'violence sanctioned' (Adidevananda, 1998), wherein all the three bring endless agony. But when a person is firmly established in ahimsa, in his/her presence, even cruel persons renounce violence (Adidevananda, 1998). Indian yogic scriptures recommend that personality of an individual gets nourished by a mix of both 'relaxing' and 'stimulating' practices by attaining a state of mental equipoise (Telles \& Reddy, 2000).

\section{Prevalence of Aggression and Violent Behavior: Indian Scriptural Perspective}

Indian scriptures answer the question, 'does aggressive and violent behavior indeed exist in us? If yes, in whom and in what ways?' Pretentiousness, arrogance, overweening pride, wrath, rudeness, aggression, scant regard for pain of others, insensitiveness to spiritual values are prevalent in those born to demoniac (Asuri) heritage'; whereas, non-violence, truthfulness, freedom 
from anger renunciation, tranquility, aversion to slander, compassion to living beings, sensitivity to the pain of others, empathy, freedom from sensuality, gentleness, modesty, steadfastness, are the qualities present in those born to divine (Daivi) inheritance' (Bhagavad Gìtā 16.2,4) (Tapasyānanda, 2003).

\section{Causes for Aggression and Violence, and Need to Address: Indian Scriptural Perspective}

Indian scriptures clearly establish the causes for aggressive and violent behavior and assert that we have propensity to be violent. Causes could range from 'sense objectivity, greed and illusion. Bhagavad Gìtā (2.62) says, if one dwells longingly on sense objects, inclination towards them is generated; inclination develops into desire; desire begets anger, and finally culminates in aggression. Bhägavatam (4.8.3) says, hypocrisy and illusion beget greed and deceitfulness, they, in turn, beget aggression and violence. Insatiable lust, uncontrolled anger, born out of 'rajas' prompt men to engage in violence (Bhagavad Gìtā 3.37). 'Rajas' is passion-based leading to craving for objective pleasures; and clinging to objects already possessed by an individual. Tamas is ignorance-born and produces delusion leading to negligence, indolence, scant regard for pain of others (Bhagavad Gìtā 14.78 ). The children (derivatives) of aggression and violence are 'hostility' and 'harsh abusive words' (verbal aggression) (Velanakar, 2013).

The gradual degradation of aggressive and violent personalities is also brought out by Indian yoga scriptures. Aggression generates delusion, delusion results in loss of memory, loss of memory brings about destruction of discriminative intelligence, and loss of discriminataive intelligence spells ruin to a man (Bhagavad Gìtā 2.63).

Bhagavad Gìtā (16.21) establishes in a pristine way that lust, aggression, and greed lead to destruction of man's spiritual nature. They form the gateway to hell; hence surely be abandoned (Tapasyānanda, 2003). Patañjali Yoga sūtra (2.30) says, ahimsā (non-violence), satya (truthfulness), asteya (non-stealing), brahmacharya (sexual self-restraint), aparigraha (non-obsessively possessive) are five yamas (moral universal commandments for self-control) (Prabhavananda, 2004). Patañjali Yoga 
Sütra (2.35) says, when a yogi is resolutely committed to non-violence, there is no hostility, wherever he is present (Prabhavananda, 2004). Manusmrti (5.43) says a Brahmin of virtuous disposition, whether dwells in (own) house, with a teacher or in the forest, must never, in times of distress, cause injury to any creature, which is not sanctioned by Vedas. Bhāgavatam (4.18.14) says, you will get the divine feet of Bhagavān Nrsimha (one of the ten incarnations of Lord Vishnu), only on your abandonment of desire, melancholy, aggression, pride, apprehension, and grief which are the causes for vicious cycle of birth and death (Velanakar, 2013).

\section{Addressing Aggression and Violent Behavior: Yoga Way}

Practical lessons of Indian yogic scriptures could provide broad framework and specific ways to fight against this delinquent behavior and answer the question, can we as human beings, bring about a paradigm shift in our personality by avoiding all these aggression and violent behavior. One of the eighteen Indian mythologies, Bhägavatam (1.18.22) says one who is in divine love with the Supreme Lord can make non-violence and peace one's dharma and strive for the ultimate realization through dhyanna (Velanakar, 2013). The word 'yoga' implies non-duality, oneness with the Supreme Soul; and the very notional duality causes fear, anger, lust and therefore reaching oneness can address this delinquent behavior (Adidevananda, 1998). Violence is attributable to ignorance caused by pretentiousness, impatience, lack of straight-forwardness, abhorrence, lack of self-control, lack of devotion and scant regard for cleanliness (Bhagavad Gìtā 13.7-11). Bhāgavatam (6.4.14) further says, a person can transcend 'Trigunas' (personality traits) by appeasing and controlling the teeming aggression by steady, indrawn, discriminating mind (Velanakar, 2013). Withdrawal of mind is nothing but 'prathyāhāra' mentioned in ashtanga yoga texts.

According to yogic scriptures, early seers (spiritual masters or yogis or prophets) of India devised and used yoga as a means to explore the external and internal realms; and to attain ultimate knowledge described in sacred Indian texts. These great masters or yogis prescribed yoga as a way of life to be in tune with the highest reality; and the importance is on individualized or one's own confirmation and not merely on religious dogmas or doctrines. 
They preached that yoga is both a way for internal bliss and external coherence. "Yoga" is derived from a Sanskrit root word 'Yuj' (join), hence "yoga" means and includes, joining of the body, mind and the 'Self'(soul) (Nagendra, 2000).

Addressing violent and aggressive behavior through yoga has been suggested by many researchers on the ground that it is very effective and be documented to promote research on violence on the lines suggested by World Health Assembly, Geneva for the benefit of member States. Yoga is an ancient science, originating in India, which includes diverse practices like physical postures (asana), regulated breathing (pranayama), meditation and lectures on philosophical aspects of yoga. The ultimate aim of yoga is to remain unperturbed in success or failure and perfection of the personality of its practitioner to remain equipoise in all conditions (Bhagavad Gìtā 2.48). The yoga texts suggest that the solution lies in developing health and personality of the individuals brought out by a mix of both 'relaxing' and 'stimulating' practices which help in reaching a state of mental equipoise (Telles, Reddy, \& Nagendra, 2000) and supports the view that combination of yoga postures interspersed with relaxation reduces arousal more than mere relaxation (Sarang \& Telles, 2006).

Asanas, which are physical movements, may give exercises to various organs and systems and provide them an avenue to deal with character, attitudes and tensions; can bring about healthy changes in several psychopathological conditions (Krishna Rao, 2000). When yoga induced non-violence in speech, thought and action is established, one's aggressive nature is relinquished; others abandon hostility in such a yogi's presence (Iyengar, 1993). Swami Vivekananda says, 'the test of ahimsa is absence of jealousy' (Prabhavananda, 2004). Generosity, acceptance, patience, freedom from self-importance, unpretending, ahimsa (non-violence), self-control and straight-forwardness are the divine qualities one can nourish through yoga (Bhagavad Gìtā 13.7-11).

Yoga is an ancient science and an art and a way of life, aimed at harmonious system of developing the body, mind and spirit. The Indian scriptures claim that yoga, with its powerful, time-tested techniques, can bring about a sense of inner peace, which can culminate in emotional stability, harmony and clarity of mind (Nagendra, 2000). Bhagavad Gìtā 
defines yoga as 'samatvam yoga ucyate', - 'always being in a state of unperturbed evenness'. Patañjali, who is quoted widely in yoga researches, defines yoga as 'Yogahcittavrittinirodah', i.e., 'Yoga is the cessation of movements in consciousness' which can lead to complete mastery over mind. Sage Vasistha, ('Yoga Vasistha') defines yoga as a technique to slow down or calm down the mind through deep internal awareness (Nagarathna \& Nagendra, 2003).

Thus, in its attempts to achieve these results, yoga offers varied techniques like asanas (bodily postures), pranayama (regulated breathing), and dhyāna (meditation) coupled with swadhyāya (sermons of philosophical aspects of yoga). Violent/aggressive individuals normally do not respond or react to oral methods only; instead, they are to be addressed through psychodynamic psychotherapies like yoga, martial arts, out-door games (Twemlow, Sacco, \& Fonagy, 2008).

The way yoga leads to reduction of aggression is understandable: anger, aggression and violence are said to be unrestrained speed in one's mind (Nagarathna \& Nagendra, 2003) whereas, yoga is the art of slowing down the mind, so that one has time to think and act. This modification is owing to increased clarity of thoughts, calmness, serenity, and control over emotions, carving out a happy living. The norms prescribed by Indian scriptures for yogic life are characterized by peace, tranquility, harmony, love, happiness, and efficiency, driven by discrimination, right thinking, right understanding, and calculated actions.

\section{Causes as per Research Studies; Aggression Theories}

Research says there is no single cause for human aggression and violence. It ranges from factors like racism (Rogers \& Prentice-Dunn, 1981), religious intolerance (Corrigan \& Neal, 2010), sex-induced (Gurvinder \& Dinesh, 2013), media influence (Gentile, Coyne, \& Walsh, 2011), violent video games (Adachi \& Willoughby, 2011), prolonged television viewing (Mitrofan, Paul, \& Spencer, 2009), low self-esteem (Bushman \& Baumeister, 1998), food insecurity (Brinkman \& Hendrix, 2011).

Aggression theories offer broader framework for these causes. Among conventional theories, instinct theory (Sigmund Freud) says, aggression is 
because of release of dammed up energy. For instance, hunting and fighting instincts are found in frustrated ones. When aroused, they over-ride other instincts like sympathy, paternal instinct and become expressive through aggression and violence. Sigmund Freud calls these instinctive drives as 'libido', which are nothing but energy derived from Eros (life instinct) (Eron \& Huesmann, 1994).

Dollard and his associates (Yale University), offered 'frustration and aggression' theory. When a person is frustrated, when his/her desires or wishes are let down, he/she responds aggressively. Thus, frustration always presupposes aggression (Dollard \& Miller, 1939).

Theory of hormones and chromosomes got popularity from 1920's. Discovery of human chromosomes led to research linking excessive male aggression with the presence of extra Y chromosome. Some researchers suggest that $\mathrm{Y}$ chromosome is the cause for aggression; and doubling $\mathrm{Y}$ chromosome doubles one's aggression and violent behavior (Jarvik, Klodin, \& Matsuyama, 1973).

Among the recent theories, cognitive neoassociation theory suggests that incidents involving aversion lead to negative affect (Berkowitz, 2012). These in turn stimulate expressions, thought process, memories, and response patterns like fight and flight. These fight and flight patterns give way to reactions like anger and fear respectively.

Social learning theory proposes that aggressive responses are acquired in similar ways, the people learn other intricate forms of social behaviors by way of direct experience or by learning from others (Bandura, 1978).

'Script theory' says that 'scripts' are situation-guided 'stored-up behaviors' (Huesmann, 1998). These stored up scripts could be retrieved later and may guide the behavior of an individual. This explanation of script theory is comparable to what yoga scriptures pronounce: consciousness has four faculties. First is the mind (manas - receiving faculty). Being nonjudgmental, it keeps receiving the knowledge through senses, good or bad. Such knowledge is passed on to next faculty - buddhi (intellect discriminating faculty). It qualifies the knowledge as good or bad, negative or positive. Such qualified knowledge is passed on to third faculty namely 'ahankara' (ego). This faculty may choose to retain either the positive or negative knowledge and reject the other. Having retained one of these two, it 
becomes part of the knowledge retained. Further, this retained knowledge is passed on to the next faculty namely 'chitta' which 'stores' the knowledge for future retrieval.

Excitation transfer theory proposes 'transfer of arousal'. When two disturbing events are disconnected by a short time period, arousal from first event is erroneously attributed to second and the person wrongly behaves aggressively to the second event (Bryant \& Miron, 2003).

Social interaction theory advocates aggression as a function of social influence (Felson \& Tedeschi, 1993). For example, coercion is employed to get something valuable, or to cause an intended change or outcome.

\section{Studies on Effect of Yoga on Aggression and Violent Behavior}

Earlier research studies on effect of yoga on human aggression and violent behavior have considered varied sample sizes, intervention periods, diverse age groups of both sexes, varied ethnic groups, nationality, on different forms of aggression and violence (physical, verbal, covert), on normal as well as high-risk individuals. With all this diversity, the outcomes appear to be remarkably similar and encouraging. Even the Indian yoga scriptures do not limit or prohibit the application of yoga to any particular age category, gender or personality type and hence the scope is very wide as for as the application is considered.

\section{Studies on Effect of Yoga on Aggression and Violent Behavior of At- Risk-Youth}

Aggression that manifests in childhood could lead to rejection from fellow children in childhood, relational problems during adolescence and criminal behavior in adulthood (Guerra, Rowell Huesmann, \& Spindler, 2003). Hence, it is desirable for the parents, elders and teachers to identify this delinquent behavior at the earliest. In a pre and post quasi-experimental control group design, 49 students (females 54.4\%) in $9^{\text {th }}$ to $12^{\text {th }}$ grades of school for at-risk youth, California, participated. The participants were academically heterogeneous, 33.3\% black, 33.3\% Hispanic, 4.3\% Native 
American, 6.2\% Asian, 2.1\% white and 20.8\% mixed races. The youth were characterized by risk factors like aggression, academic failure, poor grades, high truancy, repeated suspension and expulsion. Transformative life skills (TLS - which includes asanas, pranayama and meditation) were taught by certified yoga teachers for 3-4 days a week in the first semester for 30 minutes per day. Yoga practitioners demonstrated significant decrease in nervousness, depression, psychological anguish, intrusive views, physical provocation, emotional stimulation; and significantly less likely to approve revenge and overall less aggression, suggesting possibility for yoga-based wellness program and TLS to favorably influence emotions among high-risk youth (Frank, Bose, \& Schrobenhauser-Clonan, 2014).

As a part of countrywide violence prevention effort, Niroga Institute conducted transformative life skills (TLS) program (yogasanas, pranayama, and meditation), daily 60 minutes for 18 weeks involving 472 students from Alameda County Juvenile Justice Center. In another group 85 students participated in control group, which did not get the TLS. Additionally, a condensed 15 minutes TLS program was done in a large urban public high school. The yoga intervention was by certified yoga teachers. The scales used were perceived stress scale (PSS-10) and Tangney's self-control scale13. At the end of the study period 'at-risk-imprisoned adolescents' reported lessened perceived stress and escalated self-control and self-awareness. They showed statistically significant improvement in stress resilience, self-control, and self-awareness. PSS reduced by a mean change of 1.31; self-control improved by a mean change of 1.68 (Ramadoss \& Bose, 2010). Thus, these two studies are suggestive of feasibility of yoga intervention to youth with known background of risk factors like aggression, academic poor performance.

\section{Studies on Effect of Yoga on Verbal Aggression}

Being one of the aggression expressions, 'verbal aggression' is use of abusive words to insult/hurt another person. In one of the studies, effect of yoga on verbal aggressiveness in 173 normal healthy adults was studied (age 17 - 62 years). Yoga group practiced integrated yoga module and control group practiced moderate physical exercises for one hour a day, six days a 
week, for eight weeks. Self-administered verbal aggressive scale was used. Significant reduction in verbal aggression in yoga group $(P=0.0)$ and nonsignificant upsurge in control group was reported (Deshpande, Nagendra, \& Raghuram, 2008b). The aggression or violent behavior could manifest in any of the three kinds namely, verbal, physical or covert. Irrespective of the kind of aggression that manifests in an individual, yoga could offer a positive and a constructive change.

\section{Studies of Effect of Yoga on Perceived Well-Being}

Yoga could be a preventive intervention and a way for improving children's perceived well-being, which Berger studied as outcome measures. Pilot study compared fourth and fifth-grade students. One program was offered yoga for one hour a week for 12 weeks; other program was not offered yoga. Outcome measures were emotional well-being assessed by Harter's global self-worth and physical appearance subscales; physical well-being was assessed by flexibility and balance. Yoga group showed less negative conduct scores and heightened comfort (Berger, Silver, \& Stein, 2009). Thus the outcomes suggest that yoga, besides being a way for refining adolescents' perceived well-being, can also be a preventive intervention.

\section{Studies on Effect of Yoga on Correlates of Aggression and Violent Behavior}

Some of the reports suggests that high levels of nervousness and aggression do affect parameters like grip strength, dexterity scores and optical illusion. In order to study these correlates a study was done, wherein, in the age range 12 to 16 years, equal number of subjects were there in each of the three groups namely, community home girls trained in yoga for a period of six months, community home girls who practiced physical exercises and girls who attended their regular schools. Degree of optical illusion was significantly higher in physical exercises group when compared to yoga group and regular school group. Hand grip was significantly less in physical exercises group compared to yoga group (Raghuraj \& Telles, 1997). The 
improved performance of the yoga group compared to physical activity group suggests that yoga practice has a beneficial effect on these parameters, which are considered to be the derivatives of aggression and violent behaviors.

\section{Studies on Effect of Yoga on Personality Traits (Gunas as per Bhagavad Gītā)}

A person with calmness, purity, without pride and self-importance, having concern for others' pain, is 'sattvik'. A person with passions, cruelty, impure at heart and is subject to elation and depression in success and failure, is 'rajasic'. A person with unsteadiness, offensive, ego, deceitful, malevolent, procrastination, and indolence is 'tamasic' (Bhagavad Gìtā 18.26-28). In one of the studies self-administered "Bhagavad Gìtā Personality Inventory" was used to measure these Gunas. In the age group of 18 to 71, 226 subjects of both sexes participated. The yoga group practiced integrated yoga module and control group practiced physical exercises daily one hour, six days a week, for eight weeks. The outcomes demonstrated that the baseline scores for all areas for both groups did not differ considerably. There were noteworthy improvements in all domains in both groups. However, the number of persons who showed progress in Sattva and decline in Tamas was substantial in yoga group (Deshpande, Nagendra, \& Nagarathna, 2009; Deshpande, Nagendra, \& Raghuram, 2008a). Thus, evidencing that yoga could be a helpful tool in bringing out positive changes in personality traits, irrespective of the age and gender.

\section{Studies on Effect of Yoga on Predictors of Aggression}

Variables like empathy, emotional quotient, general well being, and beliefs about aggression are found to be good predictors of aggression levels. When these variables are addressed through yoga, effect could be found in aggression level as a correlate. A pre-post yoga intervention study measured persistent attention, emotive intelligence (EQ), general wellbeing through general health questionnaire, and Guna personality -sattva (purity), rajas (craving) and tamas (brutality). Control group was not there. In the age 
group of 17 to 63 years 108 subjects participated. Yoga practitioners demonstrated substantial changes in all variables $(\mathrm{P}<0.001)$ excepting 'sattva'. EQ and overall health variables compare considerably with each other and negatively with tamas. EQ and tamas form positive and negative forecasters of health. Sattva correlates positively with EQ signifying that a sattvic personality demonstrates improved self-control. This recommends that yoga practice may improve guna personality (traits) and can stabilize EQ (Khemka, Hankey, \& Ramarao, 2011).

\section{Studies on Effect of Yoga on Cognitive Functions}

When a person longingly dwells on sense objects, gradually preference towards them develops. This preference develops desire; desire produces anger and aggression. Aggression brings about delusion, and delusion leads to loss of memory. Loss of memory culminates in destruction of discriminative intelligence, which in turn, brings about complete devastation to the person (Bhagavad Gitta 2.62-63). Thus, aggression and violent behavior affect the cognitive functions like thinking, memory, analyzing, perception and judgment. In one of the studies, effect of yoga on cognitive functions and attitude towards violence (ATV) in 100 rural school children, aged 13-15 years, of both sexes, in $8^{\text {th }}$ and $9^{\text {th }}$ grades was studied. The subjects were divided into yoga and control groups. The yoga group practiced yoga for one hour a day for 10 days and control group practiced physical exercises. Digit letter substitution test was used to measure cognitive function, whereas ATV scale was used to measure attitude towards violence. The outcomes showed significant change in cognitive functions, $42 \%$ and $24 \%$ mean change in yoga and control groups respectively. But there were no noteworthy results in ATV, $3 \%$ and $12.8 \%$ mean change in yoga and control group respectively. However, yoga group experienced other benefits like increased flexibility, improved digestion, good sleep, relaxation and were cooperative with teachers/parents (Reddy, 2015).

Adolescence is the age when the aggression is at its peak and if uncorrected, it could manifest at all age points of an individual, say research studies. A study was done to find out the effect of yogic practices like Suryanamaskara and pranayama on 30 adolescents' logical memory, 
aggression and anxiety levels. The yoga intervention was given for a period of 25 days and the outcomes measured were logical memory, anxiety and aggression levels by aggression scale. The Result showed statistically significant decrease in post anxiety and aggression levels and improved logical memory of participants (Singh, 2015).

In another study, yoga practitioners outdid physical exercise practitioners on variables like trait anxiety, somatic anxiety, cognitive anxiety, aggression and achievement impetus (Vengatesh, 2014).

\section{Studies on Effect of Yoga on Somatic Grievances of Women and Girls}

A study on physiological and psychological effects of hatha-yoga in healthy women showed no considerable changes between the clusters regarding endocrine parameters and BP. The yoga group had substantial reduction of heart rate all through the yoga practice. The study accounted for substantial variances between groups in psychological parameters. Yoga group displayed distinctly higher scores in life fulfillment, morale, extravertedness, lower scores in nervousness and aggression, frankness, emotionality and somatic grievances. Substantial dissimilarities could be witnessed concerning handling of stress and temperament (Schell, Allolio, \& Schonecke, 1994). The study suggests that the derivatives of high levels of aggression and violent behavior like hypertension and high heart rate do get improved with the intervention of yoga.

\section{Conclusion}

It is evident from various research studies that yoga intervention on subjects of varied age, ethnicity, and nationality have shown remarkably similar results and findings are quite encouraging to deal with the problem of aggression through yoga. Researches on aggression and violence have progressed to a stage where a unifying construction is needed in the sense that different kinds of interventions (yoga, Transformative life skills, counseling, addressing predictors of aggression and violent behavior) can be blended to be more effective in addressing this delinquent human behavior. Further, there is a need for standardizing the yogic intervention module and 
period of intervention, so that this delinquent human behavior is addressed effectively and the results could be more evident. It also helps to scientifically establish the basis for transformation claimed by Indian yoga scriptures. Man is a social being. Sociability, that is one's ability to cordially blend with the fellow beings in the societal structure, is one of the important facets of health according to World Health Organization. Indian yoga scriptures deal extensively with this subject. There is a need to use this ancient wisdom, claimed by Indian scriptures. This would provide a new and effective framework to deal with the problem of human aggression and violent behavior. Research is scarce particularly concerning the effects of yoga on domains like human beliefs and attitude towards aggression and violence, normative beliefs supporting aggression, perception towards alternatives for violent methods normally adopted by aggressors, and perceptions towards social norms for aggression and alternatives.

The yoga scriptures (including scientific researches) claim that irrespective of the age, this ancient science of yoga can be taught. The detailed yoga protocol intervention to suit different age groups can be well defined and standardized and the results can be documented for the benefit of all, which helps in understanding the methods researched to be effective in correcting aggressive and violent behavior, and understanding the nature, causes, contributive factors, neuro-psychological changes, gender differences, forms of aggression (latent and manifest), relationship between select behavioral-characteristics as predictors of aggression. This could be one of the valuable, cost effective, alternative (or complementary) methods that involve no drugs and no invasive treatments to correct this delinquent human behavior.

Excepting the theory of hormones and chromosomes, most of the aggression theories deal only with the mind as the root instrumental cause for aggression and violent behavior. Yoga deals comprehensively with this subject. Hence there is a need for the researchers to look at this ancient, time tested method advocated by Indian yogic scriptures. 


\section{References}

Adachi, P. J. C., \& Willoughby, T. (2011). The effect of violent video games on aggression: Is it more than just the violence? Aggression and Violent Behavior, 16(1). doi:10.1016/j.avb.2010.12.002

Adidevananda, S. (1998). Patanjala Yogadarshana - Vyasabhashya sahita (4th print.). Mysore: Sri Ramakrishna Math.

Bandura, A. (1978). Social learning theory of aggression. Journal of

Communication, 28, 12-29. doi:10.1111/j.1460-2466.1978.tb01621.x

Berger, D. L., Silver, E. J., \& Stein, R. E. K. (2009). Effects of yoga on inner-city children's well-being: a pilot study. Alternative Therapies in Health and Medicine, 15(5), 36-42. Retrieved from http://www.ncbi.nlm.nih.gov/pubmed/19771929

Berkowitz, L. (2012). A Different View of Anger: The CognitiveNeoassociation Conception of the Relation of Anger to Aggression. Aggressive Behavior,38(4). doi:10.1002/ab.21432

Brinkman, H., \& Hendrix, C. S. (2011). Food Insecurity and Violent Conflict: Causes, Consequences, and Addressing the Challenges. Challenges, 24, 1-28. Retrieved from

http://documents.wfp.org/stellent/groups/public/documents/newsroom/ wfp238358.pdf

Bryant, J., \& Miron, D. (2003). Excitation-transfer theory and three-factor theory of emotion. In ... emotion: Essays in honor of ... (pp. 31-59). Retrieved from

http://scholar.google.com/scholar?hl=en\&btnG=Search\&q=intitle:Exci tation-transfer+theory $+\&+$ the + three-factor+theory + of + emotion 0 \nhttp://scholar.google.com/scholar?hl=en\&btnG=Search\&q=intitle:E xcitation-transfer + theory + and + three-factor + theory + of + emotion

Bushman, B. J., \& Baumeister, R. F. (1998). Threatened egotism, narcissism, self-esteem, and direct and displaced aggression: does selflove or self-hate lead to violence? Journal of Personality and Social Psychology, 75(1), 219-229. doi:10.1037/0022-3514.75.1.219

Cobban, H. (2005). Religion and violence. Journal of the American Academy of Religion, 73(4), 1121-1139. doi:10.1093/jaarel/lfi117 Corrigan, J., \& Neal, L. S. (2010). Religious Intolerance in America. Presidency. 


\section{Govindaraja et al - Effect of Yoga on Human Aggression}

Deshpande, S., Nagendra, H. R., \& Nagarathna, R. (2009). A randomized control trial of the effect of yoga on Gunas (personality) and Self esteem in normal healthy volunteers. International Journal of Yoga, 2(1), 13-21. doi:10.4103/0973-6131.43287

Deshpande, S., Nagendra, H. R., \& Raghuram, N. (2008a). A randomized control trial of the effect of yoga on Gunas (personality) and Health in normal healthy volunteers. International Journal of Yoga, 1(1), 2-10. doi:10.4103/0973-6131.36785

Deshpande, S., Nagendra, H. R., \& Raghuram, N. (2008b). A randomized control trial of the effect of yoga on verbal aggressiveness in normal healthy volunteers. International Journal of Yoga, 1(2), 76-82. doi:10.4103/0973-6131.41034

Dollard, J., \& Miller, N. E. (1939). Frustration and aggression. Frustration and aggression (pp. 91-109). doi:10.1037/10022-000

Eron, L. D., \& Huesmann, L. R. (1994). Theories of aggression: From drives to cognitions. In Rowell, L. (1994) Aggressive Behavior: Current Perspective (p. 3). Plenum Press: New York.

Felson, R. B., \& Tedeschi, J. T. (1993). A social interactionist approach to violence: cross-cultural applications. Violence and Victims, 8(3), 295 310.

Frank, J. L., Bose, B., \& Schrobenhauser-Clonan, A. (2014). Effectiveness of a School-Based Yoga Program on Adolescent Mental Health, Stress Coping Strategies, and Attitudes Toward Violence: Findings From a High-Risk Sample. Journal of Applied School Psychology, 30(1), 2949. doi:10.1080/15377903.2013.863259

Reddy, S. K. (2015). Effect of short term yoga practices on cognitive function and attitude towards violence in school children - A randomized control study. Voice of Research, 3. Retrieved from http://www.voiceofresearch.org/Doc/Mar-2015/Mar-2015 5.pdf

Gentile, D. a., Coyne, S., \& Walsh, D. a. (2011). Media violence, physical aggression, and relational aggression in school age children: A shortterm longitudinal study. Aggressive Behavior, 37(2), 193-206. doi:10.1002/ab.20380

Guerra, N. G., Rowell Huesmann, L., \& Spindler, A. (2003). Community Violence Exposure, Social Cognition, and Aggression Among Urban 
Elementary School Children. Child Development, 74(5), 1561-1576. doi:10.1111/1467-8624.00623

Gurvinder, K., \& Dinesh, B. (2013). Sexual violence against women:

Understanding cross-cultural intersections. Indian Journal of

Psychiatry, 55(3), 244-249. doi:10.4103/0019-5545.117139

Huesmann, L. R. (1998). The role of social information processing and cognitive schema in the acquisition and maintenance of habitual aggressive behavior. In Geen, R.G., \& Donnerstein, E.D. (1998) Human aggression: Theories, research, and implications for social policy (pp. 73 - 109). Academic Press: London.

Huesmann, L. R., \& Guerra, N. G. (1997). Children's normative beliefs about aggression and aggressive behavior. Journal of Personality and Social Psychology, 72(2), 408-419. doi:10.1037/0022-3514.72.2.408 Iyengar, B. K. S. M. Y. P. (1993). Light on the yoga sutras of Patañjali : Patañjala yoga pradipika (11th ed.). New Delhi: Harper Collins. Jarvik, L. F., Klodin, V., \& Matsuyama, S. S. (1973). Human aggression and the extra Y chromosome: Fact or fantasy? American Psychologist, 28(8). Retrieved from

http://ovidsp.ovid.com/ovidweb.cgi? $=\mathrm{JS} \& \mathrm{PAGE}=$ reference $\& \mathrm{D}=\mathrm{psyc}$ 2\&NEWS $=$ N\&AN=1974-21318-001

Khemka, S., Hankey, A., \& Ramarao, N. (2011). Effect of integral yoga on psychological and health variables and their correlations. International Journal of Yoga, 4(2). doi:10.4103/0973-6131.85492

Krishna Rao, P. V. (2000). Yogasanas in psychotherapy. Journal of Indian Academy of Applied Psychology, 26(1-2), 73-75. Retrieved from http://medind.nic.in/imvw/imvw3871.html

Kumar, R., Akhtar, S., Roy, D., \& Baruah, S. (1999). A study of aggression in psychotic illness. Indian Journal of Psychiatry, 41(2), 131-135. Retrieved from http://www.ncbi.nlm.nih.gov/pubmed/21455375

Miron, J. A. (2001). Violence, Guns, and Drugs: A Cross-Country Analysis. The Journal of Law and Economics, 44(S2). doi:10.1086/340507 Mitrofan, O., Paul, M., \& Spencer, N. (2009). Is aggression in children with behavioural and emotional difficulties associated with television viewing and video game playing? A systematic review. Child: Care, 
102 Govindaraja et al - Effect of Yoga on Human Aggression

Health and Development, 35(1). doi:10.1111/j.1365-

2214.2008.00912.x

Muktibodhananda, S. (2004). Hatha Yoga Pradipika (2nd ed., p. 57).

Munger, Gangadarshan, Bihar, India: Yoga Publications Trust.

Nagarathna R., \& HR.Nagendra. (2003). Yoga (p. 6). Bangalore: Swami

Vivekananda Yoga Prakashana.

Nagendra H.R. (2000). Yoga its basis and applications (1st ed.). Bangalore:

Swami Vivekananda Yoga Prakashana.

Phillips, S. H. (2010). Nonharmfulness (Ahimsa\&Macr;) In Classical Indian

Thought. In Kurtz, L. (ed) (2010) Encyclopedia of Violence, Peace,

and Conflict (pp. 1347-1356). doi:10.1016/B978-012373985-8.001148

Prabhavananda, S. (2004). Patanjali Yoga Sutra (p. 97). Myapore, Chennai: The President, Sri Ramakrishna Math.

Raghuraj, P., \& Telles, S. (1997). Muscle power, dexterity skill and visual perception in community home girls trained in yoga or sports and in regular school girls. Indian Journal of Physiology and Pharmacology, 41(4), 409-415. Retrieved from

http://www.ncbi.nlm.nih.gov/pubmed/10235665

Rajapakse, V. (1988). The Ahimsa Precept of the Indian Religious Systems and the Utilitarian Thinking of Jeremy Bentham, James Mill and John Stuart Mill. Indian Philosophical Quarterly: Journal of the Department of Philosophy University of Poona, 15(2), 137-168. Retrieve from http://philpapers.org/rec/RAJTAP

Ramadoss, R., \& Bose, B. K. (2010). Transformative life skills : Pilot studies of a yoga model for reducing perceived stress and improving selfcontrol in vulnerable youth. International Journal of Yoga Therapy, 20, 73-79. Retrieved from http://www.niroga.org/education/research/ijyt-

tls_reduces_stress.pdf

Rogers, R. W., \& Prentice-Dunn, S. (1981). Deindividuation and angermediated interracial aggression: Unmasking regressive racism. Journal of Personality and Social Psychology, 41(1), 63-73. doi:10.1037/00223514.41.1.63

Sarang, P. S., \& Telles, S. (2006). Oxygen consumption and respiration during and after two yoga relaxation techniques. Applied 
Psychophysiology Biofeedback, 31(2), 143-153. doi:10.1007/s10484006-9012-8

Schell, F. J., Allolio, B., \& Schonecke, O. W. (1994). Physiological and psychological effects of Hatha-Yoga exercise in healthy women. Int $J$ Psychosom, 41(1-4), 46-52. Retrieved from http://www.ncbi.nlm.nih.gov/pubmed/7843867

Singh, P. (2015). Effect of some yogic practices on aggression level among college girls. The International Journal of Indian Psychology, 3(1). Retrieved from http://oaji.net/articles/2015/1170-1443789527.pdf

Tapasyānanda, S. (2003). Srīmad Bhagavad Gìtā (p. 398). Mylapore, Chennai: The President, Srī Ramakrishna Math.

Telles, S., \& Reddy, S. K. (2000). Oxygen consumption and respiration following two yoga relaxation techniques. Applied Psychophysiology and Biofeedback, 25, 221-7. doi:10.1007/s10484-006-9012-8

Telles, S., Reddy, S. K., \& Nagendra, H. R. (2000). Oxygen consumption and respiration following two yoga relaxation techniques. Applied Psychophysiology Biofeedback, 25(4), 221-227.

doi:10.1023/A:1026454804927

Twemlow, S. W., Sacco, F. C., \& Fonagy, P. (2008). Embodying the mind: movement as a container for destructive aggression. American Journal of Psychotherapy, 62(1), 1-33. Retrieved from http://www.ncbi.nlm.nih.gov/pubmed/18461841

Velanakar, K. S. L. (2013). Srimad Bhagavatam. Kolkata: Gita Press, Gorakhpur.

Vengatesh P, K. P. (2014). Relative effect of physical exercises and yogic practices on anxiety aggression and achievement motivation levels of college volleyball players (Doctoral thesis). Retrieved from http://shodhganga.inflibnet.ac.in/bitstream/10603/20569/3/03_declarati on.pdf

WHO. (2014). WHO-World Health Statistics 2014. 
104 Govindaraja et al - Effect of Yoga on Human Aggression

A.G. Govindaraja Setty, Phd Scholar. Swami Vivekanda Yoga University, India. Orcid: http://orcid.org/0000-0002-3621-8699

Pailoor Subramanya, Assistant Director - Research \& Head-PhD. Swami Vivekanda Yoga University, India.

B. Mahadevan, Professor, Indian Institute of Management, Bangalore, India

Contact Address: Swami Vivekananda Yoga University (SVYASA) \#19, Eknath Bhavan, Gavipuram Circle, K.G.Nagar Bangalore - 560019, Karnataka, India. E-Mail: saphalyayoga@yahoo.co.in 


\section{HSE}

Historia Social y de la Educación

Social and Education History
Hipatia Press

www.hipatiapress.com

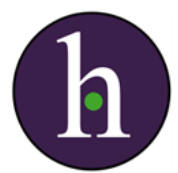

Instructions for authors, subscriptions and further details:

http://hse.hipatiapress.com

Education across Europe: a visual conversation

Estefanía Fernández Antón ${ }^{1}$

1) Universidad de Barcelona (España)

Date of publication: February $23^{\text {rd }}, 2016$

Edition period: Edition period: February 2016-June 2016

To cite this article: Fernández Antón, E. (2014). Education across Europe: a visual conversation [Review of the book]. Social and Education History 5(1), 105-107 doi:10.17583/hse.2016.1870

To link this article: http://dx.doi.org/10.17583/hse.2016.1870

PLEASE SCROLL DOWN FOR ARTICLE

The terms and conditions of use are related to the Open Journal System and to Creative Commons Attribution License (CC-BY). 


\section{Reviews (I)}

Burke, C., Grosvenor, I., Haenggeli-Jenni, B., Ribeiro de Castro, H., Tabacchi, E., Thyssen, G., \& Verstraete, P. (Eds) (2014). Education across Europe: a visual conversation. Lisboa: EERA, Network 17.

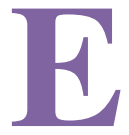

1 libro Education across Europe. A visual Conversation está constituido por el trabajo de veinticuatro investigadores que conforman la European Educational Research Association (EERA). La historia de la educación es la disciplina en la que se sitúa el escrito; por lo tanto, se parcela un pedazo de realidad del pasado y se presenta sin olvidar lo momentos sociales y políticos del momento.

El libro está dividido en veinticuatros capítulos; cada uno de ellos se centra en un país europeo para desvelar algunas de sus tradiciones y métodos pedagógicos. Los lugares de Europa seleccionados son Armenia, Austria, Bélgica, Dinamarca, Estonia, Finlandia, Francia, Alemania, Grecia, Hungría, Italia, Letonia, Luxemburgo, Países Bajos, Noruega, Polonia, Portugal, Serbia, Eslovenia, España, Suecia, Suiza, Turquía y Reino Unido.

Las secciones se conforman de una explicación breve y sencilla del pasado de la educación; no interesa tanto un análisis completo -de principio a fin-, lo que importa sobre todo son momentos fáciles de entender y abordar que, en muchos casos, fueron clave para la renovación de la pedagogía.

Las reducidas historias están acompañadas de retratos escolares realizados entre principios del siglo XIX y finales del siglo XX. Algunas imágenes ya forman parte de la memoria colectiva, al representar sistemas escolares 2016 Hipatia Press

ISSN: 2014-3567

DOI: $10.17583 /$ hse. 2016.1870

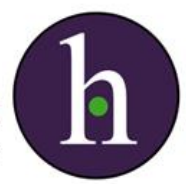




\section{Fernández - Education across Europe [Review]}

vinculados al trabajo físico, al procesamiento de materias primas y a la estratificación social. Otros ejemplos que nos recuerdan al pasado son las clases atestadas de alumnos, la escolarización de niñas por un lado y la escolarización de niños por otro, el profesor que solo explica, el alumno que solo memoriza, etc.

Sin embargo, otras imágenes y relatos nos pillan por sorpresa al no ceñirse a lo que suele entenderse como educación en tiempos remotos. Hablamos de alumnado reunido en grupo para aprender, y no solo de eso, sino de grupos en los que los alumnos están cerca los unos de los otros, y el profesorado forma parte de la agrupación. Esta reforma pedagógica recibe el nombre de Landschulerneuerung y tiene lugar en Austria después de la segunda guerra mundial. La reforma supone el despertar de la pedagogía basada en la cohesión social y en la calidez del ambiente; estos dos factores se entendían como bases cruciales para dar los primeros pasos hacia la escuela ideal.

Otro documento escrito y gráfico, que desconcierta, alberga el Seminario Didáctico-Metodológico de la Universidad de Tartu; desde el cual se formaban a los profesores de Educación Secundaria de Estonia. El método implicó una nueva forma de entender la capacitación de los docentes, al estar unido con el pensamiento pedagógico progresista o escuela nueva. Estas pedagogías, de carácter crítico y de finales del siglo XIX, apuntaron hacia la transformación del autoritarismo del profesorado y pasividad del alumnado. Respaldando, entonces, una relación democrática y colaborativa entre enseñante y aprendiz. También hay que indicar que es en la pedagogía crítica donde se apuesta por la educación como palanca de cambio de la sociedad.

En el caso español se destacan dos experiencias consideradas revolucionarias y críticas, la Institución Libre de Enseñanza y el proyecto Comunidades de Aprendizaje. En relación a las Comunidades de Aprendizaje se identifica su impacto internacional, ya que después de su surgimiento en España a finales de los años 70, este proyecto basado en las aportaciones de la comunidad científica internacional se ha transferido exitosamente a diversos países como Brasil, México o Inglaterra, entre otros. 
A largo del libro hay más ejemplos que concuerdan con la idea que tenemos de educación del pasado y otros que rompen con ella. Sin embargo, hemos seleccionado los casos del escrito que mejor representan lo uno y lo otro y, sobre todo, los que representan la revolución de la pedagogía.

El libro no solo está dispuesto a acreditar el pasado como transformador de la pedagogía, sino que también recomienda aprender de él y llevar el conocimiento al aula. Un ejemplo de esto lo encontramos en el capítulo dedicado a Bélgica, en el cual se cita el documental Herman Slosse/Blind kind 2 de Johan Van der Keuken. Lo importante de la visualización del documental es ayudar a los docentes de educación especial a desprenderse del enfoque socio-constructivista.

Teniendo en cuenta todas las ideas aportadas hasta el momento, podemos afirmar que es un escrito relevante en el campo de la historia de la educación, pues nos ayuda a obtener una compresión idónea de la presencia de la pedagogía y de su impacto en el sistema educativo. Asimismo, nos ayuda a renovar el imaginario colectivo relacionado con la educación, lleno de imágenes relacionadas con la escuela tradicional, y a aprender de las prácticas del pasado.

Estefanía Fernández Antón

Universidad de Barcelona 


\section{HSE}

Historia Social y de la Educación

Social and Education History
Hipatia Press

www.hipatiapress.com

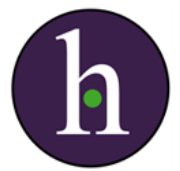

Instructions for authors, subscriptions and further details:

http://hse.hipatiapress.com

\section{Paying for the Party. How College Maintains Inequality.}

Tinka Schubert ${ }^{1}$

1) Universidad de Barcelona (Spain)

Date of publication: February 23rd, 2016

Edition period: Edition period: February 2016-June 2016

To cite this article: Armstrong, E. A., \& Hamilton, L. T. (2013) Paying for the Party. How college maintains inequality. [Review of the book]. Social and Education History 5(1), 108-110 doi:10.17583/hse.2016.1961

To link this article: http://dx.doi.org/10.17583/hse.2016.1961

\section{PLEASE SCROLL DOWN FOR ARTICLE}

The terms and conditions of use are related to the Open Journal System and to Creative Commons Attribution License (CC-BY). 


\section{Reviews (II)}

Armstrong, E. A. \& Hamilton, L. T. (2013) Paying for the Party. How college maintains inequality. Cambridge, MA: Harvard University Press.

I

$\mathrm{n}$ times when university are increasingly questioned about their capacity to properly attend the academic and social needs of their students, and especially of female students, the present book provides an excellent insight into the daily struggle of college women to find their place in society. Through an unconventional and longitudinal study Armstrong and Hamilton gain a very broad and detailed overview of the diverse variables that play into the different pathways that women this Midwestern University follow in their 4 years or more at college. Members of the research team share the living space of one cohort of freshmen women who are allocated in the "Party dorm" to explore the not only the pathways and the social determinants for these pathways, but also to evidence the social relations that emerge among the women living in these college residences.

The authors highlight that the university under research is known for its Party Pathway, which is mainly set forth by the fraternities and sororities. These particularly serve upper class students who have the means to afford their membership fees, engage in the extraordinarily time consuming social activities and stand up to the social standards of appearance. While requirements to enter these sororities are very high and specific enough to make a homogeneous selection of their members, their social network is extensive and promising future upward social mobility - which as it turns 2016 Hipatia Press

ISSN: 2014-3567

DOI: $10.17583 /$ hse.2016.1961

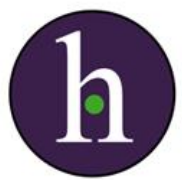


out is only true for the most privileged as the study shows. Competition to be part of this social life and its networks creates an extremely hostile environment among college women who attempt to climb the ladder of upward social mobility, based on traditional female assets such as beauty and cuteness, defined by their peers, and social class. Failure to meet these criteria or lacking interest in participating in the party culture and sorority activities leads to social exclusion and marginalization affecting the situation of college women with detrimental effects on mental health and academic outcomes. Thus, their capacity for upward social mobility is undermined in this context.

Armstrong and Hamilton distinguish between different pathways that college women in this "Party dorm" follow, which are embedded in structural landscape of social class. According to the study, more affluent women tend to be more likely to enter sororities and engage in the Party pathway. Whether this choice turns out to lead to upward or downward social mobility depends greatly on their financial resources and social skills to integrate in and navigate these networks. Academic performance is less important and only comes into play in the future if social ties to entering the labor market are lacking, thus for those not belonging to the upper social classes. On the other end of the class spectrum, lower class women tend to experience impediments for upward mobility as their routine in college involves long working hours, less to no help in navigating higher education, thus making wrong academic choices leading them to no success in terms of revenue for their investment in higher education to climb the ladder of social mobility. The only way to thrive in this pathway is inside knowledge on the academic environment to successfully achieve scholarships and funding for the college experience linked to academic effort. A third pathway includes those for whom academic attainment is more defining than the other pathways. A distinction is thus made between achievers and underachievers including women from upper and upper middle class for the first group and all social classes for the latter.

To conclude their book, the authors analyze the importance of structural elements in creating these pathways, which lead to maintaining inequalities. They highlight that reduced funding lowers the universities capacity to limit the strength of sororities and fraternities to influence campus life and the 


\section{Schubert - Paying for the party [Review]}

women's pathways. One of the more common trends is to implement online classes reducing financial issues as well as exposure to social marginalization. Yet, it further limits access to establishing social networks which appear to be crucial in the future. Thus the authors appeal to universities, policy makers, and governors to provide quality education and living conditions to students. Although not the main focus of the book it perfectly informs about the interactions that greatly influence a student's life on campus and their future to either thrive as a person or being devastated.

Tinka Schubert

University of Barcelona

tschubert@ub.edu 